UNIVERSIDADE DE BRASÍLIA

FACULDADE DE TECNOLOGIA DEPARTAMENTO DE ENGENHARIA CIVIL E AMBIENTAL

\title{
DIRETRIZES PARA UM SISTEMA DE MONITORAMENTO E AVALIAÇÃO dAS POLÍTICAS PÚBLICAS PARA INFRAESTRUTURA FEDERAL DE TRANSPORTES
}

\author{
JEAN MARLO PEPINO DE PAULA
}

\author{
ORIENTADOR: JOSÉ MATSUO SHIMOISHI \\ CO-ORIENTADORA: MARTHA VERAS RODRIGUES
}

DISSERTAÇÃO DE MESTRADO EM TRANSPORTES

PUBLICAÇÃO: T.DM - 007/2015

BRASÍLIA/DF: JUNHO - 2015 
UNIVERSIDADE DE BRASÍLIA

FACULDADE DE TECNOLOGIA

DEPARTAMENTO DE ENGENHARIA CIVIL E AMBIENTAL

\title{
DIRETRIZES PARA UM SISTEMA DE MONITORAMENTO E AVALIAÇÃO dAS POLÍTICAS PÚBLICAS PARA INFRAESTRUTURA FEDERAL DE TRANSPORTES
}

\author{
JEAN MARLO PEPINO DE PAULA
}

DISSERTAÇÃO SUBMETIDA AO PROGRAMA DE PÓS-GRADUAÇÃO EM TRANSPORTES DO DEPARTAMENTO DE ENGENHARIA CIVIL E AMBIENTAL PARA A OBTENÇÃO DO GRAU DE MESTRE EMTRANSPORTES.

APROVADO POR:

José Matsuo Shimoishi, DSc (PPGT/UnB)

(Orientador)

Josivânia Silva Farias, DSc (FACE/UnB)

(Examinador Externo)

Ana Claudia Farranha Santana, DSc (PPGT/UnB)

(Examinador Interno)

DATA: BRASÍLIA/DF, 26 de junho de 2015. 


\section{FICHA CATALOGRÁFICA}

\section{DE PAULA, JEAN MARLO PEPINO}

Diretrizes para um sistema de monitoramento e avaliação das políticas públicas para infraestrutura federal de transportes [Distrito Federal] 2015. xv, 151p., 210 x 297 mm (ENC/FT/UnB, Mestre, Transportes, 2015). Dissertação de Mestrado - Universidade de Brasília. Faculdade de Tecnologia.

Departamento de Engenharia Civil e Ambiental.

1. Abordagem sistêmica

3. Monitoramento e Avaliação

I. ENC/FT/UnB
2.Infraestrutura de transportes

4.Política Pública

II. Título (série)

\section{REFERÊNCIA BIBLIOGRÁFICA}

DE PAULA, J. M. P. (2015). Diretrizes para um sistema de monitoramento e avaliação das políticas públicas para infraestrutura federal de transportes. Dissertação de Mestrado em Transportes, Publicação T.DM-007/2015,Departamento de Engenharia Civil e Ambiental, Universidade de Brasília, Brasília, DF, 151p.

\section{CESSÃO DE DIREITOS}

AUTOR: Jean Marlo Pepino de Paula.

TÍTULO: Diretrizes para um sistema de monitoramento e avaliação das políticas públicas para infraestrutura federal de transportes.

GRAU: Mestre

ANO: 2015

É concedida à Universidade de Brasília permissão para reproduzir cópias desta dissertação de mestrado e para emprestar ou vender tais cópias somente para propósitos acadêmicos e científicos. $\mathrm{O}$ autor reserva outros direitos de publicação e nenhuma parte dessa dissertação de mestrado pode ser reproduzida sem autorização por escrito do autor.

Jean Marlo Pepino de Paula

jeanmarlo@gmail.com

Quadra 07, conjunto 04, casa 32, Condomínio Mini Chácaras do Lago Sul - Lago Sul. 71.680-621 Brasília - DF - Brasil. 


\section{AGRADECIMENTOS}

Agradeço aos meus pais pelo exemplo de vida, pelo esforço para garantir meus estudos e pelas orientações e apoio nas decisões para escolher meu caminho. Hoje só me torno mestre porque tenho o carinho e dedicação desde cedo.

Agradeço à minha esposa Mayara pela paciência, pela compreensão, pela dedicação, pelo companheirismo e, principalmente, pelo amor que me resgata nos momentos mais difíceis. Espero te retribuir em dobro!

Agradeço também aos professores do PPGT pelos ensinamentos e provocações intelectuais, em especial o Prof. José Matsuo pelo espaço na decisão do tema e às professoras Ana Cláudia Farranha e Michele Andrade pela atenção, paciência e receptividade para iluminar e esclarecer o caminho percorrido. Cabe um agradecimento especial à professora Martha Veras pelo aporte sensato, pelas "perguntas constrangedoras" que me permitiram evoluir no trabalho e pela elegância com que expôs suas orientações e contribuições no desenvolvimento deste trabalho.

Agradeço aos colegas do PPGT, que se mostraram atenciosos e unidos para complementar conhecimento; e também aos colegas do Ipea, que contribuíram voluntaria ou involuntariamente para o desenvolvimento deste trabalho com simples conversas prazerosas.

Agradeço aos amigos pela compreensão das ausências momentâneas. Mas agora temos mais um motivo para comemorar! 
Mera mudança não é crescimento.

Crescimento é a sintese de mudança e continuidade, e onde não há continuidade não há crescimento.

Clive Staples Lewis 


\section{RESUMO}

Quando os planos são idealizados sem a representação e o entendimento adequados do ambiente ao qual estará sujeito, enfrentam duros obstáculos que consomem recursos ao serem executados e comprometem a apropriação do seu produto pelos beneficiários. A dificuldade do setor público brasileiro para prover tempestivamente uma infraestrutura de transportes demonstra esta fragilidade para entender como influencia e é influenciado pelo mundo real, carecendo de ferramentas que o permita se adequar e se aprimorar.

Neste sentido, este trabalho tem como objetivo apresentar diretrizes para fomentar uma abordagem sistêmica da infraestrutura federal de transportes. Os conceitos extraídos da Teoria Geral dos Sistemas e compatibilizados com as recomendações e as práticas nacionais e estrangeiras permitiram definir diretrizes para a criação de um Sistema de Monitoramento e Avaliação (SMA) aplicáveis a qualquer área. A especificidade de um SMA para o setor de infraestrutura federal de transportes foi obtida por meio de uma pesquisa Delphi com especialistas afins, os quais opinaram sobre o estágio atual e importância dos aspectos que definem as diretrizes para o setor. Entre os doze aspectos que definem estas diretrizes se destaca a liderança operacional, que possui atualmente a maior precariedade no setor e importância equivalente aos demais. Este aspecto é pouco delimitado pelas práticas e experiências nacionais e internacionais, mas possui fundamental participação para garantir o sucesso desses sistemas no país.

Palavras-chave:Abordagem sistêmica, Infraestrutura de transportes, Planejamento de transportes, Ciclo de políticas públicas, Sistemas de monitoramento e avaliação, Pesquisa Delphi. 


\begin{abstract}
When plans are designed without adequate representation and understanding of the environment to which is submitted, they face tough obstacles that consume resources when executed and compromise the product ownership by the beneficiaries. The difficulty of the Brazilian public sector to provide adequate transport infrastructure in time demonstrates the weakness of this system to understand how it influences and is influenced by the real world, lacking tools that will enable you to adapt and improve.
\end{abstract}

Thus, this work present guidelines to encourage a systemic approach to federal transportation infrastructure. The concepts taken from the General Systems Theory and matched with the recommendations and national and foreign practices have enabled the drawing of guidelines for the creation of a Monitoring and Evaluation System (M\&E) applicable to any area. The specificity of a M\&E to the federal transport infrastructure sector was obtained through a Delphi survey with related experts, which gave their opinions about the current status and importance of the aspects that define the guidelines for the sector. Among the twelve aspects presented in these guidelines, highlights the operational leadership, which currently has the most precarious in the sector and equivalent importance to the other. This is somewhat bounded by national and international practices and experiences, but has a fundamental participation to ensure the success of these systems in the country.

Keywords: System approach, Transport infrastructure, Transport planning, Policy cycle, Monitoring and evaluation systems, Delphi survey. 


\section{SUMÁRIO}

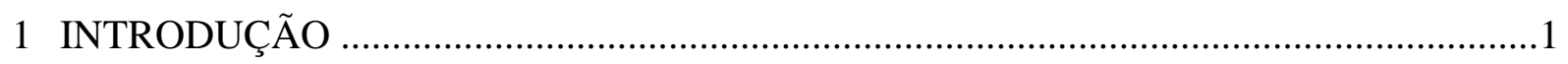

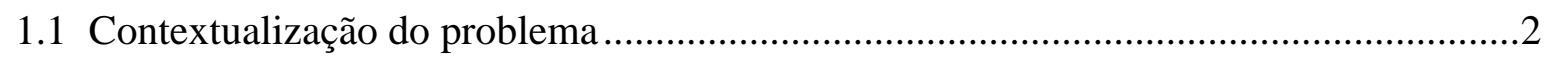

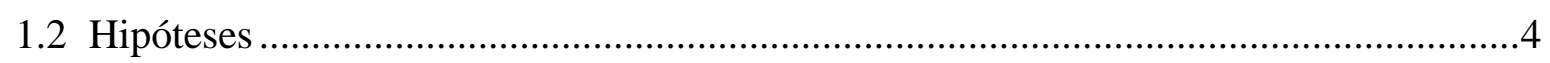

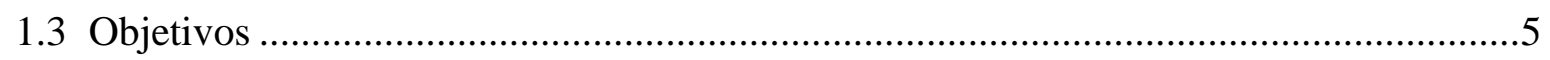

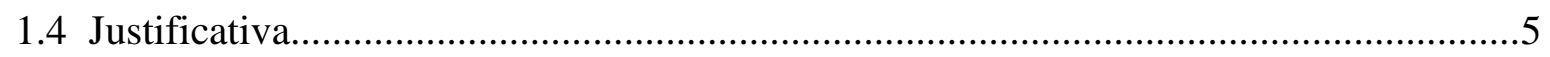

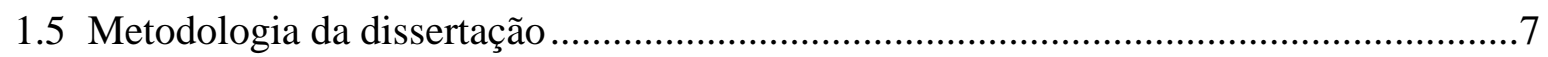

1.5.1 Classificação da dissertação ……………………………………………………..7

1.5.2 Etapas da dissertação..........................................................................................

1.5.3 Procedimentos da dissertação ........................................................................

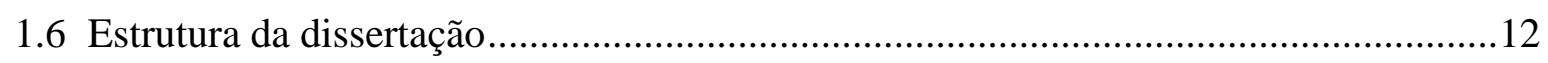

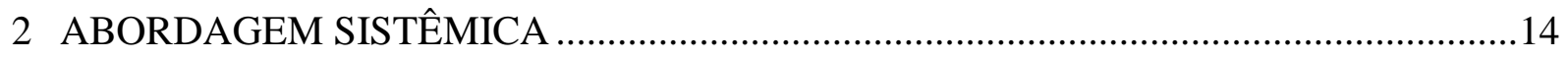

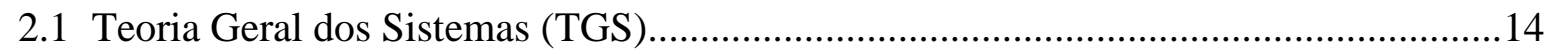

2.1.1 Aspectos gerais e específicos de um sistema .........................................................17

2.1.2 O subsistema de retroação: o Monitoramento e a Avaliação (MeA) .......................24

2.2 O Ciclo de Políticas Públicas (CPP) e o MeA ……………………………………........26

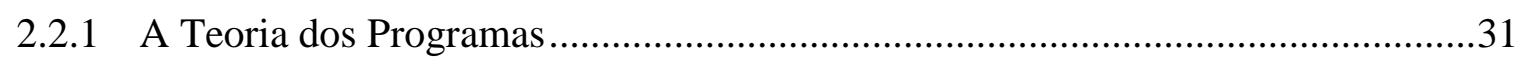

3 PRÁTICAS E EXPERIÊNCIA NACIONAIS E ESTRANGEIRAS COM SMA..................34

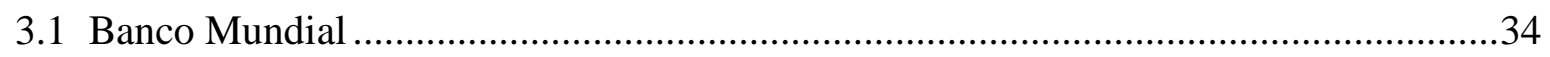

3.2 Práticas e experiências nacionais e internacionais em MeA ……………………….......4

3.2.1 Organizações das Nações Unidas (ONU) ……………………………………......4

3.2.2 Governo Federal Brasileiro …………………………………………………....52

3.2.3 Países da América Latina .....................................................................................59

4 MÉTODO PARA DEFINIÇÃO DAS DIRETRIZES DE UM SMA DAS POLÍTICAS PÚBLICAS PARA A INFRAESTRUTURA FEDERAL DE TRANSPORTES .......................65

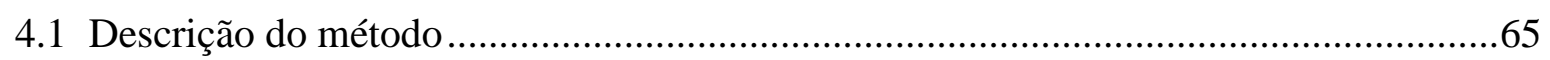

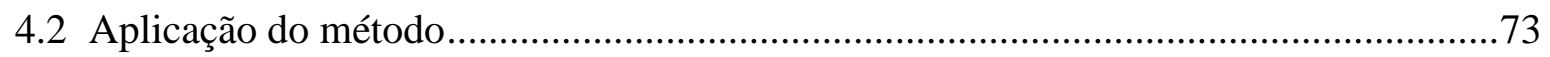

4.2.1 Identificação das diretrizes gerais para um SMA ………………………………....73

4.2.2 Elaboração do questionário Delphi ........................................................................

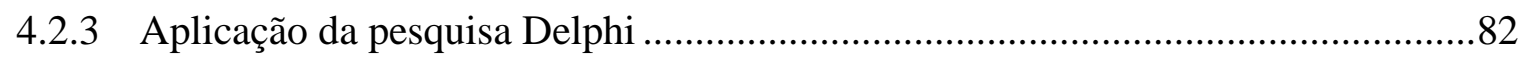

5 APRESENTAÇÃO E ANÁLISE DOS DADOS ……………………………………....... 
6 DIRETRIZES DE UM SMA DAS POLÍTICAS PÚBLICAS PARA A

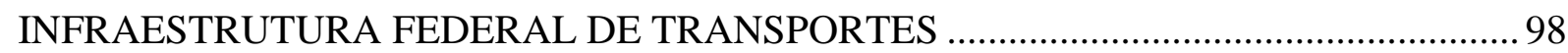

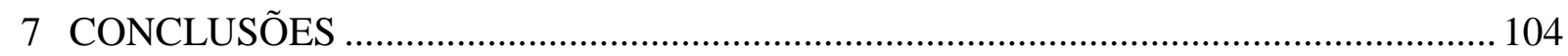

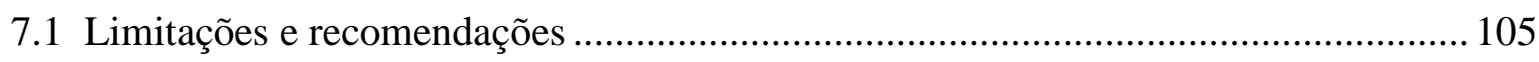

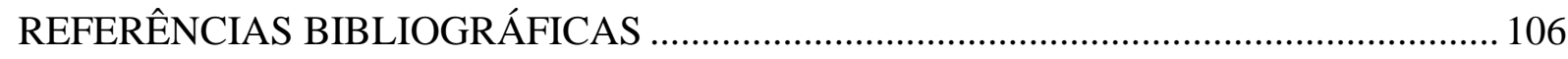

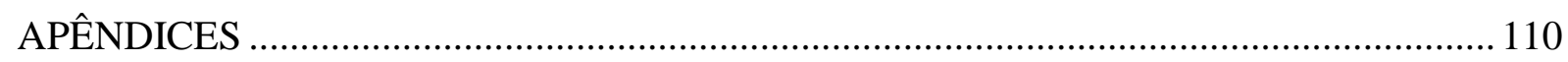

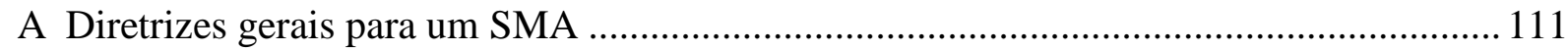

B EXEMPLOS DEFORMULÁRIOS UTILIZADOS NA PESQUISA DELPHI ................ 115

C COMENTÁRIOS ENVIADOS PELOS ESPECIALISTAS ........................................... 120

C.1 Tópico 1 - Estágio atual dos aspectos específicos ................................................ 121

C.2 Tópico 2 - Grau de importância dos aspectos específicos ......................................... 134 


\section{LISTA DE SIGLAS}

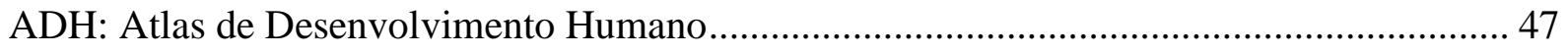

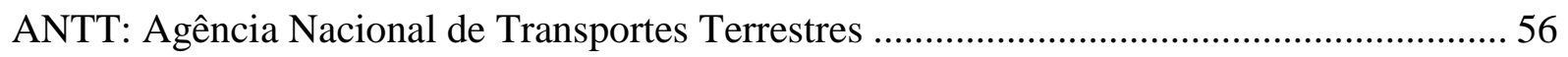

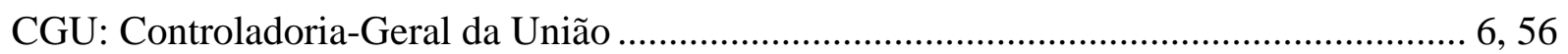

CPP: Ciclo de Políticas Públicas .................................................................................... 13, 26

DEMAS: Departamento de Monitoramento e Avaliação do SUS .......................................... 55

DNIT: Departamento Nacional de Infraestrutura Terrestre .................................................. 56

EPL: Empresa de Planejamento Logístico ......................................................................... 2

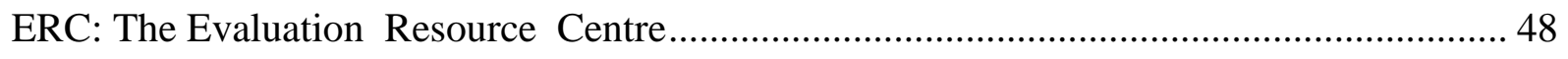

Finatec: Fundação de Empreendimentos Científicos e Tecnológicos .................................... 54

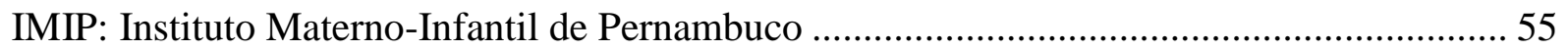

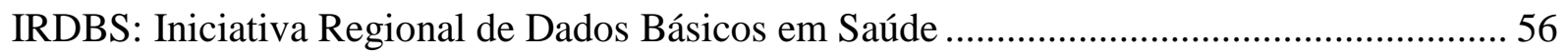

MeA: Monitoramento e a Avaliação........................................................... 24, 26, 31, 44

MPOG: Ministério de Planejamento, Orçamento e Gestão ................................................... 54

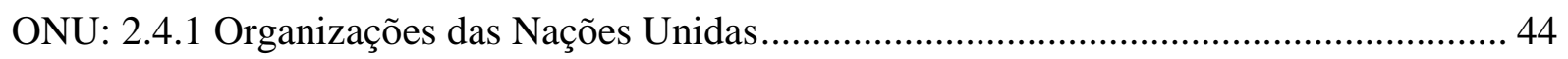

OPAS: Organização Pan-Americana da Saúde .................................................................... 56

PAC: Programa de Aceleração do Crescimento ..................................................................... 2

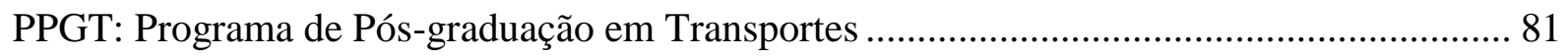

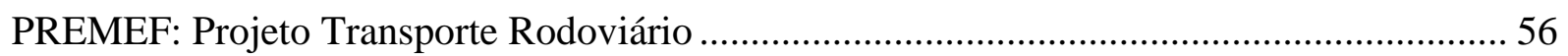

RAG: Relatório Anual de Gestão....................................................... 55, 79, 101, 113

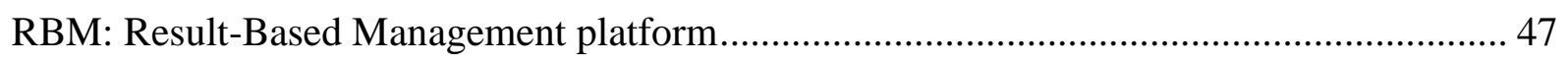

SAGI: Secretaria de Avaliação e Gestão da Informação ....................................................... 53

Sigplan: Sistema Integrado para gestão e Planejamento...................................................... 54

SINERGIA: Sistema Nacional de Avaliação da Gestão e Reaultados ....................................... 60

SISER: Sistema de Acompanhamento e Avaliação da Gestão Pública por Resultado............. 62

SMA: Sistema de Monitoramento e Avaliação.................................................................... 1

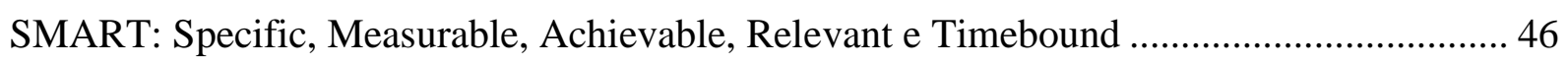

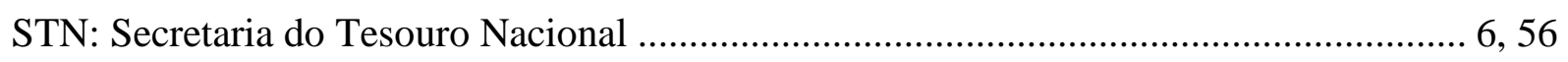

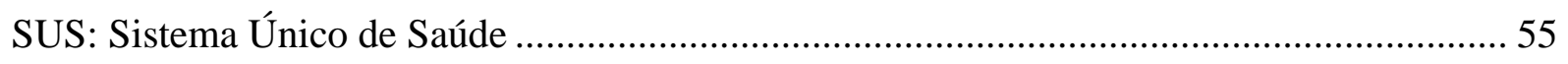

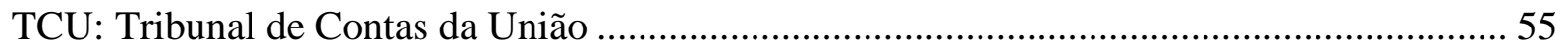

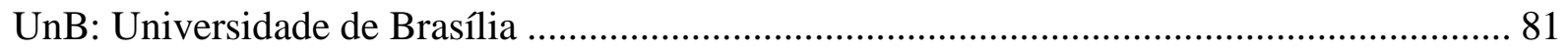

UNDAF: United Nations Development Assistance Framework ........................................ 47 


\section{LISTA DE FIGURAS}

Figura 1.1 - Delimitação do objeto de estudo. ........................................................................

Figura 2.1 - Modelo simplificado de um sistema................................................................18

Figura 2.2 - Tipos de lideranças em um sistema. ................................................................23

Figura 2.3 - Aspectos gerais e específicos de um sistema.....................................................24

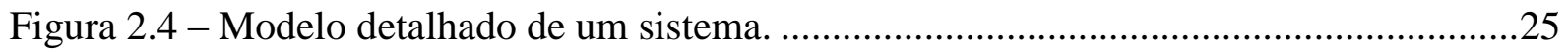

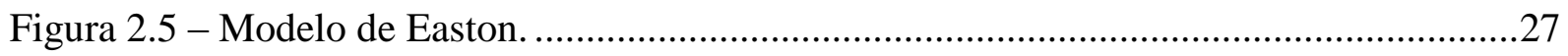

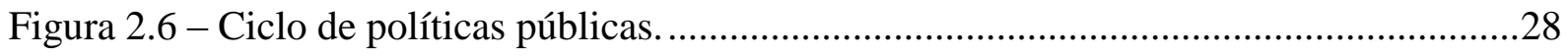

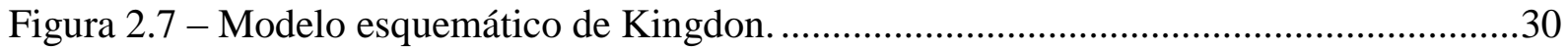

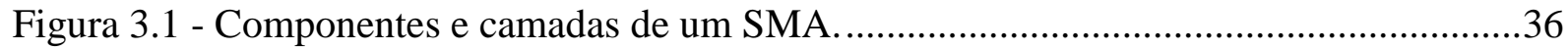

Figura 4.1- Apresentação esquemática do método................................................................65

Figura 4.2-Apresentação detalhada das fases do método proposto.........................................66

Figura 4.3 - Critérios para continuidade ou conclusão da pesquisa Delphi.............................70

Figura B.1 - Seções da pesquisa Delphi........................................................................115

Figura B.2 - Exemplo de questões dos Tópicos 1 e 2 aplicadas na $1^{\mathrm{a}}$ rodada da pesquisa

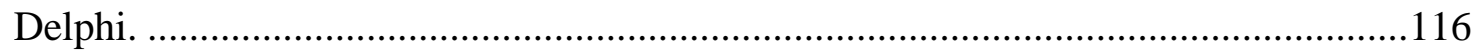

Figura B.3 - Exemplo de questão do Tópico 1 aplicada na $2^{a}$ rodada da pesquisa Delphi para qualificação do resultado anterior e para a crítica dos especialistas sobre os comentários

Figura B.4 - Exemplo de questão do Tópico 2 reaplicadas integralmente na $2^{\mathrm{a}}$ rodada da pesquisa Delphi.

Figura B.5 - Exemplo da sétima seção da $2^{\mathrm{a}}$ rodada da pesquisa Delphi para os especialistas registrarem comentários sobre a rodada e os comentários enviados na $1^{\text {a }}$ rodada. .....119 


\section{LISTA DE GRÁFICOS}

Gráfico 5.1 - Área de atuação dos especialistas respondentes. 85

Gráfico 5.2 - Perfil dos especialistas respondentes segundo os cargos ocupados. 85

Gráfico 5.3 - Percentual de especialistas respondentes segundo a formação. 86

Gráfico 5.4 - Percentual de especialistas respondentes segundo a quantidade de anos de experiência na área. 86

Gráfico 5.5 - Quantidade de opiniões válidas por aspecto específico e tópico 87

Gráfico 5.6 - Estágio atual dos aspectos específicos de um SMA no setor de infraestrutura federal de transportes. 88

Gráfico 5.7 - Valor médio da opinião dos especialistas sobre o estágio atual dos aspectos específicos de um SMA no setor de infraestrutura federal de transportes. .89

Gráfico 5.8 - Grau de importância dos aspectos específicos de um SMA para o setor de infraestrutura federal de transportes......

Gráfico 5.9 - Mediana das respostas dos especialistas sobre o estágio atual e grau de importância dos aspectos específicos de um SMA para o setor de infraestrutura federal de transportes .92

Gráfico 5.10 - Resultado da questão 10 na $1^{\mathrm{a}}$ rodada. 96 


\section{LISTA DE QUADROS}

Quadro 1.1-Detalhamento da metodologia da dissertação......................................................13

Quadro 2.1 - Definições de sistemas segundo autores...........................................................15

Quadro 3.1 - Atividades desenvolvidas na operacionalização do MeA. ..................................50

Quadro 4.1 - Correspondência das escalas de resposta dos tópicos 1 e 2 ..............................68

Quadro 4.2 - Comparação entre os aspectos de um SMA segundo a teoria e as práticas

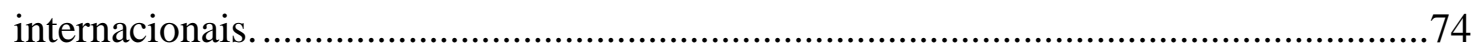

Quadro 4.3 - Descrição dos aspectos específicos das diretrizes gerais para um SMA. ...........76

Quadro 4.4 - Aspectos favoráveis e ações necessárias segundo aspectos específicos.............78

Quadro 4.5 - Aspectos desfavoráveis e ações necessárias segundo aspectos específicos........79

Quadro 5.1 - Relação de instituições presentes na pesquisa Delphi e grupos de atividade (quantidade de respondentes).

Quadro 5.2 -Quantidade de respondentes e citações indiretas atribuídos a cada aspecto

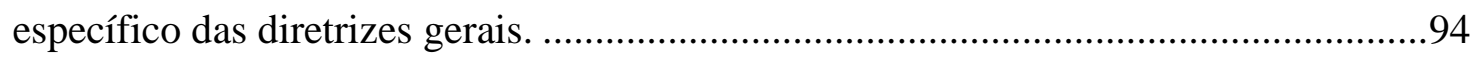

Quadro 6.1 - Descrição dos aspectos gerais das diretrizes definitivas..................................98

Quadro 6.2 - Descrição dos aspectos específicos das diretrizes preliminares gerais...............99

Quadro 6.3 - Aspectos favoráveis e ações necessárias segundo aspectos específicos...........100

Quadro 6.4 - Aspectos desfavoráveis e ações necessárias segundo aspectos específicos......101

Quadro 6.5 - Quantidade de respondentes e citações indiretas sobre as dificuldades presente nos comentários enviados pelos especialistas respondentes....................................103

Quadro A.1 - Descrição dos aspectos específicos das diretrizes preliminares gerais. ...........111

Quadro A.2 - Aspectos favoráveis e ações necessárias segundo aspectos específicos..........112

Quadro A.3 - Aspectos desfavoráveis e ações necessárias segundo aspectos específicos.....113 


\section{LISTA DE TABELAS}

Tabela 5.1- Similaridade entre os grupos de respostas com importância intermediária e muito

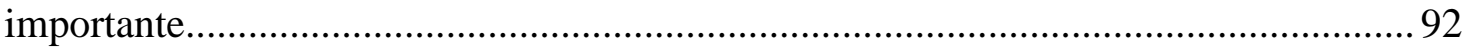





\section{INTRODUÇÃO}

O transporte é um importante elemento para promover a dinamicidade de uma sociedade e dos mercados, motivo pelo qual as inversões neste setor são frequentemente relacionadas à integração e ao desenvolvimento regional e nacional.Entretanto, as dificuldades financeiras vivenciadas na segunda metade do século XX levaram o país a acumular um passivo de investimentos em infraestrutura de transportes que se revelam na medida em que as economias nacionais e internacionais revigoram. Neste período, os governos brasileiros elaboram planos para modernizar os sistemas de transportes, criando novas rotas e resgatando outras iniciativas relegadas pela incapacidade momentânea de execução.

Mesmo com o restabelecimento da atividade econômica, a concorrência dos recursos financeiros por diversas áreas impede a realização concomitante de todas as atividades necessárias em um sistema de transporte. Além disto, a longa maturação destes ativos e as restrições mercadológicas e tecnológicas dificultam o súbito resgate do sistema de transportes de um país. Por conseguinte, a precária manutenção dos ativos resulta em um crescimento exponencial de serviços e dos custos para intervenção; que associada às inadequadas geometrias, interseções e integração entre modais de transportes comprometem a sua eficiência, a segurança dos indivíduos e o meio ambiente. Impõe-se a este ciclo os interesses sociais e difusos que surgem com os vultosos investimentos envolvidos no setor, requisitando do Estado uma crescente transparência das decisões e dos gastos realizados.

Para evitar constrangimentos como estes, um sistema de transportes deve gerar, sistematizar e avaliar uma gama de dados para aprimorar os processos envolvidos e para subsidiar a escolha tempestiva e adequada da melhor solução. Enquanto as análises dos quesitos técnicos, físicos e financeiros permitem a antecipação de intervenções para reduzir custos, o planejamento destes sistemas deve assimilar a forma como o transporte participa, influencia e é influenciado pela sociedade.

O fluxo de informação adequado promove uma melhor priorização, uma maior qualificação das intervenções e, consequentemente, resultados mais condizentes e efetivos. Esta sinergia é normalmente proporcionada por Sistemas de Monitoramento e Avaliação (SMAs), responsáveis pela sistematização, utilização e disseminação das informações provenientes do ambiente, de atores, de processos internos e dos resultados obtidos. 


\subsection{Contextualização do problema}

Mesmo com as iniciativas recentes para retomar os investimentos federais na infraestrutura de transportes - a exemplo da criação da Empresa de Planejamento Logístico (EPL) e do Programa de Aceleração do Crescimento (PAC) -, as atividades públicas da União no setor ainda são conduzidas de forma estanque. Tal fato pode ser atribuído a pouca sinergia horizontal e transversal entre os atores e a inexistência ou desuso de avaliações e informações consistentes, pertinentes e úteis dos seus processos e dos componentes externos ao ambiente técnico nos resultados obtidos.

Duas constatações do Tribunal de Contas da União (TCU) sinalizam a precariedade da coordenação e sistematização destas informações. A primeira constatação foi resultado de um levantamento mais amplo dos Sistemas de Monitoramento e Avaliação em 25 Órgãos da Administração Direta do Poder Executivo, quando o tribunal apontou as fragilidades no uso das informações pelo setor público brasileiro (TCU, 2011). A segunda constatação foi obtida a partir de uma auditoria realizada no Departamento Nacional de Infraestrutura de Transportes (DNIT), onde identificou a baixa interação entre as coordenações do órgão (TCU, 2012).

Estas e outras dificuldades já foram destacadas por diversos estudos que abordaram a ação de defesa de interesses de cidadãos, mesmo que eles não reconheçam que determinado fato lhe diga respeito - iniciativa denominada de advocacy por (Morais, 2013) -, e sinalizaram as incipiências do uso de indicadores e de avaliações e as deficiências na gestão e avaliação dos programas governamentais (Garcia, 2000; Calmon \& Gusso, 2002; TCU, 2011; Santos, 2012 e Serpa, 2014). Existem também trabalhos relevantes mas pouco explorados para uma eficiente gestão da infraestrutura de transportes, como o desenvolvimento de indicadores para o setor (MT, 2007), de metodologias para identificar a qualidade e as informações necessárias para o planejamento e a definição de políticas públicas do transporte (Correia \& Yamashita, 2004 e Silva, 2009) e a presença de instrumentos institucionais para coletar, manipular e avaliar dados e gerar informações (DNIT, 2007); além do desenvolvimento e do maior acesso a novas tecnologias.

Mesmo tendo à disposição técnicas e estudos para se aprimorar e garantir uma maior sinergia interna e externa, o setor de transportes encontra dificuldades para gerar, se apropriar e 
disseminar informações correlatas. Identificar quais são os aspectos necessários para garantir que o transporte atue de forma sistêmica - se aprimorando por meio de uma maior interação interna e sob determinado cenário - é, portanto, fato importante para contribuir na superação destas dificuldades.

Neste sentido, esta pesquisa objetiva contribuir para o planejamento e desenvolvimento dos sistemas de transportes por meio da identificação e caracterização em linhas gerais dos principais aspectos necessários para fomentar uma abordagem sistêmica da infraestrutura federal de transportes, apresentando-os sob a forma de um SMA e delimitando o objeto de estudo da forma apresentada a seguir.

Magalhães et al. (2007) descreve que um sistema de transportes é formado pelo sujeito, pelo meio e pelo objeto. Segundo Galindo (2009), o sujeito representa seus usuários e o objeto o material transportado - elementos sob um menor controle do sistema. O meio reúne os componentes lógicos e físicos, objeto deste estudo. As atividades desempenhadas por um SMA estão presentes como atividades de gestão, de análise e de planejamento da estrutura de controle do componente lógico. As infraestruturas são parte integrante dos componentes físicos e concentram grande parte dos recursos humanos e financeiros.

Apesar da significativa extensão viária sob responsabilidade das administrações públicas estaduais e municipais, os percalços que vêm comprometendo o desenvolvimento brasileiro envolvem, principalmente, as infraestruturas viárias sob a administração pública federal direta - uma vez que viabiliza a integração nacional, o intercâmbio de pessoas e mercadorias entre as unidades federativas e com os mercados internacionais.

E em relação aos problemas da infraestrutura federal de transportes, este trabalho está voltado para a dificuldade do setor para uma abordagem mais integrada e totalitária do setor sob a forma de um SMA. A Figura 1.1 a seguir apresenta esquematicamente a delimitação do objeto de estudo. 


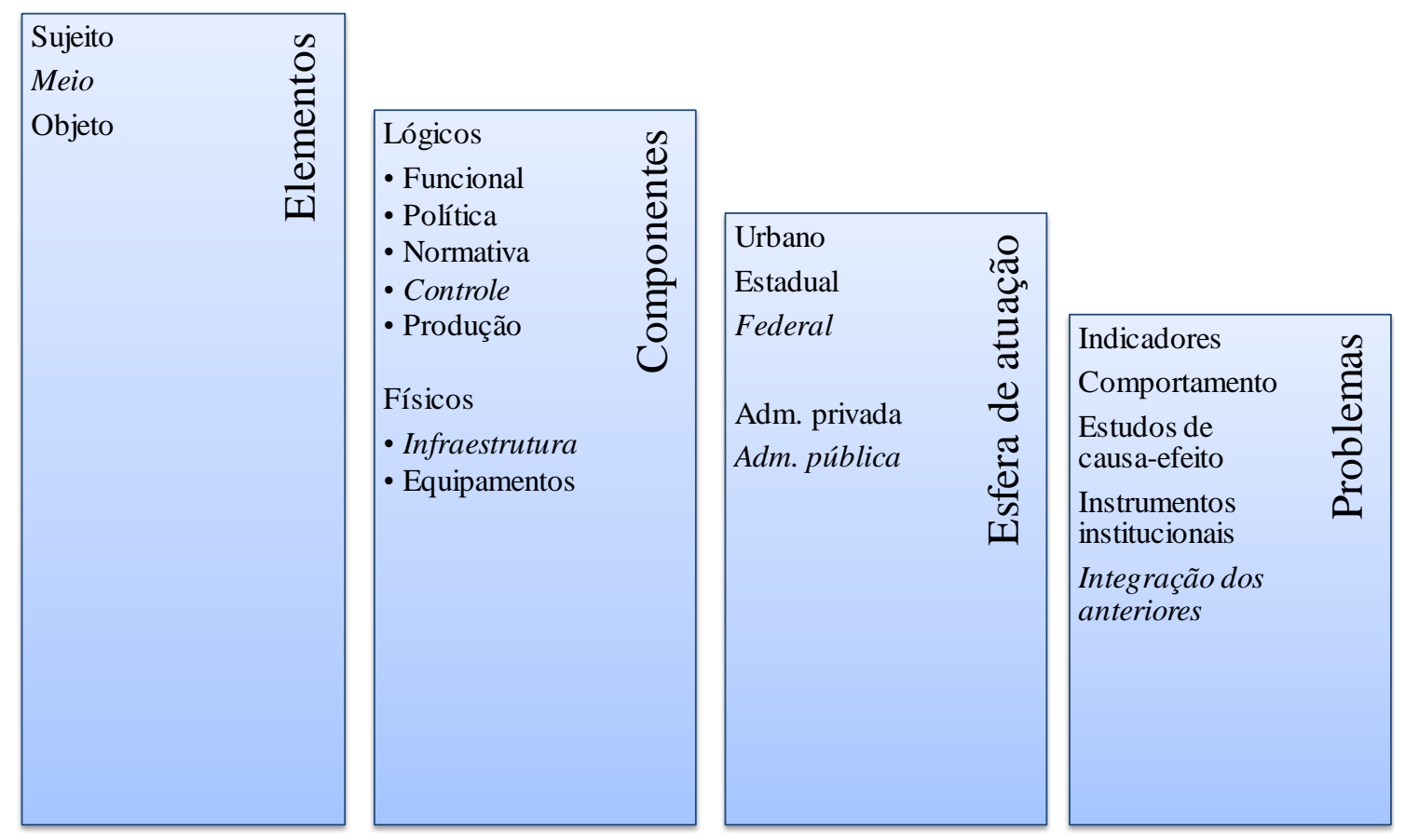

Figura 1.1 - Delimitação do objeto de estudo.

Fonte: Elaborado pelo autor.

Diante do exposto, este trabalho foi desenvolvido para responder à seguinte pergunta: O setor público federal responsável pela infraestrutura de transportes apresenta aspectos que caracterizam um SMA efetivo de forma a contribuir para uma abordagem sistêmica destes ativos?

Entende-se como SMA efetivo aquele sistema que fomenta finalidades relevantes como a accountability, as pesquisas, a gestão e os planejamentos público e privado e possui como motivos da sua continuidade, a participação colaborativa dos atores, a sua eficiência, a sua utilidade e a sua credibilidade.

\subsection{Hipóteses}

As hipóteses para responder à pergunta de pesquisa são as seguintes:

H1: O setor de infraestrutura de transportes apresenta precariamente os aspectos necessários para a criação e manutenção de um SMA efetivo das suas políticas públicas; e 
H2: O setor de infraestrutura federal de transportes carece do aspecto da liderança em um sistema - sob a forma de um empreendedor operacional -, o qual possui importância equivalente aos demais previstos pela literatura e práticas internacionais.

\subsection{Objetivos}

O objetivo geral deste trabalho é propor diretrizes para a criação de um SMA efetivo das políticas pública federais para a infraestrutura de transporte no Brasil, tendo como objetivos específicos:

1. Identificar os principais aspectos de uma abordagem sistêmica na literatura e no cenário de políticas públicas, estabelecendo um arcabouço comum a partir da correlação com recomendações internacionais para a criação de um SMA;

2. Conhecer experiências internacionais e nacionais, principalmente, em SMAs para verificar a pertinência dos aspectos definidos anteriormente e para complementá-los com os fatores relevantes que favoreceram ou dificultaram sua adoção em outros setores, caso oportuno;

3. Definir as diretrizes gerais para a criação de um SMA a partir dos aspectos ratificados anteriormente e das experiências semelhantes em outros setores;

4. Adaptar as diretrizes gerais à realidade da infraestrutura federal de transportes por meio da opinião de especialistas da área sobre a presença e a importância atuais das diretrizes gerais no setor.

\subsection{Justificativa}

A gestão da informação é utilizada por diversos países desenvolvidos e organismos internacionais para desenhar novas políticas e iniciativas, bem como para prestar contas dos gastos e resultados aos seus integrantes e patrocinadores. Além disto, auxilia a redirecionar e ajustar as iniciativas que desenvolvem para alcançarem os objetivos desejados e aprimorar os processos de outras em andamento e futuras. Estas práticas tem resultado na criação e no reconhecimento internacional da importância dos SMAs, responsáveis pela integração de bases de dados e atores, pelo estabelecimento de rotinas e metodologias para o tratamento das informações, pela realização de avaliações e pela divulgação de informações para qualificar as decisões envolvidas e manter a unicidade e coerência da iniciativa entre os participantes e interessados. 
No Brasil, esta prática ainda é incipiente, se restringindo a poucos setores que nos últimos anos estão estruturando suas informações com o auxílio de organismos internacionais. Com os impactos da deficiência dos sistemas de transportes para o desenvolvimento do país, a criação de um SMA voltado para tais políticas representa um importante passo para a qualificação das intervenções necessárias, o planejamento de longo prazo e a oportunidade de melhoria da gestão, refletindo em maiores aplicação e celeridade no desenvolvimento de tecnologias e do conhecimento em prol do desenvolvimento do país.

Uma auditoria realizada pela Controladoria-Geral da União (CGU) teve como objeto uma iniciativa desenvolvida na Secretaria do Tesouro Nacional (STN) para a criação de um SMA para os investimentos em infraestrutura de transportes. A partir dos apontamentos da controladoria, percebe-se que tal iniciativa foi interrompida por apresentar fragilidades na sua finalidade e na relação com stakeholders.

Estes e outros aspectos são reconhecidos internacionalmente pela importância que representam para a criação e sucesso de um SMA das políticas públicas. Tal fato corrobora para demonstrar que, apesar dos reconhecidos benefícios que proporcionam, do primor técnico envolvido e do atual avanço tecnológico, um SMA deve ser revestido por cuidados que garantam e dêem credibilidade à sua criação e manutenção - motivo pelo qual devem ser explicitados, monitorados e fortalecidos.

Adicionalmente, as etapas e níveis de um ciclo de políticas públicas carecem de uma maior integração entre si e constantes aprimoramentos para maximizar a eficiência, a eficácia e a efetividade dos recorrentemente escassos recursos. É sob esta perspectiva que a ideologia do novo gerencialismo introduzida no Brasil no final da década de 1990 acolheu como princípio trazer maior eficiência ao Estado por meio da orientação das iniciativas para o resultado. Um importante parâmetro para determinar o desempenho das políticas públicas diz respeito à disponibilidade e confiabilidade de informações. Entretanto, desde a implementação deste modelo no Brasil, o déficit e descrédito de informações tem se sobressaído e as poucas informações disponíveis ainda são pouco utilizadas. 


\subsection{Metodologia da dissertação}

\subsubsection{Classificação da dissertação}

Vergara (1997) propõe dois critérios básicos para classificar o tipo de pesquisa: quanto aos meios e quanto aos fins. Segundo estes critérios, esta pesquisa pode ser classificada como bibliográfica e documental quanto aos meios e como descritiva e aplicada quanto aos fins. Adicionalmente, este trabalho também pode ser classificado como quali-quantitativo segundo a descrição de Prodanov e Freitas (2013) e de campo segundo Gil (2010).

São objetos de análise os diversos documentos e publicações nacionais e internacionais produzidos que consolidam as lições aprendidas por instituições públicas federais que implantaram - ou tentaram implantar - um SMA em seus respectivos países e setores. Assim, este estudo pode ser considerado como bibliográfico e documental.

Na medida em que uma pesquisa explicita o problema e contribui para solucioná-lo, este trabalho pode ser classificado como de natureza aplicada segunda as definições de Vergara (1997), Gil (2010) e Silva e Menezes (2011). Apesar da dependência que este tipo de trabalho possui da pesquisa pura para enriquecer e se desenvolver, por um lado o estudo possui como característica fundamental o interesse na aplicação, na utilização e nas consequências práticas dos conhecimentos (Gil, 2010). Por outro, se distingue da pesquisa intervencionista uma vez que propõe as soluções, mas não tem como objetivo resolver o problema de forma mais efetiva e participativa (Vergara, 1997).

Outra classificação a ser atribuída a este trabalho é quanto aos seus objetivos. A proposta de diretrizes para um SMA das políticas públicas para a infraestrutura federal de transportes é formulada a partir da consolidação do entendimento na literatura sobre os elementos de uma abordagem sistêmica, o ciclo de políticas públicas e as práticas recomendada pelo Banco Mundial - dada a reconhecida atuação do banco no uso destes SMAs em projetos complexos e multidisciplinares. O confronto dos aspectos específicos identificados com as experiências semelhantes em SMA de políticas públicas federais no Brasil e em outros países permitiu verificar a pertinência destes e identificar a necessidade de incorporar outros aspectos específicos não identificados na literatura. 
Por isto, a partir das definições de Vergara (1997) percebe-se que este estudo possui um caráter epistemológico, abordando sobre a transmissão objetiva de determinado conhecimento para outras instâncias. O trabalho também apresenta um caráter dedutivo - segundo as definições de Vergara (1997) e de Gil (2010) - uma vez que parte de conhecimentos gerais para aplicação específica e que busca por meio do silogismo apresentar diretrizes que contribuam para uma abordagem sistêmica das políticas públicas de infraestrutura de transportes. Além disso, este estudo possui predominantemente um caráter descritivo dos problemas e das soluções segundo o mesmo autor.

A aplicação da pesquisa Delphi com especialistas garantiu que todos os componentes sejam analisados individualmente e que os respondentes registrassem suas críticas e observações.Por consequência, este trabalho também é quali-quantitativo - uma vez que trata estatisticamente as respostas obtidas (Prodanov e Freitas, 2013) -, de campo - dada a interrogação direta de pessoas do setor - e com universo finito (Gil, 2010) -devido ao número limitado de especialistas que atuam na área.

\subsubsection{Etapas da dissertação}

A $1^{\text {a }}$ etapa deste trabalho foi desenvolvida para atender a necessidade de apresentar a definição de sistemas e das suas principais características, bem como identificar como esta teoria é abordada em um ambiente organizacional. Tendo em vista o objeto em questão (a infraestrutura federal de transportes), impôs-se também a necessidade de discorrer sobre a abordagem sistêmica no setor público, identificando suas etapas e destacando a importância que um SMA representa.

Ainda nesta $1^{\mathrm{a}}$ etapa, as diversas experiências nacionais e internacionais foram consultadas para identificar a recorrência destes aspectos e incorporar melhorias e particularidades regionais não identificadas até então às diretrizes para a criação de um SMA das políticas públicas para a infraestrutura federal de transportes.

Em seguida, para verificar as hipóteses e atender ao objetivo geral deste estudo, a $2^{\text {a }}$ etapa se concentrou em definir o método para definição das diretrizes para um sistema de monitoramento e avaliação das políticas públicas para infraestrutura federal de transportes. 
Este método se resume pela identificação das diretrizes gerais, submetidas à apreciação de especialistas em infraestrutura de transportes para opinarem sobre o estágio atual e o grau de importância dos aspectos específicos no setor. O método de consulta utilizado nesta etapauma pesquisa Delphi - garantiu que todos os componentes sejam analisados individualmente e que os respondentes registrassem suas críticas e observações.

$\mathrm{Na} 3^{\mathrm{a}}$ etapa as diretrizes para um sistema de monitoramento e avaliação das políticas públicas para infraestrutura federal de transportes são definidas a partir da aplicação do método definido na etapa anterior. A partir da coleta e análise dos dados obtidos pela pesquisa Delphi, esta etapa se dedicou a verificar a necessidade de ajustar os aspectos específicos segundo as peculiaridades do setor e a acrescentar aos fatores favoráveis e desfavoráveis gerais aqueles fatos atinentes às peculiaridades do setor, segundo a opinião dos especialistas respondentes.

A avaliação final deste trabalho foi realizada na última etapa, anotando as conclusões, as limitações do estudo e as recomendações para trabalhos futuros.

\subsubsection{Procedimentos da dissertação}

O material consultado para desenvolver esta pesquisa foi obtido a partir de livros, artigos, relatórios e planos do governo brasileiro disponíveis na internet. Está em grande parte disponível em portais de buscas ampla - como Google - e acadêmica - como o Periódicos CAPES e o Google Shoolar -, encontrados a partir da utilização de um conjunto de palavrachave que associam o termo "Transporte" a outros como "Ciclo de Política Pública", "Policy Cycle" e "Sistema de Monitoramento e Avaliação".

As referências utilizadas subsidiaram a definição conceitos, caracterizar e contextualizar a abordagem sistêmica e destacar sua relevância e importância. Incluem trabalhos desenvolvidos em outros países de forma a abordar as recentes práticas e entendimentos internacionais neste domínio. A relevância dos materiais a serem utilizados será verificada, além do seu reconhecido valor, por meio da quantidade de citações do trabalho nos próprios mecanismos de busca ou em outros sites de buscas acadêmicas. Ainda assim, determinados trabalhos foram utilizados tendo em vista a clareza e profundidade que abordam os temas afins. 
Consultando diversos estudos sobre abordagens sistêmicas em diferentes disciplinas, notou-se sistematicamente referência aos trabalhos de Ludwig von Bertalanffy, idealizador da TGS. Entretanto, Bertalanffy (1975) discorre sobre a TGS de forma fragmentada, utilizando casos em áreas como a biológica, a cibernética, a química, a antropológica, a psicológica e a matemática para apresentar e detalhar seus conceitos e suas características. Tal amplitude de aplicação da teoria faz com que o autor reconheça que estudar a TGS requer um melhor detalhamento segundo as necessidades de cada área. Por isto, o caráter institucional do SMA proposto pelo presente trabalho resultou em uma maior aproximação da TGS com o ambiente organizacional. Katz e Kahn (1978) são autores reconhecidos pelas abordagens organizacionais da TGS, motivo pelo qual foram utilizados para descrever a TGS neste ambiente.

As características elencadas por Katz e Kahn (1978) (denominadas de aspectos neste trabalho) foram detalhadas para ilustrar o funcionamento de um sistema e destacar neste a participação da retroação. Tal descrição é importante para apresentar os próprios aspectos da retroação uma vez que os sistemas são formados por subsistema e que, por isto, também se aplicam a um (sub) sistema de retroação - e foi fundamental para identificar um importante aspecto para um SMA das políticas públicas da infraestrutura de transportes: a liderança.

A revisão da literatura seguinte à TGS enfatizou a abordagem sistêmica no ciclo de políticas públicas por meio dos trabalhos de Dye (2013) e Jann e Wegrich (2007), destacando de igual maneira a participação da retroação por meio das atividades de monitoramento e avaliação. Os estudos sobre CPP permitiram identificar a complementaridade das teorias e simplificar, de certa forma, o entendimento sobre o CPP. Enquanto o modelo de Kingdon apresentado por Capella (2007) reúne as complexidades presentes nas primeiras etapas do processo - não sendo em si o objeto principal deste trabalho -, a teoria dos programas abordada por Chen (2005) e Bamberger, Rugh e Mabry (2011) discorre de forma mais estruturada sobre os aspectos operacionais das políticas públicas. Mesmo apresentando brevemente métodos e ferramentas para desenhar as políticas públicas - como a árvore de problemas -, a teoria dos programas discutida nos trabalhos de Wholey; Hatry; Newcomer (2010) e Chen (2005) permitiu enfatizar a importância e participação que um SMA representa para todo o ciclo. 
O material de referência para compatibilizar o arcabouço sobre um SMA descreve as práticas recomendadas pelo Banco Mundial, o qual apresenta componentes de um SMA a partir da sua experiência internacional com projetos multidisciplinares e complexos. De forma mais objetiva, o Banco Mundial discorre sobre os componentes para a criação de uma instância responsável pela retroação de um sistema - os SMAs. O material elaborado por Görgens e Kusek (2009) para a instituição apresenta de forma didática e sistematizada doze componentes para a criação e manutenção de um SMA, organizados em três camadas (dados ou insumos, institucional, e de finalidade).A partir da identificação e descrição dos aspectos mais relevantes de uma abordagem sistêmica na TGS, no CPP e nas recomendações do Banco Mundial, eles foram comparados segundo a familiaridade que apresentam.

Para complementar a revisão bibliográfica e documental, mostrou-se oportuno verificar nesta fase a importância dos elementos identificados até então em lições aprendidas por instituições nacionais e internacionais de diferentes áreas de atuação sobre o tema. A experiência da ONU foi estudada por meio da síntese de manuais e normas que discorrem sobre os processos e as ferramentas utilizados pelos projetos que implementam, permitindo explorar a aplicação prática e a forma como um SMA se integra em uma organização.

As demais experiências foram estudadas por meio de publicações para entender como elementos identificados até então estiveram presentes na criação de um SMA. Dado que estas informações ilustram como as dificuldades foram superadas, elas foram organizadas na forma de lições aprendidas para subsidiar a criação de um sistema de monitoramento e avaliação das políticas públicas para infraestrutura federal de transportes.

Os resultados obtidos anteriormente foram consolidados para viabilizar a elaboração e aplicação de uma pesquisa Delphi com especialistas envolvidos com a infraestrutura federal de transportes com o principal objetivo de verificar, segundo a opinião dos participantes,o estágio atual e a importância dos aspectos específicos identificados anteriormente. Adicionalmente, esta pesquisa permitiu ao estudo coletar comentários e sugestões dos respondentes para aprimorar e adequar as diretrizes gerais às peculiaridades do setor de infraestrutura federal de transportes. 
A partir das críticas de especialistas da área sobre as diretrizes gerais, foram elaboradas as diretrizes definitivas de um SMA das políticas públicas para a infraestrutura de transportes. Os dados obtidos pela Delphi foram utilizados para verificar a pertinência de cada aspecto específico e a necessidade de ajustes ou revisão da proposta para incorporar peculiaridades do setor. Os comentários dos especialistas sobre as dificuldades ou aspectos favoráveis no setor foram organizados e reunidos com as lições aprendidas em diversos setores. Estes dados foram acrescentados às diretrizes definitivas como forma de subsídio e complementaridade.

\subsection{Estrutura da dissertação}

Este estudo foi estruturado em sete seções, seguidas da seção única de referências. A presente seção realiza a introdução do trabalho e apresenta as delimitações, o problema, as hipóteses, os objetivos, as justificativas, a metodologia e a estrutura da dissertação.

A seção dois faz uma revisão da literatura para reunir definições e conceitos teóricos sobre a abordagem sistêmica dos problemas.Especificamente, a seção 2.1 apresenta-se como a principal referência do trabalho, motivo pelo qual descreve com um maior detalhamento a TGS para resgatar o entendimento e identificar e definir os conceitos dos aspectos de uma abordagem sistêmica dos problemas. Dado o caráter público a que o objeto do estudo está sujeito, a subseção 2.2 discorre sobre o ciclo de políticas públicas e se concentra em discutir sobre os SMAs de forma a correlacionar a abordagem sistêmica à governança da infraestrutura de transportes.

Para compatibilizar os termos encontrados na literatura, a seção três discorre sobre práticas reconhecidas e principais experiências nacionais e estrangeiras com SMAs. Conforme comentado, as recomendações do Banco Mundial apresentadas na subseção 3.1são adotadas como principal referência para a elaboração das diretrizes de um SMA das políticas públicas para a infraestrutura federal de transportes - tendo em vista a reconhecida atuação do banco e a forma objetiva com que aborda o assunto. Na subseção 3.2, as experiências nacionais e estrangeiras com SMAs, utilizando o exemplo das Organizações das Nações Unidas (ONU) para ilustrar como um SMA se integra nas organizações, seguidas dos fatores que favoreceram ou dificultaram a criação de SMA no país e na América Latina. 
A seção quatro apresenta o método utilizado para definir as diretrizes para a criação de um SMA das políticas públicas para as infraestruturas federais de transportes, apresentando as fases da pesquisa e os procedimentos utilizados. Nesta mesma seção são apresentados os resultados da aplicação do método, especificamente as informações sobre a aplicação do questionário Delphi.

A apresentação e a análise dos demais dados são realizadas na seção cinco, permitindo que a seção seis apresente as diretrizes para a criação de um SMA das políticas públicas para as infraestruturas federais de transportes. Por fim, a seção sete finaliza o trabalho apresentando as conclusões, limitações e recomendações para novos estudos e aplicações do método. O Quadro 1.1 a seguir esquematiza a estrutura deste trabalho segundo a metodologia descrita sucintamente neste subitem 1.5.

Quadro 1.1-Detalhamento da metodologia da dissertação.

\begin{tabular}{|c|c|c|c|}
\hline Etapa & Título & Descrição & Capítulo \\
\hline \multirow[t]{11}{*}{ Etapa 1} & \multirow[t]{7}{*}{ Introdução } & INTRODUÇÃO & \multirow[t]{7}{*}{ Capítulo 1} \\
\hline & & Contextualização do problema & \\
\hline & & Hipóteses & \\
\hline & & Objetivos & \\
\hline & & Justificativa & \\
\hline & & Metodologia da dissertação & \\
\hline & & Estrutura da dissertação & \\
\hline & \multirow{2}{*}{$\begin{array}{l}\text { Referencial } \\
\text { teórico }\end{array}$} & Teoria Geral dos Sistemas (TGS) & \multirow[t]{2}{*}{ Capítulo 2} \\
\hline & & O Ciclo de Políticas Públicas (CPP) e o MeA & \\
\hline & \multirow{2}{*}{$\begin{array}{l}\text { Práticas e } \\
\text { experiências }\end{array}$} & Banco Mundial & \multirow[t]{2}{*}{ Capítulo 3} \\
\hline & & Práticas e experiências nacionais e internacionais em MeA & \\
\hline Etapa 2 & Método & Descrição do método & Capítulo 4 \\
\hline \multirow[t]{3}{*}{ Etapa 3} & \multirow{3}{*}{$\begin{array}{l}\text { Aplicação } \\
\text { do método }\end{array}$} & Aplicação do método & \\
\hline & & APRESENTAÇÃO E ANÁLISE DOS DADOS & Capítulo 5 \\
\hline & & Elaboração das diretrizes definitivas & Capítulo 6 \\
\hline Etapa 4 & Conclusões & Conclusões, limitações e recomendações & Capítulo 7 \\
\hline
\end{tabular}

Fonte: Elaborado pelo autor. 


\section{ABORDAGEM SISTÊMICA}

\subsection{Teoria Geral dos Sistemas (TGS)}

Segundo Ferreira (2010), sistema é um conjunto de elementos organizados e que apresentam alguma relação entre si, reunidos para atingir objetivos específicos. Na literatura, as discussões sobre o tema são polarizadas pelas contribuições feitas por Ludwig Von Bertalanffy desde os anos 1920. Voltado para a ciência biológica, Bertalanffy encampou a ideia de que o organismo vivo é uma entidade em contínua interação com o ambiente, de tal modo que os estudos não poderiam se limitar a uma visão estanque das várias disciplinas (Do Vale, 2013).

Àquela época, a ciência contemporânea já apresentava avanços em busca de estudar os sistemas como uma entidade, considerando a interação entre partes e não apenas uma reunião destas. Segundo as descrições de Lhullier (1978) e do Vale (2013), percebe-se naquela campanha o envolvimento de estudiosos de diversas áreas como a matemática, a médica, a econômica, a ciências sociais, a psiquiatria, a cibernética, a biomatemática e a fisiologia; demonstrando a convergência de entendimento em várias disciplinas.

Na teoria do planejamento, Faludi (1973) atribui a incorporação dos conceitos sobre uma abordagem sistêmica que emergiam na época por meio das publicações de Mcloughlin e Chadwick. Uhlmann (2002) corrobora para ilustrar a congruência deste raciocínio mostrando que a teoria foi igualmente desenvolvida em outras regiões, muita delas isoladas entre si pelas limitações de mobilidade e de comunicação da época. Por isto, Bertalanffy é reconhecido pelo esforço em desenhar um referencial universal que permitiria a interação de conhecimentos por meio da criação de modelos aplicáveis a áreas de estudo distintas, criando, assim, a TGS (Do Vale, 2013).

Com a multidisciplinaridade da teoria, diversos autores desenvolveram definições de sistemas que se distinguem pelo seu detalhamento, alternam termos ou apenas buscam reestilizar os principais conceitos. O Quadro 2.1 a seguir consolida as definições encontradas nas referências consultadas, ilustrando a diversidade de abordagem sobre o tema. 
Quadro 2.1 - Definições de sistemas segundo autores.

\begin{tabular}{|c|c|}
\hline Autor & Definição de sistema \\
\hline Abbagnano $(2000)^{2}$ & Conjunto formado por premissas e conclusão. \\
\hline Avanir Uyemov $^{2}$ & $\begin{array}{l}\text { Agregado de elementos, complexos ou não, que tenham um conjunto de } \\
\text { relações que agem sobre o conjunto de elementos agregados fazendo com que } \\
\text { daí surja a emergência de novas propriedades não existentes nos elementos } \\
\text { isolados }\end{array}$ \\
\hline Bertalanffy (1975) & Um complexo de elementos em interação. \\
\hline Chiavenato $(2003)^{5}$ & $\begin{array}{l}\text { Conjunto de elementos interdependentes e interagentes que formam um todo } \\
\text { organizado no sentido de alcançar um objetivo. }\end{array}$ \\
\hline Churchman $^{2}$ & $\begin{array}{l}\text { Conjunto de componentes com funcionalidades relacionadas complexas } \\
\text { interconectadas. }\end{array}$ \\
\hline Frattini (1993) ${ }^{4}$ & $\begin{array}{l}\text { Conjunto integrado e ordenado de partes que atuam juntas, sinergicamente, } \\
\text { para a realização de determinado objetivo, dada uma série de restrições ao seu } \\
\text { funcionamento. }\end{array}$ \\
\hline Johnson $(1963)^{3}$ & $\begin{array}{l}\text { Todo organizado ou complexo, uma montagem ou combinação de coisas ou } \\
\text { partes for complexo ou todo unitário. }\end{array}$ \\
\hline Kant $^{2}$ & Unidade de múltiplos conhecimentos, reunidos sob uma única ideia. \\
\hline Mario Bunge $^{2}$ & $\begin{array}{l}\text { Tripla ordenada "a coisa [o sistema]", a "outra coisa [o ambiente]" é um } \\
\text { "conjunto de relações entre a coisa e a outra coisa". }\end{array}$ \\
\hline Miller $(1965)^{1}$ & $\begin{array}{l}\text { Conjunto de unidades com relações entre si e o seu grau de organização } \\
\text { permite que assuma função de um todo que é maior do que a soma de suas } \\
\text { partes. }\end{array}$ \\
\hline Optner (1966) ${ }^{34}$ & $\begin{array}{l}\text { Conjunto de objetos com um dado conjunto de relacionamento entre os objetos } \\
\text { e seus atributos. }\end{array}$ \\
\hline Thornes \& Brunsden (1977) ${ }^{1}$ & $\begin{array}{l}\text { Conjunto de objetos ou atributos de suas relações, que se encontram } \\
\text { organizados para executar uma função particular. }\end{array}$ \\
\hline Wolff $^{2}$ & com seus princípios. \\
\hline
\end{tabular}

Fontes: Adaptado de ${ }^{1}$ do Vale (2013); ${ }^{2}$ Uhlmann (2002); ${ }^{3}$ Monobe (1998); ${ }^{4}$ Frattini (1993);

${ }^{5}$ Chiavenato (2003).

Em sua tese inicial, Bertalanffy (1975) aborda os transportes ao citar que o tráfego aéreo ou mesmo o automóvel já não podem mais ser vistos apenas como número de veículos em operação, mas formando sistemas que devem ser planejados e organizados. Outros autores também exemplificam a abordagem sistêmica por meio dos transportes. Siegel (1971), por exemplo, comenta que a inclusão da atmosfera na definição de um sistema de transportes 
incorpora a poluição emitida pelos veículos, trazendo uma maior complexidade às análises. Hutchinson (1979) enfatiza que a interação sistema-meio ambiente é o principal desafio na definição de um problema no transporte urbano. Manheim (1979) também infere aspectos sistêmicos dos transportes ao destacar a interação e modificação das suas estruturas ao longo do tempo; e Banister e Berechman (2003) indicam a importância de considerar nas análises prévias dos investimentos em infraestrutura de transportes às externalidades que proporcionam.

Corroborando também para área, Bojović (2002) destaca os primeiros ensaios que utilizaram a TGS para discorrer sobre os engarrafamentos no trânsito; Almeida et al. (2009) fazem um exercício utilizando a TGS para sugerir uma metodologia de caracterização do transporte rodoviário interestadual semiurbano de passageiros no Distrito Federal e entorno; e Tedesco (2010) utiliza a teoria para propor uma metodologia para elaboração do diagnóstico de um sistema de transporte. A abordagem sistêmica nos transportes também pode ser observada em estudos recentes sobre segurança viária (Larsson, Dekker e Tingvall, 2010 e Hughes, Anund e Falkmer, 2015), transportes urbanos (Dahua, 2010) e logística (Halim, Tavasszy e Seck, 2012; Tavasszy, Ivanova e Halim, 2015 e Ekwall e Lantz, 2013). Especificamente, o monitoramento e avaliação das políticas públicas em transportes são destacados nos estágios e nas ferramentas apresentados por Nieto-Parra, Oliveira e Tibocha (2013).

Tedesco (2010) consolida reconhecidas definições de sistemas para o transporte, as quais antecipam alguns aspectos abordados neste estudo: as finalidades dos transportes como objetivo e sua interação com o ambiente na forma do uso do solo, dos aspectos institucionais e operacionais envolvidos, das relações entre oferta e demanda e dos condicionantes externos (políticos, socioeconômicos, culturais, infraestrutura, insumos e morfoclimáticos). As restrições que induzem um sistema à especialização podem ser constatadas no trabalho da autora por meio dos atributos considerados na escolha do serviço - confiabilidade, acessibilidade, tempo de deslocamento, conveniência, conforto, segurança, custos, disponibilidade e qualidade -; e a definição de planejamento de Wingo e Perloff (1961) apresentada por Tedesco (2010) aproxima-o da definição de um sistema ao descrevê-lo como um processo de sucessivas decisões, sujeitas a restrições. Portanto, pela complexidade que envolve o sistema de transporte, seu propósito está relacionado às perspectivas dos seus 
atores, a partir das quais é possível identificar as necessidades e oportunidades de melhoria nas respectivas atribuições.

Apesar de Bertalanffy (1975) indicar os principais aspectos da TGS, o próprio autor enfatiza que a maior ou a menor complexidade de um sistema requer a aplicação de modelos compatíveis com a natureza do caso e dos fatores operacionais. Para o contexto da governança pública da infraestrutura federal de transportes, os aspectos a serem abordadas serão subsidiados pelas questões organizacionais apresentados por Katz e Kahn (1978).

\subsubsection{Aspectos gerais e específicos de um sistema}

Na TGS apresentada por Bertalanffy (1975) se percebe fatores intrínsecos de uma abordagem sistêmica (denominados neste trabalho como aspectos gerais): o ambiente, a totalidade e a finalidade. Citando a evolução da ciência, o autor exemplifica a abordagem mecanicista da época na interpretação do mundo mental como um curioso e inconsequente epifenômeno dos acontecimentos materiais, desmembrando a realidade física dos elementos.

A exaustão da visão do mundo como um produto do acaso expôs o comportamento teleológico como um problema legítimo da ciência, onde a existência de um sistema está relacionada a algum tipo de intencionalidade e de interação dinâmica das partes nos problemas. Por este motivo, Katz e Kahn (1978) enfatizam que a teoria está interessada pelos problemas de relação, estrutura e interdependência em lugar dos atributos de cada elemento que o compõe.

O primeiro aspecto geral de um sistema, o ambiente, decorre da relevância do estudo dos problemas sob a forma de sistemas abertos, onde existe uma interação dos seus elementos com outros presentes no ambiente em que estão inseridos.Chiavenato (2003) considera que o ambiente é algo que está fora do controle do sistema e composto por variáveis indeterminadas e incontroláveis, dificultando a previsibilidade dos resultados dos sistemas. Mesmo assim, determinados sistemas buscam entender e mapear estes fatores intervenientes, reunidas em determinadas disciplinas sob a denominação de riscos. 
Uhlmann (2002) assevera a discussão destacando que todo sistema tem um ambiente e com este interage em vários graus de intensidade, fazendo com que os conceitos de sistemas abertos sejam expandidos a todos os sistemas. Nos transportes, Hutchinson (1979) denomina meio ambiente como o conjunto de fatores externos ao sistema que influencia o comportamento do sistema ao mesmo tempo em que é influenciado por ele; e Ceftru (2007) descreve o ambiente de transporte como um conjunto de fenômenos que influenciam e/ou é influenciado pelo transporte.

Os sistemas abertos se mantêm pelo contínuo fluxo de energia interno e com o ambiente por meio das entradas e saídas, e se conserva pela construção e decomposição de componentes em busca de um estado estacionário (Bertalanffy, 1975). Pela ótica organizacional, entre os noves aspectos apresentadas por Katz e Kahn (1978) para definir um sistema aberto, três estão relacionadas diretamente a este fluxo: a importação, a transformação e as saídas. A primeira permite a absorção dos insumos atinentes às funções endógenas do sistema, que seguem para serem decompostos e/ou combinados durante o processo para a formação de um produto, expelido para o ambiente por meio da saída. A Figura 2.1 a seguir apresenta esquematicamente estes aspectos em um modelo simplificado de sistemas proposto pela TGS.

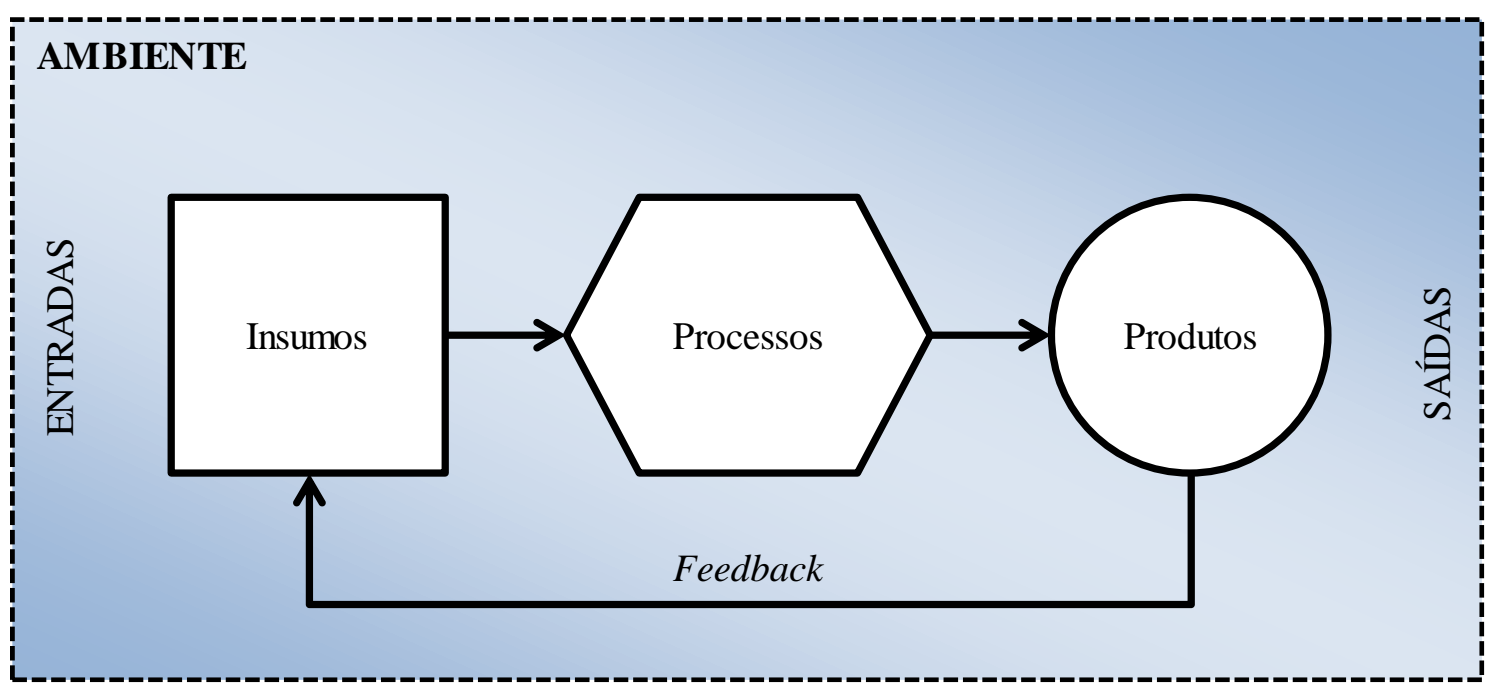

Figura 2.1 - Modelo simplificado de um sistema.

Fonte: Elaborado pelo autor.

A interação com o ambiente faz com que os sistemas sejam formados e influenciados por outros sistemas a montante - os subsistemas - ou que componham e influenciem da mesma 
forma outros sistemas a jusante - os supra sistemas. Este intercâmbio também ocorre internamente ao sistema, o qual gera e consome certo tipo de energia sobre sua própria atividade (a informação, abordada ao final no aspecto específico da retroação) em busca de um estágio estacionário e da sua especialização. O inter-relacionamento entre estes vários níveis garante que a energia despendida para a geração de determinado produto seja compensada na entrada do sistema progenitor. Este aspecto específico é indicado por Katz e Kahn (1978) como ciclo de eventos e representa a participação colaborativa dos atores em um sistema.

Relacionado ao aspecto geral da totalidade, a citada busca pelo estado estacionário representa o fluxo interno de energia e podem ser deduzidas por outras três características descritas por Katz e Kahn (1978) que estão relacionados à eficiência de um sistema: a entropia negativa, a homeostase dinâmica e a equifinidade.

Segundo os autores, a necessidade de mitigar a tendência natural da matéria para se desordenarem - denominado de entropia - faz com que a energia a ser absorvida pelo sistema seja suficiente para executar suas funções e para mitigar tal desordem - excedente este denominado de entropia negativa. Por este motivo, os sistemas abertos não alcançam o mesmo estágio de equilíbrio observado nos sistemas fechado - onde as quantidades de energia entrantes e expelidas se anulam -, mas buscam por um pseudo-equilíbrio que o mantém em um estágio estacionário em meio a constantes trocas de energia com o ambiente, denominado de homeostase dinâmica. A ênfase destes aspectos demonstra que os sistemas buscam insistentemente meios para minimizar imperfeições intrínsecas.

Estas trocas de energia ou matéria em um sistema proporcionam a realização contínua de trabalho para atender a finalidade para qual foi criado. Ainda que as entradas sejam as mesmas ou similares, o resultado final pode ser alcançado por diferentes caminhos em um sistema (Bertalanffy, 1975). Este aspecto é destacado por Katz e Kahn (1978) como equifinalidade - remetendo à organização das funções do sistema previsto na TGS - e contribui para demonstrar que a simples reunião de elementos não garante a produção de determinado resultado. 
Por isto, Bertalanffy (1975) indica que um sistema requer algum tipo de organização dinâmica e energeticamente eficiente e equilibrada. Sob esta ótica, a TGS considera que as funções de um determinado sistema dependem da sua estrutura e organização, as quais devem garantir que um sistema contorne as restrições impostas pelo ambiente, aumentando incondicionalmente sua especialização e ampliando, ao mesmo tempo, sua significância.

O contínuo fluxo de energia, o ciclo de eventos e a busca pelo equilíbrio dinâmico remetem ao terceiro aspecto geral do sistema, a finalidade, e representam a utilidade de um sistema. Determinado sistema é criado, aprimorado e incorporado neste ciclo de eventos para atender necessidades. O aspecto da diferenciação ou especialização apontado por Katz e Kahn (1978) torna seus processos e suas saídas cada vez mais elaborados e diferenciados para manter a si próprio e o supra sistema organizados e eficientes.

$\mathrm{O}$ ciclo energético e material que se forma pela interdependência com o ambiente e outros sistemas também é observado internamente sob a forma de um fluxo de informações. Citando um modelo utilizado por estudiosos americanos (a regulação retroativa), Bertalanffy (1975) destaca que todo sistema gera em sua saída informações sobre o processo e o produto que são enviadas ao início do processo para se tornarem insumos juntamente com a energia absorvida. Este aspecto específico - denominado de retroação por Bertalanffy (1975) e de feedback por Katz e Kahn (1978) - garante que haja um ciclo interno de eventos, trazendo consigo características completares que garantem a credibilidade de um sistema: a entrada de informação, a codificação e a autorregulação.

Além da energia e/ou matéria, os sistemas absorvem informações que fornecem sinais aos seus componentes controláveis (os elementos e os filtros ou codificadores de entrada) para corrigir os desvios de direção ou preservar as operações em curso. Enquanto as informações direcionadas aos codificadores de entrada visam aprimorar a seleção dos insumos compatíveis com a finalidade dos elementos, o próprio processo recebe informações em busca de explorar sua equifinalidade (Lhullier, 1978).

As informações são os produtos do subsistema de retroação, o qual analisa, por sua vez, os dados brutos sobre: i) as restrições do ambiente em que o sistema está inserido, ii) seu próprio 
funcionamento (fornecidos por meio de um micro controle) e iii) os produtos entregues (fornecidos por meio de um macrocontrole), conforme detalha Barbieri (2000). Desta forma, o autogoverno de um sistema é dirigido por adequados fluxo e processamento de dados e pela capacidade de reflexão e análise (processamento) do subsistema de retroação.

Segundo ainda Barbieri (2000), a reflexão (ou o processamento e a análise dos dados) na retroação é a fonte estabilizadora do sistema e que contribui para sua evolução. Sem ela, a excessiva carga de dados brutos geradas pelos feedbacks resulta em um aumento da entropia do sistema, congestionando e desestabilizando-o. No caso de sistemas pequenos e menos complexos, a reflexão pode ser integrada pela totalidade dos seus membros, acelerando a eficiência das informações a montante e a jusante. Desta forma, o adequado dimensionamento da retroação é responsável pela eficiência do sistema.

O caráter cíclico citado anteriormente requer que um sistema seja composto por mecanismos capazes de regular constantemente o desempenho das suas funções e seus resultados a partir da integração de informações. Bertalanffy (1975) se preocupa em diferenciar inicialmente dois tipos de regulação presente nos sistemas orgânicos: os primários e os secundários. As regulações primárias são as mais primitivas, onde a ordem é estabelecida nas fases iniciais dos sistemas por meio de uma inter-relação dinâmica dos elementos - assim como nos sistemas pequenos e menos complexos. Na medida em que o sistema evolui e dispõe de um número maior de informações, surgem em seguida as regulações secundárias, realizadas por dispositivos fixos do tipo retroativo para tornar suas partes mais eficientes.

O autor considera que a homeostase e a retroação formam uma classe especial de sistema autorregulador. Considerando-os como regulações secundárias, Bertalanffy (1975) inclui entre os critérios essenciais para tais atividades o fluxo exclusivo de informações - o que o torna, portanto, um sistema relativamente fechado à matéria e energia.

Além dos nove aspectos indicados anteriormente, Katz e Kahn (1978) dedicam um capítulo do seu trabalho à discussão sobre liderança. Os autores consideram que a essência da liderança se refere no uso das bases de poder para além das rotinas organizacionalmente 
decretadas, requisitando capacidades criativa, de revisão e de improvisação para "fazer a coisa funcionar".

Apesar do esforço para especificar e desenhar a estrutura e as interações de um sistema, o seu contato com o ambiente revela uma complexidade real que requisita iniciativas complementares. Na sua estrutura, por exemplo, o envolvimento de afiliações humanas nos sistemas organizacionais acrescenta uma concorrência dos seus objetivos com os interesses próprios dos indivíduos, necessitando de uma ação contínua no comportamento e conduta dos seus elementos. Nestes casos, a liderança é um aspecto específico com características peculiares que está presente em determinados elementos de um sistema.

Segundo Katz e Kahn (1978), a liderança surge na literatura a partir de três significados de maior importância provenientes das ciências sociais - o atributo de uma posição, a característica de uma pessoa e a conduta -, os quais podem ser associados aos cinco tipos distintos de poder que os próprios autores resgatam de French e Raven (1959) - os poderes legítimos, de recompensa, de punição, referente e do saber. Os poderes legítimos, de recompensa e de punição são concedidos pela organização aos líderes conforme os atributos de uma posição em hierarquias formais e por normas organizacionais. Entretanto, o uso inadequado destes poderes pode resultar em impactos negativos.

As influências baseadas na afeição e no respeito - o poder referente -, bem como na sabedoria organizacional e técnica - o poder do saber - se tornam complementares aos poderes formais para mitigar tais reflexos negativos e potencializar o uso dos poderes formais. Enquanto a afeição e o respeito estão relacionados à conduta, a sabedoria organizacional e técnica refletem as características de uma pessoa.

Além disso, a suposição trazida por Katz e Kahn (1978) de que a menor subparte de uma organização requer uma líder para ser exitosa expõe a perspectiva do ciclo de eventos dos sistemas e a importância da liderança em cada esfera. Cada subsistema requer um elemento com perspectiva sistêmica capaz de entender e atuar positivamente nas perspectivas internas e externas, estimulando por meios organizacionais não nocivos seus elementos - ou seja, explorando sua equifinidade. Katz e Kahn (1978) destacam que lideranças mais efetivas 
diminuem o hiato em relacionamentos pessoais e organizacionais de diversas maneiras, promovendo um pseudo-equilíbrio do sistema e a maior integração deste em um ciclo de eventos. A Figura 2.2 a seguir ilustra o empreendedor operacional em um sistema.

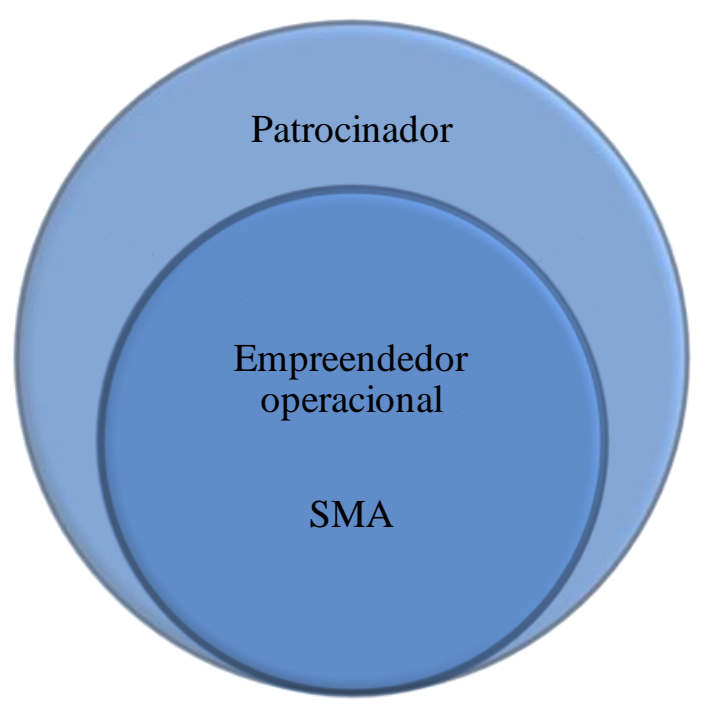

Figura 2.2 - Tipos de lideranças em um sistema.

Fonte: Elaborado pelo autor.

A atuação do líder para garantir a eficiência e a credibilidade de um sistema - por meio da atuação contra imprevisibilidades e instabilidades internas -, bem como para promover a participação colaborativa dos atores e a promoção da sua utilidade - por meio de uma maior inserção em um ciclo de eventos - resultam no acúmulo de atribuições e na necessidade de maior atenção deste ator para estrutura sob sua responsabilidade imediata. Por este motivo, a preocupação apenas em capturar um líder formal de alta hierarquia a um sistema pode comprometer o seu êxito uma vez que tais líderes formais respondem por esferas superiores dos sistemas - os supra sistemas -, resultando na consequente concorrência de atribuições.

Percebe-se que a liderança é um décimo aspecto específico de um sistema que interage com todos os demais, explorando as informações geradas pela retroação e as prerrogativas de poder para garantir a finalidade do sistema dentro de um ciclo de evento.

Assim, os aspectos específicos dos sistemas abordados anteriormente podem ser esquematizados conforme apresenta a Figura 2.3 a seguir. 


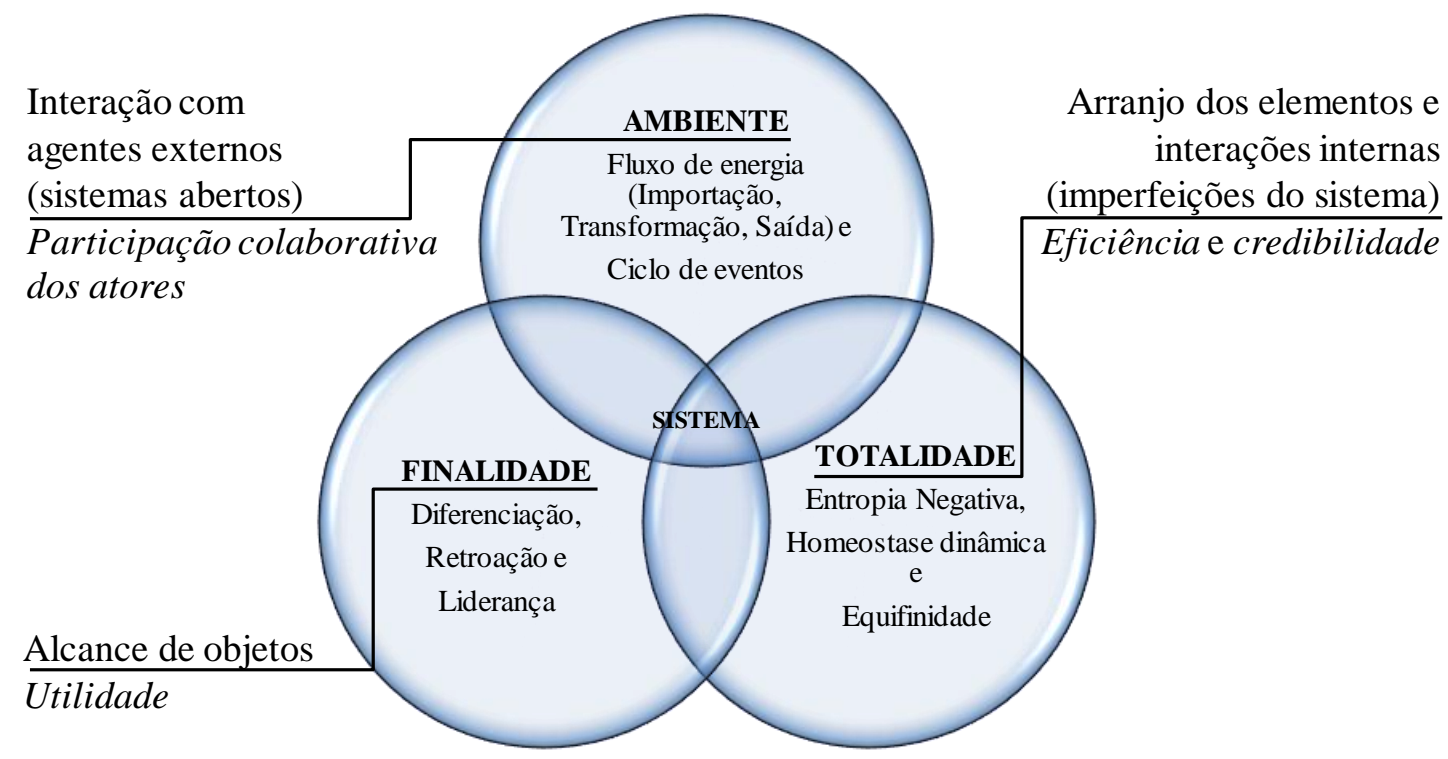

Figura 2.3 - Aspectos gerais e específicos de um sistema.

Fonte: Elaborado pelo autor.

\subsubsection{O subsistema de retroação: o Monitoramento e a Avaliação (MeA)}

A presença do subsistema de retroação mostra que um sistema é formado por um processo constante de monitoramento e avaliação das condições do ambiente, dos insumos, dos processos e dos produtos para garantir sua finalidade, sua homeostase dinâmica e sua entropia.

O monitoramento e a avaliação são diferenciados por Wholey, Hatry e Newcomer (2010) segundo sistemas de monitoramento de desempenho (performance) e estudos de avaliação, ou ainda por Chen (2005) como estratégias de monitoramento e de avaliações de desempenho, respectivamente. $\mathrm{O}$ monitoramento está relacionado aos resultados de uma iniciativa sem a preocupação em associá-los aos efeitos que proporcionam. São informações frequentemente geradas por um significativo número de iniciativas e utilizadas normalmente para a gestão operacional e para verificar as discrepâncias entre o planejado e o realizado, permitindo ajustar o sistema para o curso desejado.

Já as avaliações são realizadas com uma menor frequência e abrangência de iniciativas uma vez que requer um maior número de recursos e complexidade, apresentando informações entre os produtos das iniciativas e os resultados observados. As avaliações são mais 
informativas e subsidiam a tomada de decisões de um programa ou de políticas. Segundo Chen (2005), são realizadas nos programas que apresentam um estágio mais avançado de maturidade da implementação. Quatro das sete avaliações apresentadas por Bamberger, Rugh e Mabry (2011) iniciam as avaliações juntamente com os projetos, por exemplo, buscando confrontar os dados ex-ante com os demais observados durante de depois dos programas.

A presença dos sistemas de monitoramento e avaliação é apresentada no modelo detalhado na figura 7 a seguir.

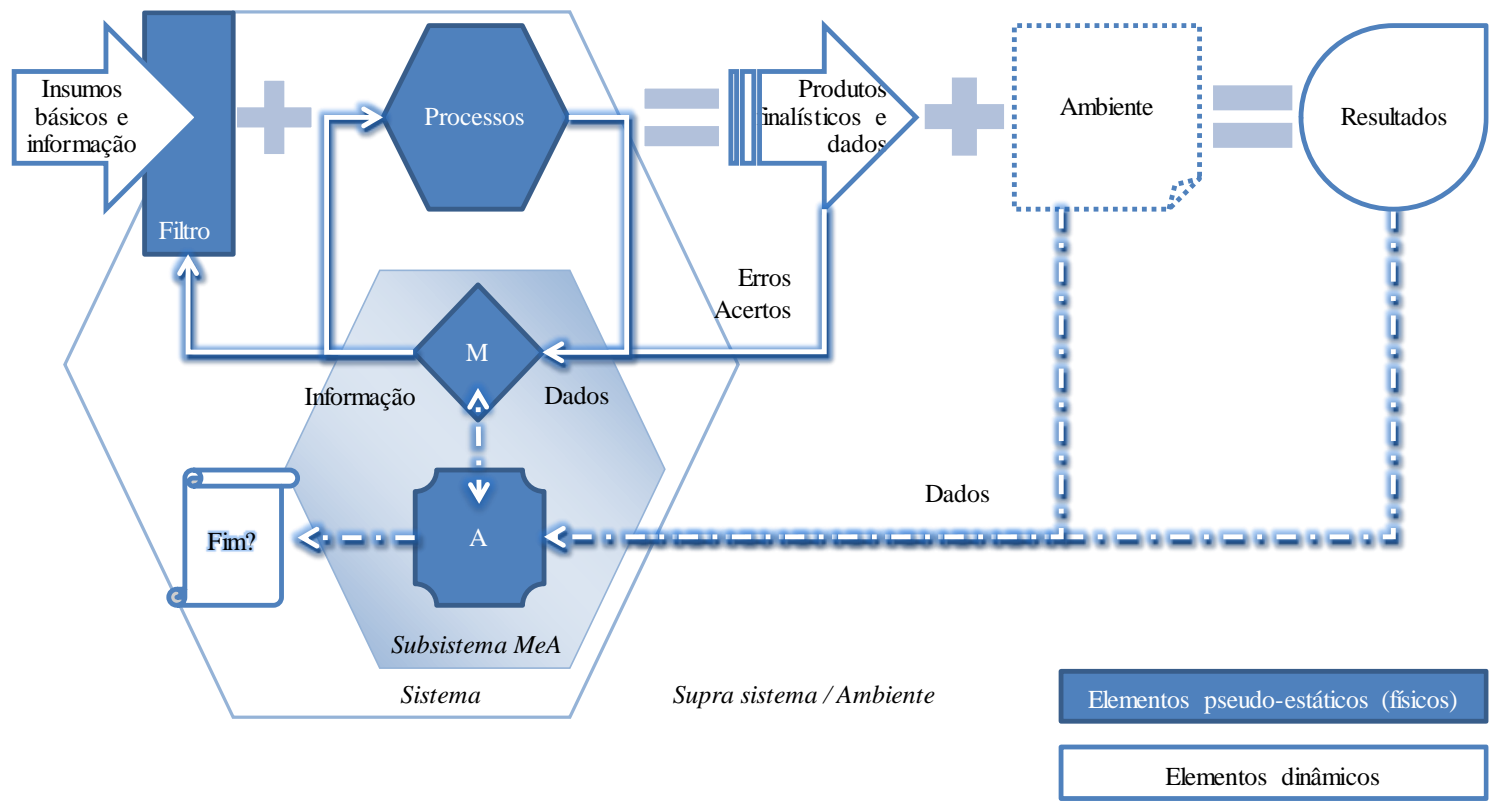

Figura 2.4 - Modelo detalhado de um sistema.

Fonte: Elaborado pelo autor.

Apesar da distinção, Wholey, Hatry e Newcomer (2010) destacam a relação entre estas duas atividades e, de certa forma, a maturidade dos sistemas - onde a presença do monitoramento do desempenho estimula a realização de avaliações. Por um lado, a geração de informação fomenta o surgimento de questões sobre a efetividade dos resultados - avaliando o quão melhor ou pior foram - e subsidiam o entendimento destes resultados em profundidade condizente ao interesse dos stakeholders. Por outro, a regularidade na disponibilização de informações sobre os resultados permite um aprimoramento das habilidades dos avaliadores por meio de uma maior sistematização das avaliações. 
Esses autores destacam a necessidade de uma combinação entre elas, alternando entre um maior monitoramento de desempenho e avaliações menos frequentes. Mas é notório no trabalho de Wholey, Hatry e Newcomer (2010) o caráter central do monitoramento, que fomenta tanto as iniciativas de implementação (a execução propriamente dita) como subsidia as avaliações - que por sua vez gera informações mais elaboradas voltadas para a tomada de decisão e o processo de accoutability.

\subsection{O Ciclo de Políticas Públicas (CPP) e o MeA}

$\mathrm{Na}$ medida em que as iniciativas relacionadas aos transportes recaem sobre o ambiente estatal, associam-se a ela as complexidades das atividades públicas. Esta esfera envolve intensas discussões entre atores e interesses variados, que resultam em políticas públicas com visões holísticas sobre determinado tema onde o todo assume maior importância que a soma das partes, conforme descreve Souza (2006). Buscando simplificar o debate, Dye (2013) sintetiza a definição de políticas públicas às escolhas governamentais sobre o que fazer e não fazer, se tornando uma ferramenta para regular comportamentos, organizar burocracias, distribuir benefícios e auferir taxas, cada qual utilizada individualmente ou combinada.

Uma discussão feita por Souza (2006) agrupa os principais modelos de políticas públicas existentes: o incrementalismo, o ciclo da política pública, o modelo garbage can, a coalizão de defesa, as arenas sociais, o modelo do equilíbrio interrompido e os modelos influenciados pelo novo gerencialismo público e pelo ajuste fiscal. Nestes sete modelos, além de se notar a presença de vários atores, o caráter formativo e a definição de um objetivo para nortear as ações, percebe-se também a iteração e a articulação entre os atores, as ferramentas e o ambiente.

Ao discorrer sobre alguns destes e outros modelos, Dye (2013) destaca que o uso de modelos no estudo das políticas públicas contribui para desmitificar os entendimentos, identificar aspectos importantes dos problemas, auxiliar na comunicação focada nos recursos essenciais, direcionar as iniciativas para entender melhor as importâncias dos fatores envolvidos, sugerir explicações e antecipar consequências das políticas públicas. 
Nesse sentido, Dye (2013), Jann e Wegrich (2007) utilizam dois modelos de atividades políticas para entender como são elaboradas as políticas públicas: o processo e o ciclo das políticas públicas - ou policy cycle, em inglês. Conforme lembram Jann e Wegrich (2007), Lasswell esboçou em 1956 o processo das políticas públicas baseado em sete estágios. Sua lógica teve grande importância para o avanço dos estudos em políticas públicas, dando origem a diversas tipologias que se diferenciavam por meio de um maior ou menor número de subestágios.

Mais especificamente, Jann e Wegrich (2007) distinguem o processo de políticas públicas do policy cycle por meio do modelo de entradas e saídas de David Easton. Easton (1957) aplicou a TGS à ciência política enfatizando o processo de feedback, o caráter contínuo, a influência do ambiente e os impactos esperados e inesperados dos produtos das iniciativas nos grupos objeto das políticas, conforme mostra esquematicamente a Figura 2.5 a seguir.

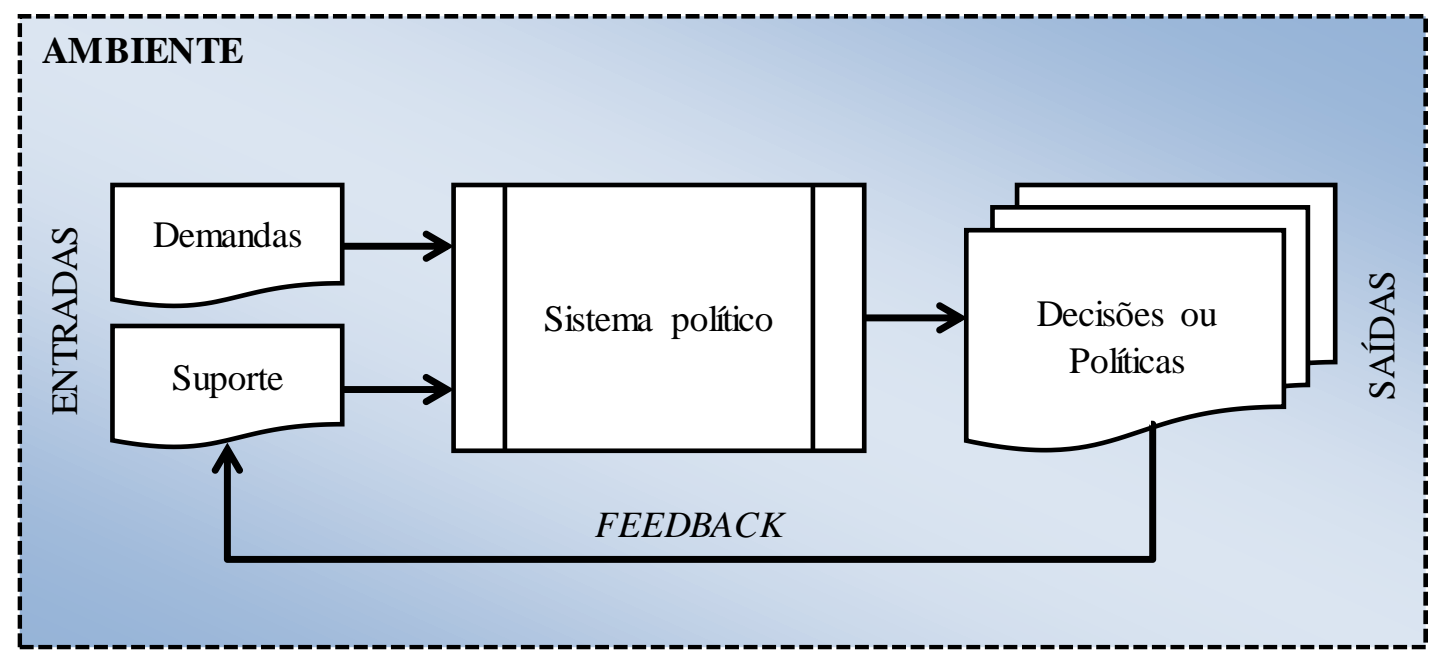

Figura 2.5 - Modelo de Easton.

Fonte: Adaptado de Easton (1957)

Desta forma, Jann e Wegrich (2007) destacam que, assim como apontado por Katz e Kahn (1978), o ciclo de políticas públicas se dedica mais a características genéricas que aos atores, às instituições, aos problemas particulares ou aos respectivos programas. Mas apesar da utilidade que a abordagem cíclica proporciona, Dye (2013), Jann e Wegrich (2007) destacam que é limitada. A complexidade que envolve as políticas públicas não permite que haja um fluxo organizado e contínuo dentro do ciclo - o que enfatiza o papel do ambiente no sistema 
político. Entender esta interação com estas peculiaridades possui, portanto, fundamental importância para o seu sucesso.

No Brasil, Rua (2009) corrobora para sistematizar o policy cycle apresentado na Figura 2.6 a seguir a partir de uma distinção entre politics e policies.

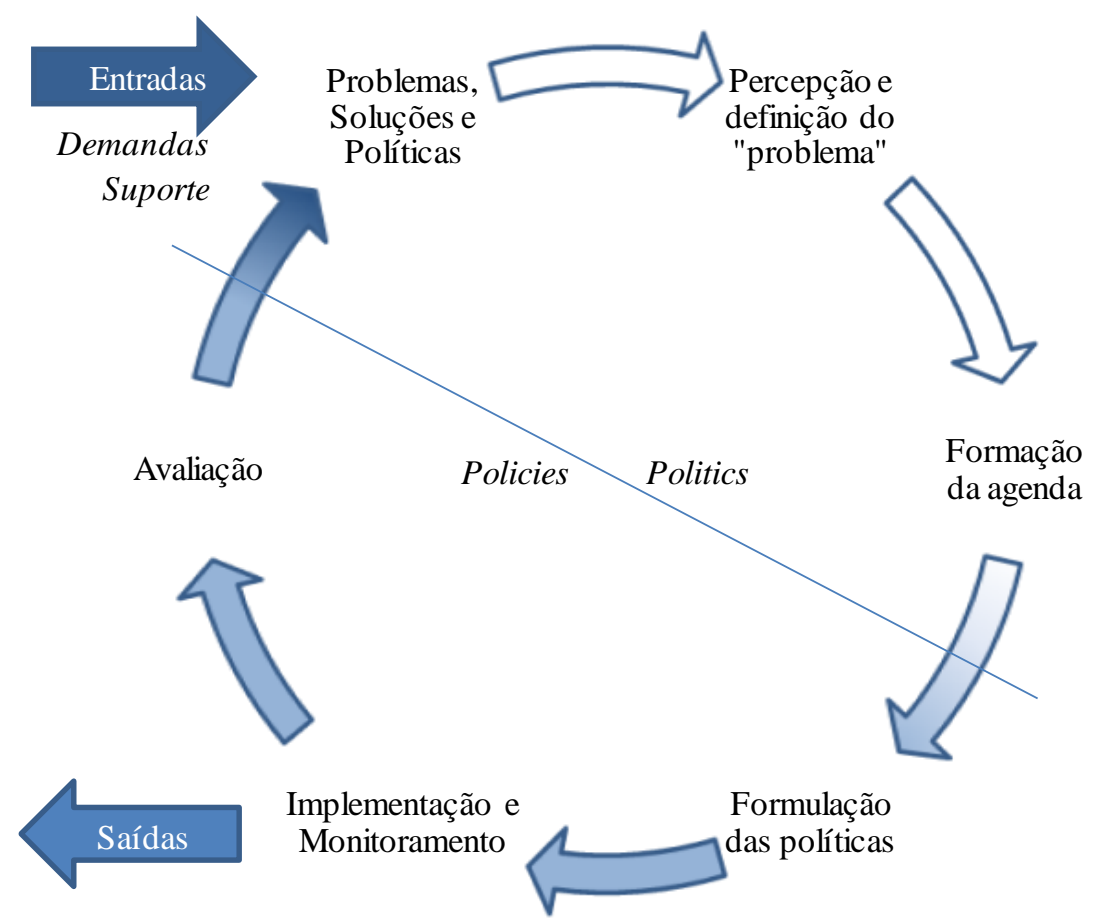

Figura 2.6 - Ciclo de políticas públicas.

Fonte: Elaborado pelo autor.

As atividades políticas - as politics - iniciam-se pela seleção de soluções a partir de particularidades que buscam adequar os meios aos fins desejados. Capella (2007) apresenta um modelo que destaca os tipos de demandas e como estas são selecionadas. O modelo de Kingdon foi criado pelo governo norte-americano para a análise da formulação das políticas públicas nas áreas de transportes e de saúde, e considera que a criação e a mudança da agenda pública é resultado da convergência de três fluxos: os problemas, as soluções e a política.

Estes três elementos orbitam, em tese, na entrada do ciclo de políticas públicas em busca de uma oportunidade para compor a agenda de políticas públicas. Conforme explica Capella (2007), a seleção dos problemas, das soluções e das políticas que formarão a agenda 
governamental - representando os filtros de um sistema proposto pela TGS - não necessariamente seguem critérios lógicos como o grau de importância ou criticidade; mas está associada a quesitos como a interpretação, o grau de receptividade das questões, a divulgação consistente de determinado problema ou solução e a atuação das forças políticas envolvidas.

Frey (2009) também destaca estes filtros na entrada do ciclo político ao enfatizar que um fato só é inserido uma agenda na medida em que adquirem relevância de ação do ponto de vista político e administrativo. Esta abordagem mostra que determinado fato pode ter tratamentos distintos, fazendo com que sua ênfase pelos atores interessados tenha um papel importante para sua inclusão na agenda. Portanto, o primeiro passo de uma política pública é a percepção e definição de problemas, onde determinados fatos preexistentes e potenciais podem assumir relevância por meio de uma maior ênfase do problema existente ou potencial.

Ainda relacionado à politics e ao modelo de Kingdon, a formação da agenda governamental envolve a discussão e a disputa pela pauta por vários atores. Além do uso argumentativo e do grau de atuação e de influência dos agentes (denominados também como polity), este processo é normalmente subsidiado por informações que buscam desmistificar as diversas demandas existentes (Frey, 2009) - como informações básicas sobre custos e benefícios ou aquelas disponibilizadas pelos subsistemas de monitoramento e avaliação.

Em meio à intensa disputa que ocorre nestas primeiras etapas do sistema político, Capella (2007) enfatiza um elemento fundamental apresentado por Kingdon para a promoção de uma mudança na agenda política: os empreendedores políticos ou os policy entrepreneurs. Segundo a autora, os empreendedores políticos são indivíduos empenhados em um propósito, especialistas em determinada questão, revestidos de autoridade e de habilidades para defender ideias próprias ou de terceiros e para manter conexões políticas; influenciando no processo decisório de forma a conciliar problemas e ideias no momento adequado. A figura 9 a seguir esquematiza o modelo de Kingdon e ilustra o caráter central do empreendedor político nestas etapas do ciclo de políticas públicas. 


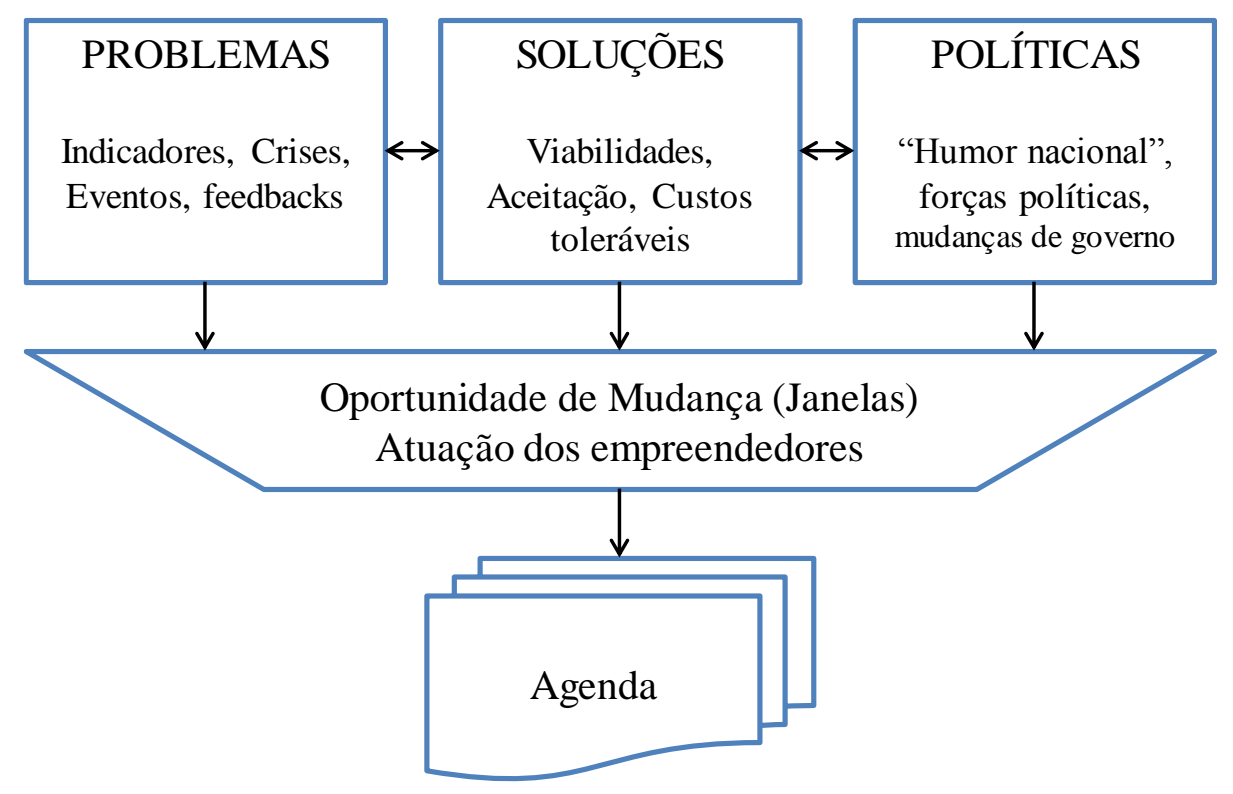

Figura 2.7 - Modelo esquemático de Kingdon.

Fonte: Adaptado de Capella (2007).

Apesar das atividades políticas prevalecerem nesta primeira metade do processo, são acompanhadas pela materialização de diversas decisões e consolidação das informações relacionadas, dando início à formulação das políticas públicas - as policies.

As policies transcrevem o conjunto de decisões e ações tomadas e que envolvem a alocação imperativa de valores sob o uso dos bens públicos (Rua, 2009). A partir da aprovação das políticas públicas (etapa que não será individualizada no presente estudo, mas é denominada por Dye (2013) como Legitimação das Políticas - Policy Legitimation), dá-se seguimento à sua implementação, etapa que busca articular os recursos para alcançar os objetivos estabelecidos.

Conforme lembra Frey (2009), uma vez que os resultados e impactos reais de certas políticas públicas podem não correspondem aos efeitos esperados, existem as atividades de monitoramento e de avaliação das iniciativas. Assim como abordado na TGS, enquanto o monitoramento busca melhorias das iniciativas em andamento de determinada política pública, a avaliação observa também os impactos e resultados das atividades implantadas no ambiente. 
Os produtos das avaliações são entregues para os agentes envolvidos, retroalimenta o ciclo (o ambiente) para permitir o aprimoramento do processo e fornece insumos para a elaboração de novas políticas públicas. Estas atividades são comumente agrupadas pela literatura sobre avaliação de políticas públicas por meio da Teoria dos Programas.

\subsubsection{A Teoria dos Programas}

A primeira metade do ciclo de políticas públicas definem as demandas que serão objeto das iniciativas públicas. Entender esta demanda ou problema e delineá-lo, por tanto, é o principal desafio de um programa. A teoria dos programas elabora um modelo lógico - denominados na literatura internacional como logics models, logframe, logics frameworks ou apenas frameworks - que organiza esquematicamente as intervenções necessárias para a solução do problema por meio do estabelecimento das relações e dos fluxos casuais entre elementos correlatos.

Além de o modelo lógico contribuir para a formulação das políticas públicas, permite também uma melhor comunicação entre os atores envolvidos durante a implementação ao estabelecer uma linguagem simplificada entre os atores. Assim, o modelo pode indicar, por exemplo, onde e como um determinado programa deve ser ajustado ou ainda como adequar o modelo à realidade. Portanto, o modelo lógico viabiliza os processos de feedback e de retroalimentação do sistema, motivo pelo qual é brevemente apresentado nos parágrafos a seguir.

Cassiolato e Gueresi (2010) desenvolvem um modelo lógico para organizar avaliações das intervenções governamentais que integram o Plano Plurianual (PPA) do governo brasileiro, sugerindo um roteiro para formular ou adequar a implementação dos programas futuros ou em andamento. A proposta é composta por três etapas: a explicação do problema e referências básicas do programa (objetivos, público-alvo e beneficiários), a estruturação do programa para alcance de resultados (resultado final e impactos) e a identificação de fatores relevantes de contexto.

A primeira etapa do modelo lógico apresentado por Cassiolato e Gueresi (2010), portanto, reúne os elementos necessários para identificar, delimitar e entender o problema pré-definido e seu relacionamento com outros elementos. Uma técnica utilizada neste componente é 
denominada de árvore de problemas, metodologia que descreve de forma simples e útil a questão e quais os principais eventos intervenientes por meio da identificação de relações de causa-efeito. Tal explicitação simplifica também o entendimento sobre a situação a ser alterada, o público-alvo, as ações que irão integrar o programa e os critérios de priorização.

A segunda etapa do modelo lógico está relacionado à estruturação do programa, buscando representar os insumos, elementos, produtos e resultados, bem como a relação entre eles. Esta etapa representa o desenho da implementação das políticas públicas e tem por objetivo tornála verificável por meio da enumeração dos fatos que a evidenciam.

A última etapa proposta por Cassiolato e Gueresi (2010) está relacionada ao ambiente em que o programa está inserindo, buscando identificar os fatores relevantes de contexto que podem favorecer ou comprometes o desenvolvimento das ações ou ainda o alcance dos resultados esperados.

A Teoria dos Programas sistematiza como uma iniciativa deve ser estruturada e indica algumas ferramentas que contribuem para o seu alcance por meio das atividades de monitoramento e avaliação (MeA). A construção do modelo lógico, por exemplo, permite definir os indicadores mais adequados para aferir o desempenho do programa - seja ele quali ou quantitativo. Por este motivo, Cassiolato e Gueresi (2010) enfatizam que os indicadores selecionados devem apresentar validade, confiabilidade, perenidade, pertinência, mensurabilidade e economicidade.

Uma vez que os propósitos e a estrutura do programa foram identificados, explicitados e definidos em um modelo lógico, a implementação se torna a etapa operacional de um sistema especializado que explora sua equifinalidade e otimiza energias por meio da sua capacidade de auto-organização. Nesta fase, o processo de retroação é realizado pelas atividades de monitoramento e avaliação, abordados por Chen (2005) como um (sub) programa de monitoramento e avaliações dos processos e dos resultados das iniciativas públicas.

Chen (2005) enfatiza que o programa de monitoramento de uma iniciativa sintetiza informações e reúnem as estatísticas mais importantes sobre os processos e produtos para 
auxiliar os stakeholders no diálogo com grupos de interesse (financiadores e outros) e em questões administrativas internas. São normalmente definidas juntamente com os avaliadores, mas apesar da importância, não fornecem informações mais abrangentes. Este programa é composto pelos monitoramentos do processo e dos produtos, destinados a avaliar as características observadas destes elementos durante o andamento da iniciativa com o planejado.

Segundo ainda Chen (2005), o programa de monitoramento deve ser composto por uma normatização da coleta e disseminação dos dados, por sistemas informatizados para auxiliar nestes processos, pela capacitação dos recursos envolvidos e pelo apoio à alta gestão. Para o monitoramento do processo, o autor destaca que algumas informações importantes estão relacionadas, por exemplo, às características sócio demográficas dos clientes, os riscos relacionados a estes e os progressos das atividades e subatividades. O monitoramento dos resultados, por sua vez, está relacionado à identificação das metas, seus indicadores e fontes de dados complementares e temporalidade (antes e depois das iniciativas).

No programa de avaliação, as informações fornecidas pelo monitoramento são complementadas por aquelas destinadas às avaliações dos processos e dos resultados, as quais agrupam também dados mais abrangentes e que incorporam informações dos resultados (outcomes) proporcionados pelos produtos (outputs) no ambiente em que são inseridos. Por isto, o monitoramento dos processos e dos produtos devem contemplar, no mínimo, as informações necessárias para a avaliação, ampliando sua finalidade. 


\section{PRÁTICAS E EXPERIÊNCIA NACIONAIS E ESTRANGEIRAS COM SMA}

\subsection{Banco Mundial}

O Banco Mundial foi criado em 1944 a partir de uma iniciativa para a reconstrução e o desenvolvimento dos países no pós-guerra, avançando atualmente para atuar na redução da pobreza em todo o mundo por meio de uma globalização inclusiva e sustentável. Hoje é constituído por cinco instituições formadas por equipes multidisciplinares com representantes em diversos países (World Bank, 2014).

Segundo o banco, apesar dos programas de desenvolvimento em que participa serem requisitados para entregarem resultados, o valor das ideias, das sugestões e das iniciativas têm ganhado crescente espaço - motivo pelo qual o banco destaca que o conhecimento gerado durante estes processos possui igual importância. É um processo normalmente realizado por eficientes sistemas de monitoramento e avaliação a partir da análise periódica dos problemas e ao longo das atividades de implementação. Entretanto, a instituição reconhece que as iniciativas para a sistematização do conhecimento não tem sido suficientes para capturar e compartilhá-lo uma vez que ficam restritos a projetos específicos e se extinguem ao termino dos investimentos externos.

Kusek e Rist (2004) destacaram dez passos para a implantação de iniciativas voltadas para os resultados, reunidos sob a forma de um SMA:

1. Avaliar as capacidades e preparo das instituições e seus parceiros, identificando patrocinadores ou a ausência deles, barreiras, candidatos e opositores;

2. Definição acordada a partir das prioridades estratégicas dos outcomes a serem monitorados;

3. Desenvolver indicadores chaves para monitorar outcomes;

4. Estabelecer coletivamente linhas de base;

5. Realizar um planejamento para melhorias tendo em mente que grande parte dos outcomes são de longo prazo, complexas e de difícil alcance;

6. Uma vez que envolve atividades administrativas e institucionais, devem ser bem definidas e especificadas; 
7. Gerar informações para subsidiar as tomadas de decisões;

8. Analisar e compartilhar achados;

9. Permitir a utilização das análises para melhorar a tomada de decisão, a accountability, a transparência e alocação de recursos; e

10. Dar sustentabilidade ao SMA, que depende da sua demanda, estrutura, veracidade e qualidade da informação, accountability, incentivos e capacidade, cada dimensão deve ser mantida sob constante atenção.

Os autores enfatizam a influência do ambiente nas práticas que serão criadas, desenvolvidas e mantidas. As etapas comuns observadas na literatura, segundo os autores, privilegiam em maior ou menor grau de detalhamento as etapas internas do processo, destacadamente a definição das metas e seus indicadores, o levantamento de informações para acompanhamento do progresso e a divulgação dos resultados obtidos.

A inclusão do ambiente na proposta de Kusek e Rist (2004) ocorre, principalmente, por meio dos estudos sobre as características institucionais e as condições - favoráveis ou não - que podem impactar o processo (item 1), o desenvolvimento e a revisão progressivos e em conjunto do planejamento com os diversos atores (presentes nos itens 2, 4, 5 e 6) e a maior ênfase na sustentabilidade de um SMA (itens 9 e 10).

Atentos à crescente demanda de diversos atores por melhores desempenho e accountability,Görgens e Kusek (2009) elaboraram para o Banco Mundial um manual para subsidiar seus parceiros na implantação de um SMA sustentável, composto por doze componentes que auxiliam neste caminho.O desenho elaborado para o banco destaca o papel desses doze componentes e os reúne em três grandes grupos - denominados de camadas -, conforme esquematiza a Figura 3.1 a seguir. 


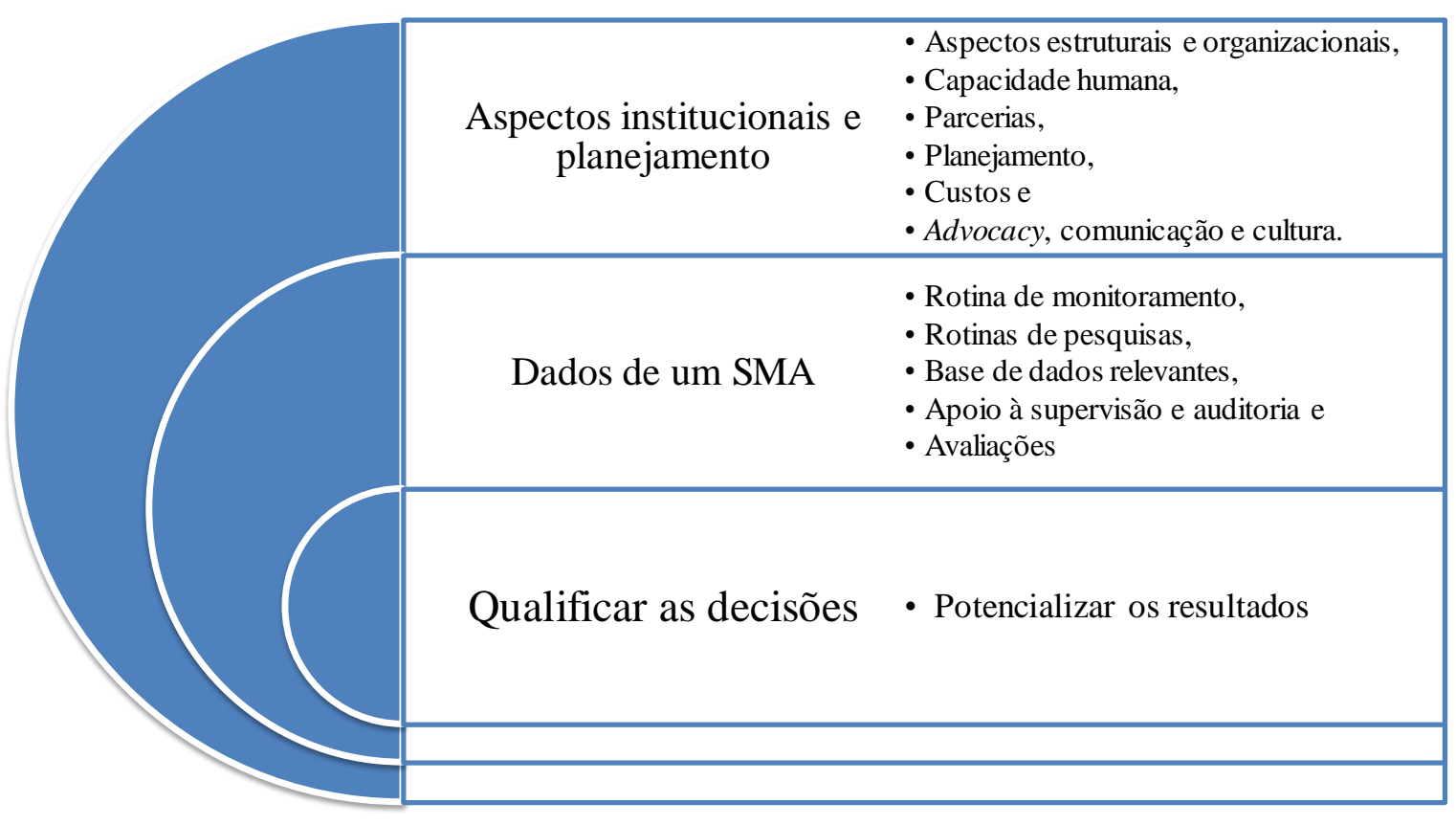

Figura 3.1 - Componentes e camadas de um SMA.

Fonte: Adaptado de Görgens e Kusek (2009).

Na primeira camada, mais externa, os recursos qualificados atuam em conjunto para planejar as iniciativas, os orçamentos, os cursos e devem estar motivados para manter o SMA. Está relacionada aos aspectos institucionais como recursos humanos, as parcerias e o planejamento, agrupados sob a forma de seis componentes: aspectos estruturais e organizacionais, capacidade humana, parcerias, planejamento, advocacy, comunicação e cultura. A camada intermediária agrupa as atividades relacionadas aos dados de um SMA, onde são definidos os componente de rotina de monitoramento, pesquisas periódicas, base de dados relevantes, apoio à supervisão e auditoria dos dados e as avaliações e pesquisa. Está voltada para a coleta, agrupamento e verificação de todos os tipos de dados de um SMA, fundamentais para a consolidação da terceira camada, formada pela gestão por resultados, a finalidade e a utilidade do sistema. Na proposta, todos os componentes estão integrados, não representam necessariamente uma sequência de requisitos, são multidisciplinares e perpassam por todas as camadas - representando a interdependência presente nos sistemas.

Portanto, a descrição e sistematização dos aspectos necessários para uma abordagem sistêmica sob a forma de doze componentes - descritos nas subseções a seguir - estão voltados para auxiliar as lideranças ou os empreendedores operacionais no processo de 
criação e manutenção de um SMA; exigindo deles habilidades e conhecimentos adicionais para atuar frente as diversidades a que os sistemas estão sujeitos. Dada a expertise acumulada pelo banco e a proximidade que possuem com a governança das infraestrutura federal de transportes, as subseções seguintes discorrem sobre os doze componentes a partir do trabalho de Görgens e Kusek (2009).

\subsubsection{Camada institucional}

O primeiro componente tratado pelo Banco Mundial reúne os elementos relacionados aos aspectos institucionais, destacadamente sua estrutura. Conforme apresenta o manual, a estrutura organizacional descreve a hierarquia, os relacionamentos e o arranjo do trabalho em uma organização, normalmente representados por meio de gráficos e organogramas que ilustram as disposições e como as diversas partes interagem. A localização de um SMA nesta estrutura deve ser definida segundo a finalidade que desempenhará, apresentando vantagens e desvantagens quanto ao seu maior ou menor vinculo com a instituição (terceirizada, autônoma ou institucionalizada). Em qualquer um dos casos, a criação desta nova estrutura é facilitada pela identificação de atores favoráveis e contrários à iniciativa e depende da definição e da clareza dos objetivos, da necessidade para a instituição, do agrupamento lógico e da descrição das atividades a serem desempenhadas - incluindo as responsabilidades entre os postos de trabalho mais relevantes, minimamente.

Enquanto algumas dessas atividades necessitam de recursos integramente dedicados - a exemplo dos escritórios de MeA e das equipes de dados e estatísticos -, outras podem ser desempenhadas concomitantemente com atividades regulares. Em casos como o suporte técnico aos parceiros, sua grande solicitação para a criação e desenvolvimento de um SMA requer um eficiente gerenciamento das atividades e recursos, algumas delas passíveis de ser realizada por consultorias e autônomos a partir das vantagens e desvantagens identificadas segundo os interesses da instituição.

A gestão destes recursos - principalmente aqueles dedicados - deve buscar a retenção e o desenvolvimento do capital intelectual da instituição, garantindo as habilidades individuais necessárias para desenvolver tarefas, conforme enfatiza o segundo componente. As capacidades humanas representam as habilidades individuais para desenvolver as funções de 
um sistema eficientemente, efetivamente e sustentavelmente. Uma vez que apresenta fundamental importância para o SMA, devem ser desenvolvidas em todas as esferas dos programas - incluindo as esferas nacional, estadual e local.

Segundo o manual, a gestão destes recursos deve privilegiar uma combinação de competências para que o sistema seja funcional e com visões holísticas. Para isto, recomenda contínuos mapeamentos, avaliações e desenvolvimento das competências por meio de um planejamento específico, elaborado conjuntamente com especialistas sênior e instâncias políticas e de gestão dos recursos para incorporar expertises e garantir a aprovação e alocação de recursos financeiros. A continuidade deste processo permite que capacidades adicionais sejam incorporadas ao SMA para garantir tanto o pleno atendimento das suas funções atuais como outras requisitadas por instâncias superiores.

Além de contribuir para a gestão destas competências, estabelecer e manter parcerias fortes amplia sua finalidade e corroboram com o desenvolvimento de um SMA. Atento a esta configuração, o terceiro componente enfatiza a forma na qual um grupo de pessoas de diferentes organizações podem trabalhar juntas em torno de uma seleção de objetivos - a finalidade do sistema. A exemplo do nível Ministerial de um governo, as parcerias internas são formadas por instancias próprias enquanto as externas são firmadas com outras instancias do próprio governo ou setoriais.

Algumas ferramentas utilizadas para estes casos exploram mecanismos como força-tarefa, grupos de trabalhos e de estudos, avaliações e missões em conjunto. Mas, conforme lembram Görgens e Kusek (2009), as principais questões que levam a estabelecer e manter as parcerias estão relacionados a princípios como confiança mutua, transparência, dinamicidade, alinhamento, esforço conjunto para atingir objetivos comuns e relevantes, unicidade interna e organizacional, harmonia entre os objetivos das corporações/organizações e globais/nacionais, o reconhecimento de parcerias bem sucedidas e a cooperação para preencher lacunas e evitar falhas.

Görgens e Kusek (2009) indicam que a instância adequada para perenizar parcerias é por meio de um grupo multidisciplinar e multisetorial - denominado pelo banco como Monitoring 
and Evaluation Technical Working Group (M\&E TWG) -, envolvendo instituições que integram seus planejamento e orçamentos a instancia governamental para se manter familiarizado e atualizado sobre as políticas governamentais. O M\&E TWG é uma instância nacional que reúne todos os patrocinadores envolvidos com MeA e que assumem diversas funções peculiares a cada país para coordenar as atividades, oferecer orientações técnicas e fomentar um fórum de parcerias e para consultas.

Os insumos e as atividades envolvidos e necessários, seus produtos e as estratégias de parcerias e comunicação compõe o plano de $M e A$, quarto componente do modelo elaborado pelo Banco Mundial. Além do caráter descritivo, o plano possui como principal objetivo a integração do SMA com outros instrumentos e instâncias de planejamento. Görgens e Kusek (2009) destacam três vínculos que o SMA deve possuir com os planos estratégicos, dos programas, setoriais e institucionais: i) ser formado por e formar elementos para o acompanhamento dos objetivos, das estratégias e dos programas; ii) estes por sua vez devem incorporar objetivos e estratégias necessárias para tornar o SMA funcional; e iii) ser formado por diversas fontes de dados, como estudos, pesquisas, avaliações e dados rotineiros orientados para subsidiar a gestão e a tomada de decisão sobre o futuro dos programas. Especificamente em relação à contribuição para tornar funcional um SMA, este processo se inicia com a apropriação das informações fornecidas por ele durante a concepção dos planos e estratégias nacionais, indicando a forma que contribuirá para auxiliar no alcance das estratégias e objetivos desejados e enfatizando a necessidade mantê-lo e aprimorá-lo.

A citada integração também proporciona uma melhor otimização dos recursos das diversas instâncias e parceiros envolvidos, evitando duplicações, sobreposições e sobrecarga de atividades nos eventuais SMA setoriais, subnacionais e locais. Da mesma forma acontece com a integração do plano nacional de MeA com os organizacionais. Uma vez que é estabelecida e estruturada uma fonte de informações confiável e integrada, cada organização passa apenas a indicar os indicadores que contribuem com os objetivos nacionais bem como utilizar as informações fornecidas nos relatórios finais das instâncias superiores para o planejamento interno. 
Em meio à participação de diversos patrocinadores e atividades, para garantir a sustentabilidade orçamentária de um SMA, a identificação, o detalhamento temporal das atividades e a organização dos custos segundo períodos, os níveis e os segmentos de um plano de trabalho são importantes ferramentas para permitir priorizar, planejar e coordenar as atividades e recursos financeiros e humanos. Por isto, o quinto componente do modelo proposto por Görgens e Kusek (2009) é categórico em afirmar que os diretores financeiros dos patrocinadores também devem se envolver no processo de custos e entender como o orçamento do plano impactará e será integrado e sincronizado ao orçamento mais amplo, estabelecendo os orçamentos dos parceiros que oferecem contribuições e assistências técnicas.

A cultura, a advocacy e a comunicação de MeA estão reunidos no sexto componente do modelo de SMA elaborado pelo Banco Mundial, pois representa uma seleção de crenças, suposições e valores que levam a uma maior ou menor receptividade de um SMA na instituição. Isto porque a resistência à gestão, a disseminação e a utilização de dados na cultura organizacional contribuem negativamente para tornar o SMA funcional e eficaz; e uma vez que é implícita e informal, são fortemente influenciadas pelas lideranças das organizações. Os autores reconhecem que na advocacy a paixão e o comprometimento são fatores motivadores para fazer mais do que requerido pela rotina, mas relativizam suas atribuições entre patrocinadores, os responsáveis de um SMA e um elemento da organização com conhecimento e atitude positiva sobre MeA.

As principais questões sobre este componente refletem a necessidade de reiterar seus objetivos e importância para os atores,de afastar perspectivas negativas sobre suas funções, de identificar os atores relevantes para promover e divulgar um SMA e agregar parceiras e recursos. De forma mais ofensiva, Görgens e Kusek (2009) sugerem que o planejamento deste componente deve ser direcionado para o contexto das mensagens e público ainda resistente, identificando os canais de comunicação e técnicas de sensibilização mais eficientes e a escolha do ator ou da equipe adequados para disseminarem o seu valor e esclarecer sobre os resultados desejados por meio de uma comunicação clara e objetiva.

Pela importância que representa, percebe-se na proposta de Görgens e Kusek (2009) para o manual alguns procedimentos que podem auxiliar na criação de uma cultura favorável e 
referências em MeA, a saber: i) realizar uma avaliação preliminar da receptividade e preparo da instituição para a gestão por resultados frente a visão geral da cultura institucional instituída, ii) identificar potenciais opositores e desenvolver e iii) implantar, consequentemente, estratégias para influenciar na cultura organizacional.

\subsubsection{Camada de dados}

A camada intermediária do modelo proposto por Görgens e Kusek (2009) é composta por componentes relacionadas aos dados necessários para o monitoramento e avaliação. Esta camada é composta por atividades que visam garantir os monitoramentos regular, esporádico, confiável e contínuo, uma vez que é um insumo indispensável para um SMA.

O sétimo componente do modelo é dedicado às rotinas de monitoramento para levantar dados quantitativos sobre as etapas do ciclo (entrada, processamento e saída) e que podem ser complementadas por métodos qualitativos. Estas atividades devem garantir adequadas seletividade dos dados coletados e capacidade de geração de relatórios, vinculando-os ao processo de planejamento e a diferentes instituições.

A atividade regular de monitoramento requer além da criação e capacitação das equipes enfatizados anteriormente,a padronização da rotina e das ferramentas para o levantamento destes. As rotinas a serem estabelecidas são definidas segundo a natureza, local e tipo de instituição e dos dados; e devem estabelecer processos claros de gerenciamento. Assim como todos os demais dados e informações e etapas necessárias, devem atender às dimensões de qualidade de representatividade, confiabilidade, "ser completa" - uma alusão ao maior grau de utilidade dos dados -, precisa, tempestiva e íntegra.

Destaca-se que o banco já enfatiza a necessidade de seletividade das informações que serão manipuladas, tendo em vista o grande volume de dados disponíveis e que podem ser sem representatividade. Destaca também que a taxa de emissão de relatórios inicia-se de forma modesta, avançando ao longo do tempo com o aprimoramento e assimilação das atividades necessárias, da padronização das informações. 
Além dos dados gerados regulares, o oitavo componente representa a coleta de dados relacionados aos produtos e resultados por meio de pesquisas periódicas. Estes tipos de dados podem ser obtidos ocasionalmente, por meio de pesquisas regulares ou de amostragens mais amplas do ambiente.

Entretanto, tendo em vista o alto custo que podem representar, são preferencialmente desenvolvidas por instâncias nacionais do Governo - a exemplo de institutos de estatística e pesquisa -, mas são realizadas apenas quando a possibilidade de utilização de dados rotineiros é esgotada. Caso sejam necessárias, o banco recomenda que o levantamento destes dados respeite a questões éticas - como consentimento dos respondentes e confidencialidade -, utilizem critérios científicos e recursos especializados, envolvam as equipes de MeA para compatibilizar o formato das pesquisas aos indicadores a serem divulgados e apresente um realismo orçamentário.

O nono componente discute sobre as bases de dados utilizadas para reunir os dados coletados durante o monitoramento rotineiro e as pesquisas esporádicas e específicas. Estas informações são relevantes para a formulação de políticas e o gerenciamento de programas, proporcionando melhorias em um ambiente duradouro. Devem atender as necessidades imediatas para a tomada de decisão e disseminação de informações sobre as iniciativas em todos os níveis de um programa e setor, bem como são relacionados a diferentes e relevantes bases de dados consistentemente e sem duplicações.

As questões envolvidas neste componente desmitificam a necessidade de utilização de bases de dados automatizadas, sendo estas recomendadas para instâncias povoadas por uma grande quantidade de dados. Nestes casos, devem coadunar com as políticas institucionais para tecnologia da informação, serem funcionais e seguras, conter informações suficientes e estar disponível para o uso como um sistema de gerenciamento. Tal automação deve também utilizar ferramentas familiares aos usuários, estar vinculada a outras bases de dados e envolver equipe capacitada para a criação e gestão para incrementar o uso e acesso à informação.

O décimo componente tem o objetivo de aumentar a qualidade dos dados e fomentar a qualificação das equipes por meio de melhores supervisões e auditorias dos dados. As 
questões frequentes sobre a implementação deste componente destacam a necessidade de integrá-lo às rotinas do SMA, de dispor de adequados recursos financeiros, humanos, físicos e ferramental, de permitir melhorias por meio das experiências ao fim das iniciativas, de enfatizar a abrangência de componente de qualidade dos dados em todos os setores e níveis institucionais e de estabelecer linhas gerais e protocolos para garantir a uniformidade e qualidade das atividades de supervisão e auditoria.

A distinção entre pesquisa e avaliação - assunto reunido no décimo primeiro componente do manual - é feita a partir da intenção da atividade. Ambos utilizam os mesmos métodos científicos para coletar e analisar os dados, mas a intenção do primeiro se destina à generalização do conhecimento. As avaliações buscam analisar alguns aspectos particulares de um projeto, programa ou política, gerando um conhecimento para um propósito específico. Segundo o manual, para perenizar estas atividades é necessários disponibilizar mais de uma fonte de informação para auxiliar da condução de políticas, na programação e nas intervenções necessárias. As principais questões relacionadas a este componente são a definição da oportunidade adequada para desenvolvê-las, descrever previamente o escopo e ponto de início das atividades (ToR), estabelecer as normas para conduzir as atividades em padrões éticos, e fazer com que seus resultados sejam utilizados. Apesar da semelhança com o oitavo componente (a coleta de dados relacionados aos produtos e resultados por meio de pesquisas periódicas), as atividades de pesquisa e avaliação são desenvolvidas com uma menor frequência, por amostragem.

\subsubsection{Camada de potencialização do SMA}

O componente central (décimo segundo componente) do SMA idealizado para o Banco Mundial tem por objetivo dar finalidade a este, fazendo com que as informações geradas sejam utilizadas nas decisões sobre estratégias, programas, planos, orçamentos, alocação de recursos, capacitação e a implementação das iniciativas. Entretanto, nem toda a informação disponível no SMA possui este propósito. A seleção de informações depende de diversos fatores como as características da forma com que as decisões são tomadas, a natureza e a clareza da informação, a cultura organizacional, a dinamicidade dos grupos e a natureza e dimensão da decisão que precisará ser tomada. 
As estratégias sugeridas para promover o uso das informações são o foco no problema institucional ou setorial e como poderá ser abordado, estabelecer protagonistas de apoio e uma cultura organizacional informacional, entendimento dos negócios das organizações e como as informações podem ser disseminadas, estabelecer padrões no processo de gestão dos dados para viabilizar o maior acesso às informações e potencializar sistemas de gerenciamento do desempenho, resguardar a qualidade em todos os processos, estabelecer e acessar diferentes clientes, divulgar informações relevantes e de forma clara, padronizar os produtos do SMA.

\subsection{Práticas e experiências nacionais e internacionais em MeA}

\subsubsection{Organizações das Nações Unidas (ONU)}

A ONU é uma entidade não governamental composta atualmente por 193 países que se reúnem voluntariamente para trabalhar pela paz e o desenvolvimento mundiais. Além da notória atuação para a resolução de conflitos e manutenção da paz, suas metas atuais também demonstram uma diversificada participação em questões como os direitos humanos, a justiça e segurança internacional, o progresso econômico e social e questões climáticas e de saúde (UN, 2014).

A organização busca justificar sua importância aos parceiros e membros por meio da apresentação de resultados tangíveis, requisitando de igual maneira dos países em que atua uma maior accountability para avaliar como os recursos são utilizados, quais os resultados obtidos e a efetividade destes para o desenvolvimento humano (UNDP, 2009). Entretanto, frequentemente a ONU encontra em outros países uma grande diversidade de planos, estratégias, programas e projetos, e a qualidades destes e dos recursos envolvidos dificulta o alcance dos objetivos.

A partir destas constatações, a organização destaca algumas das áreas que comumente necessitam de maior atenção para se alcançar o sucesso em um programa ou projeto: o planejamento, o envolvimento de stakeholders, a comunicação e os processos de monitoramento e avaliação. São áreas que devem ser constantemente reforçadas tendo em vista que (UNDP, 2009): i) o planejamento adequado reduz incertezas durante a implementação; ii) o monitoramento e avaliação permitem manter o projeto no custo, no tempo, na qualidade e no escopo desejados e atuar preventivamente para reorientá-lo; e iii) a 
comunicação eficaz aproxima os stakeholders do projeto, alinha as expectativas e mantém em tela os objetivos e o desempenho do projeto. Por isto, a ONU reconhece que a falta de planejamento, monitoramento e avaliação das iniciativas dificulta verificar se os esforços estão corretamente direcionados, se o avanço e o sucesso serão alcançados e como iniciativas futuras podem ser melhoradas.

Com a complexidade e diversidade das iniciativas, a organização desenvolveu uma metodologia para consolidar e uniformizar procedimentos e informações sobre a execução dos seus projetos. A necessidade de mensurar os resultados refletiu na elaboração de documentos específicos para auxiliar na definição do que precisa ser feito, por quem e quando, bem como para fornecer ferramentas que demonstram como as diretrizes podem ser utilizadas. Estas e outras orientações podem ser encontradas em documentos como o Monitoring and Evaluation Training Resource, o Evaluation Technical Notes e o Handbook on Planning, Monitoring and Evaluating for Development Results - HPMEfDR.

É oportuno destacar inicialmente que sua metodologia está voltada para que a arquitetura dos projetos e programas sejam compatível com sua atual organicidade e se integrem às práticas locais quando presentes. Espera-se extrair dos documentos consultados, práticas, ferramentas, insumos e requisitos reconhecidos que complementem as linhas gerais apresentadas por Görgens e Kusek (2009).

\subsubsection{O SMA da ONU}

Em linhas gerais, a metodologia utilizada pelo SMA da ONU enfatiza o planejamento das iniciativas de forma a identificar o problema a ser abordado, a forma com que será enfrentado e as responsabilidades dos atores envolvidos; sugerindo ferramentas e práticas que auxiliam no acompanhamento e avaliação do progresso das ações e o alcance dos objetivos em questão. As atividades do SMA da ONU são concebidas de forma a integrar as atividades de monitoramento e avaliação com iniciativas e metas regionais, explorando a geração e disseminação da informação como um importante processo para o aprimoramento dos programas, para fomentar a sinergia entre os atores em busca de objetivos comuns bem definidos e mensuráveis e para garantir a sustentabilidade dos resultados obtidos. 
Por esse motivo, a primeira etapa do processo de MeA dos programas e projetos da ONU se concentra mais no detalhamento do planejamento da iniciativa (UNDP, 2009) que nas demais etapas de operacionalização das atividades e de fomento do seu uso pelas instâncias de gerenciamento e tomada de decisões. Isso porque a organização reconhece que não é possível realizar adequadamente estas atividades a partir de um planejamento impróprio e que não apresente uma clara articulação e entendimento dos resultados.

As iniciativas da organização são desenhadas em torno de três camadas de resultados com crescente interação com o ambiente: os produtos (outputs), os resultados (outcomes) e os impactos (impacts). Enquanto os produtos do processo representam os resultados diretos e primários dos projetos, os resultados reúnem os reflexos intermediários que proporcionam no ambiente no curto e médio prazos. Segundo Cassiolato e Gueresi (2010), os resultados intermediários evidenciam mudanças nas causas do problema e, por sua vez, levam ao resultado final esperado, que está diretamente relacionado ao objetivo do programa, refletindo a mudança no problema. Portanto, a camada de impactos se equipara aos resultados finais citados por Cassiolato e Gueresi (2010), ambos associados aos efeitos de longo prazo proporcionados pelas iniciativas e que levam a alterações mais amplas nas condições do ambiente.

Ao diferenciar os resultados imediatos dos efeitos diretos e indiretos em uma aplicação do modelo lógico no Programa Segundo Tempo do Governo Federal, Cassiolato e Gueresi (2010) constataram a importância em se elaborar uma representação adequada dos vínculos causais. Evidenciou-se, nesta aplicação, que os dirigentes justificam seus programas pelos efeitos que proporcionam e que normalmente não podem ser atribuídos exclusivamente aos resultados do programa. Por isto, a definição dos resultados das iniciativas propostos pelas autoras coaduna com as orientações da ONU, que recomenda que sejam específicos, mensuráveis, registráveis, relevantes e delimitados no tempo - conceitos reunidos pela ONU pela sigla em inglês SMART, que representa os termos Specific, Measurable, Achievable, Relevant e Timebound.

Para isto, diversas informações devem ser coletadas para respaldar as discussões desde as primeiras reuniões sobre o projeto e a definição de prioridades, obtidas nas próprias 
organizações, localmente ou por meio de pesquisas específicas. É um processo correspondente ao entendimento do problema no ciclo de políticas públicas abordado anteriormente para circunscrever as iniciativas e definir os resultados a serem alcançados. A disponibilidade e confiabilidade dos dados necessários influenciam no escopo das atividades de MeA, podendo ser desempenhadas explorando as capacidades e recursos preexistentes e preenchendo as lacunas identificadas.

No Brasil, a ONU destaca como ferramenta para auxiliar no planejamento o Atlas de Desenvolvimento Humano (ADH), lançado em 1998 e pioneiro em desagregar estas informações no nível municipal. Esta ferramenta permite uma abordagem multidimensional do tema em questão, permitindo acessar e manipular informações sobre serviços básicos, níveis de escolaridade, vulnerabilidade social, entre outros temas. A própria ONU mantém uma ferramenta para organizar, armazenar e apresentar os dados sobre o desenvolvimento humano (denominada DevInfo), possibilitando o compartilhamento destas informações entre os atores envolvidos e interessados pelo tema.

Para auxiliar os gestores na condução dos projetos, UNDP (2009) propõe ainda na primeira etapa a elaboração de produtos intermediários durante o planejamento que auxiliam a sintetizar e esclarecer as questões principais, os problemas a serem abordados, a influência e importância dos stakeholders e os resultados esperados do programa ou projeto. A ferramenta fundamental para o SMA da ONU são os mapas (ou frameworks) validados pelos principais stakeholders, elaborados no processo de planejamento de um programa ou projeto. $\mathrm{O}$ documento United Nations Development Assistance Framework (UNDAF) é destinado a formalizar o acordo entre as instâncias da ONU e os governos locais sobre as orientações e metas envolvidas nas iniciativas e maximizar o impacto dos programas (UNICEF, 2007). Assim como discutido anteriormente no modelo lógico da teoria dos programas, o UNDAF permite aos stakeholders realizar uma análise do problema e da situação utilizando um modelo semelhante (a árvore de problemas, ou the problem tree) para identificar as principais causas e os maiores efeitos envolvidos. Em conjunto com os outros documentos, a etapa de planejamento define as informações que melhor representarão os resultados da iniciativa e que fomentarão plataformas de informação da ONU (o Result-Based Management platform RBM e o Atlas). 
Assim como enfatizado anteriormente por Chen (2005), a ONU também destaca a importância do MeA das suas iniciativas por meio do planejamento particularizado destas atividades ainda na primeira etapa do processo. Com base nos entendimentos firmados entre os atores envolvidos em uma iniciativa, são elaborados mapas (o $M \& E$ framework) que consolidam as principais informações sobre o monitoramento e avaliação para facilitar consultas posteriores, dentre outras finalidades. Após a aprovação do programa, o respectivo plano é enviado a um sistema específico da ONU (o The Evaluation Resource Centre - ERC) que permite a consolidação, acompanhamento e amadurecimento das práticas da organização por meio da gestão integrada com outros programas e projetos. Adicionalmente, para garantir a accountability das iniciativas, a ONU recomenda que entre $20 \%$ e $30 \%$ das iniciativas previstas para determinado programa sejam avaliadas, o que demonstra o caráter específico que representam em relação ao monitoramento.

Da mesma forma com que ocorre no desenho de um programa ou projeto abordados anteriormente, os processos de MeA são representados por mapas compostos por narrativas das atividades, dos resultados mapeados e de planos de monitoramento. Definem as metas e estratégias em comum, sinalizam os recursos necessários, estabelecem os ritos para sua revisão e avaliação, identificam como potencializar os resultados e como outras iniciativas podem contribuir. Torna-se um plano para o MeA das iniciativas pois especifica quais atividades devem ser monitoradas, como serão desenvolvidas (as atividades, os métodos e os recursos), quem são os responsáveis e quando serão (re) planejadas.

Ao disponibilizar diversos sistemas e modelos de ferramentas para auxiliar na elaboração e processamento das informações, a ONU formaliza e deixa em evidência os principais requisitos para o $\mathrm{MeA}$ dos seus programas e projetos: os recursos financeiros e humanos, a participação dos stakeholders e a capacidade local.

Segundo UNDP (2009), os recursos financeiros e humanos devem ser considerados como parte integrante dos programas e projetos - e não como atividades e custos adicionais. $\mathrm{O}$ manual recomenda que os recursos financeiros sejam planejados previamente, sejam claramente identificáveis e independentes entre os demais e elaborados de forma a dar maior 
realismo e previsibilidade orçamentária e minimizar os riscos comuns de falta de recursos ao final da implantação dos programas e projetos. Tais recursos podem ser provenientes de mais de uma fonte - surgindo arranjos mais elaborados normalmente em projetos de maior porte e relevância - e são normalmente calculados segundo os prazos do projeto e a disponibilidade e métodos de coleta de dados. A organização recomenda que os recursos humanos sejam dedicados a estas atividades e que apresentem capacidades suficientes para desenvolver atividades típicas como a elaboração de documentos, o auxílio à stakeholders na avaliação dos progressos, a identificação de lições, de boas práticas e de necessidades de capacitação, a disseminação de resultados para qualificar os processos decisórios e políticas públicas, assegurar a qualidade do MeA e manter-se atualizado sobre as prioridades emergentes.

A participação dos stakeholders tem por finalidade dar maior utilidade às atividades de monitoramento e avaliação (UNDP, 2009). Uma vez que estes atores possuem uma elevada capacidade de persuasão para realizar ajustes ou encerrar o projeto, estão mais aptos para identificar quais informações e processos são mais relevantes para garantir que os resultados esperados sejam atingidos. Sua participação também proporciona maior eficácia à comunicação visto que a divulgação dos resultados iniciais por meio deles permite uma maior adesão e apoio de outros atores às iniciativas, uma maior difusão dos resultados dos projetos para outros beneficiários e fomenta o aprimoramento e sustentabilidade das práticas.

Entretanto, a participação voluntária dos stakeholders é limitada, motivo pelo qual UNDP (2009) recomenda a institucionalização desses processos, que ocorre por meio do envolvimento ou formação de conselhos e comitês em todos os níveis da iniciativa - nacional, setorial, do programa e do projeto, preferencialmente associados àqueles preexistentes. Nos países em que está presente, a ONU normalmente atua como o empreendedor operacional participando de estruturas nacionais (nível estratégico) para explicitar a relação entre suas iniciativas e as prioridades locais. Assim, espera promover parcerias para atingir objetivos comuns, fomentar a sinergia entre interessados, sensibilizar parceiros para estratégias para resultados e monitorar os resultados alcançados. Nos demais níveis (setorial, de programa e de projeto), a institucionalização se dá por meio de reuniões regulares para avaliar o progresso dos resultados, aprovar mudanças e rever as metas anuais, envolvendo de igual maneira os atores importantes em cada nível da iniciativa. 
Visando essa integração, as iniciativas de planejamento devem inicialmente avaliar a capacidade local de MeA para desempenhar e planejar as atividades relacionadas. Algumas questões apresentadas pela ONU que sinalizam esta capacidade são: i) processos de elaboração dos orçamentos nacionais, ii) ferramentas de planejamento de médio e longo prazos (na forma de planos ou frameworks), iii) instâncias de coordenação setorial, iv) sistemas nacional e setoriais de monitoramento e avaliação, v) mecanismos de revisão das iniciativas e vi) a existência de grupos ou conselhos que permitam uma discussão multisetorial integrada em torno de objetivos comuns e com significativa autonomia dos integrantes para responderem pelo setor para assumir responsabilidades. A presença ou não destes e outros elementos sinalizam as áreas que poderão contribuir com o SMA e onde deve haver um maior fortalecimento das capacidades.

As etapas seguintes ao planejamento detalham a operacionalização das atividades de MeA das iniciativas e fortalece o uso dos produtos do SMA. A ONU a esquematiza estas atividades em quatro estágios, apresentados no Quadro 3.1 a seguir:

Quadro 3.1 - Atividades desenvolvidas na operacionalização do MeA.

\begin{tabular}{|l|l|l|}
\hline Etapa & Monitoramento & Avaliação \\
\hline Inicialização & $\begin{array}{l}\text { Verificar as políticas e o } \\
\text { contexto operacional e } \\
\text { esclarecer regras e } \\
\text { responsabilidades }\end{array}$ & Verificar a capacidade avaliativa da iniciativa; \\
\hline Preparação & $\begin{array}{l}\text { Revisar e detalhar o } \\
\text { planejamento e o MeE } \\
\text { framework }\end{array}$ & $\begin{array}{l}\text { Validar a estrutura para avaliação e } \\
\text { responsabilidades; } \\
\text { Elaborar e organizar documentos relevantes; } \\
\text { Selecionar os avaliadores; }\end{array}$ \\
\hline Execução & $\begin{array}{l}\text { Coletar dados, analisar e } \\
\text { divulgá-los; }\end{array}$ & $\begin{array}{l}\text { Acompanha e auxilia os avaliadores; } \\
\text { Avalia os relatórios elaborados }\end{array}$ \\
\hline Utilização & $\begin{array}{l}\text { Utilizar os dados e } \\
\text { informações no } \\
\text { gerenciamento e processos }\end{array}$ & $\begin{array}{l}\text { Elaborar orientações gerenciais; } \\
\text { Acompanhar as iniciativas subsequentes; } \\
\text { Preparar e dissemina os resultados das }\end{array}$ \\
\hline
\end{tabular}




\begin{tabular}{|l|l|l|}
\hline decisórios. & $\begin{array}{l}\text { avaliações e organiza eventos para compartilhar } \\
\text { o conhecimento gerado; } \\
\text { Reavaliar as prioridades de avaliações para os } \\
\text { próximos períodos. }\end{array}$ \\
\hline
\end{tabular}

Fonte: Elaborado pelo autor.

As primeiras atividades da etapa de execução do monitoramento e avaliação (a inicialização e preparação) são destinadas a uma revisão da iniciativa e das responsabilidades dos parceiros envolvidos no projeto e a criação das equipes, bem como a complementação, o detalhamento e a organização dos documentos relevantes e elaborados no planejamento inicial. Este processo deve ser contínuo e progressivamente melhorado, permitindo que novos dados e projetos sejam incorporados para aprimorar a descrição dos objetos monitorados, aumentando da mesma forma sua realidade, efetividade e qualidade.

A execução do MeA se dedica ao levantamento, a manipulação e a interpretação de uma grande quantidade de dados e informações, motivo pelo qual utiliza ferramentas que garantem a veracidade e confiabilidade dos insumos. Além disto, uma vez que o SMA busca subsidiar o processo de tomada de decisão dos gerentes de projeto ou de programa, estes, por tanto, são importantes atores para a definição das informações a serem monitoradas - vinculando suas atividades ao longo de todo o desenvolvimento da iniciativa.

Além das informações utilizadas e fornecidas pelo próprio subsistema de monitoramento, as avaliações também utilizam relatórios e resultados de outras fontes como programas globais, nacionais, regionais e sub-regionais, dados de agências, instituições oficiais e atores reconhecidos, pesquisas, questionários, entrevistas, observações diretas e informações financeiras e gerenciais, entre outras. Entretanto, dificilmente a utilização isolada destes mecanismos e ferramentas satisfazem as necessidades para a adequada condução das iniciativas, motivo pelo qual a ONU recomenda que o gestor calibre no uso destas ferramentas em cada iniciativa para também não sobrecarregarem os respondentes. Comumente são utilizados os relatórios e o planejamento anuais e as visitas, mas a complexidade dos projetos, os diversos níveis de uma iniciativa e as práticas dos parceiros podem resultar na inclusão ou 
adequação e seleção das ferramentas utilizadas neste processo. Portanto, assim como os frameworks, as ferramentas também são especificadas e aprimoradas segundo o projeto.

A última etapa para implantação do monitoramento e avaliação enfatizada pela ONU é o fomento do seu uso pelas instâncias de gerenciamento e tomada de decisões. Esta etapa possui fundamental importância para dar finalidade a um SMA e garantir sua contínua utilização em todos os níveis das iniciativas, tendo como principais objetivos: i) esclarecer e analisar processos, problemas, mudanças e lições; e ii) consolidar ações e decisões que impactam no planejamento e recursos envolvidos.

Além destas finalidades, a ONU também reconhece que o monitoramento fornece dados robustos para as avaliações das iniciativas, as quais exploram diversas variáveis em conjunto como os próprios dados, relatórios, análises e decisões baseados nas evidências do monitoramento. E na medida em que um SMA envolve diversos parceiros e interessados, deve se preocupar também em disponibilizar uma gama considerável de informações para atender públicos distintos. O mapeamento adequado dos stakeholders contribui, neste quesito, para otimizar seu esforço e delimitar os tipos de informações a serem disponibilizadas.

\subsubsection{Governo Federal Brasileiro}

O surgimento dos SMAs no Brasil estão relacionados a diferentes iniciativas e necessidades, como o apoio da assessoria ministerial (Vaitsman, Rodrigues e Paes-Sousa, 2006), a crescente importância das atividades para o país (Rocha et al., [S.d.]; Carvalho et al., 2012 e Brasil, 2012) e a necessidade de maior eficiência nas políticas públicas (Souza, 2006).

As principais experiências nacionais com SMA foram identificadas nas áreas sociais, de educação e de saúde, além da iniciativa incipiente relacionada à qualidade dos investimentos públicos em transportes e do planejamento do governo federal. Dos trabalhos selecionados para discorrer sobre estas experiências serão extraídos os aspectos que contribuíram ou dificultaram a implementação de um SMA nestes setores. 


\subsubsection{Ministério do Desenvolvimento Social e Combate à Fome (MDS)}

Vaitsman, Rodrigues e Paes-Sousa (2006) relatam que a criação da Secretaria de Avaliação e Gestão da Informação (SAGI) no Ministério do Desenvolvimento Social e Combate à Fome (MDS) para exercer as funções de avaliação e monitoramento das políticas e programas com o mesmo nível hierárquico das demais secretarias finalísticas da instituição representou uma inovação na gestão pública. A maior dificuldade encontrada nesta atividade, segundo os autores, foi em integrar os sistemas existentes.

Em meio à constatação de uma variação entre os sistemas sob os aspectos relacionados às variáveis, magnitude, escopo, maturação, localização da hospedagem e esfera dos inputs (municipal, institucional, etc.); os indicadores foram definidos segundo atributos específicos para dar maior clareza do que representam a cada programa para alinhar tais aspectos. A partir do levantamento das variáveis relativas aos programas existentes e a rotina de recebimento dos dados primários, iniciou-se a construção dos indicadores (Vaitsman, Rodrigues e PaesSousa, 2006).

Primeiramente foram validados pelas áreas finalísticas aqueles mais simples e viáveis de operacionalização - a exemplo dos indicadores físicos-financeiros -, estabelecendo uma rotina para que estas áreas enviassem à SAGI os dados primários com periodicidade predefinida de forma a permitir operacionalizar o sistema de monitoramento. Conforme enfatizam Vaitsman, Rodrigues e Paes-Sousa (2006), a diversidade de fontes e falta de padrão dos formatos dificultou sobremaneira o esforço para uniformização dos dados e integração das bases, restringindo as variáveis apenas aquelas necessárias para o cálculo dos indicadores. Para manipular e uniformizar as informações geradas nessas etapas, foram criadas ferramentas informatizadas que permitiam a consulta de definições utilizadas para a concepção do sistema (por meio dos dicionários) e a manipulação direta dos indicadores e informações sociais disponíveis pelos atores envolvidos.

A estratégia de contratação das avaliações permitiu o ganho em escala, de diversidade e de qualidade, tendo o IBGE como um importante parceiro para a realização de grandes pesquisas. Tais possibilidades foram atribuídas por Vaitsman, Rodrigues e Paes-Sousa (2006) aos recursos humanos envolvidos - formando uma equipe enxuta, qualificada, 
multidisciplinar capaz de contratar e avaliara os produtos necessários - e à gestão não burocrática, flexível que viabilizou a condução das equipes para um melhor uso das expertises envolvidas.

\subsubsection{Ministério da Educação (MEC)}

Segundo Rocha et al. ([S.d.]), a falta de utilidade para os gestores do Ministério da Educação (MEC) e a instabilidade das ferramentas utilizadas pelo governo federal (o Sistema Integrado para gestão e Planejamento - Sigplan) resultou na resistência ao uso desta. Este cenário levou ao ministério a criação de procedimentos para utilizar planilhas eletrônicas na gestão dos dados. As iniciativas para a melhoria deste processo iniciaram em outubro de 2003 com uma parceria do MEC com a Fundação de Empreendimentos Científicos e Tecnológicos (Finatec) para realizar estudos e pesquisas sobre governança, planejamento e monitoramento de ações governamentais.

Rocha et al. ([S.d.]) destacam que os resultados positivos obtidos preliminarmente impulsionaram a expansão da metodologia para as demais ações do ministério presentes no PPA, levando consequentemente ao aprimoramento da ferramenta desenvolvida. Segundo ainda os autores, a ampliação da utilização do Simec por usuários externos foi essencial para a transformação do padrão de relacionamento e apoio do MEC aos estados, municípios, universidades e instituições de educação profissional. A ampliação dos usuários externos também levou ao alcance do sistema a diferentes públicos alvo, como os estados, os municípios, a Presidência da República e o Ministério de Planejamento, Orçamento e Gestão (MPOG).

Em relação ao desenvolvimento da ferramenta, Rocha et al. ([S.d.]) relatam que o seu monitoramento e sua avaliação foram realizados frequentemente por meio de reuniões com o secretário executivo, o diretor de TI e o coordenador de desenvolvimento do sistema e quando necessário, as equipes das demais áreas interessadas, existindo uma equipe em cada módulo destinado ao apoio aos gestores. Por isto, a participação do secretário executivo foi fundamental para a evolução e sucesso da ferramenta, o que vem resultando num maior interesse por outras instâncias pelo sistema. 


\subsubsection{Ministério da Saúde (MS)}

A crescente importância social que o Sistema Único de Saúde (SUS) vem representando para o país, as mudanças nos procedimentos legais e administrativos na gestão, a maior complexidade do perfil epidemiológico brasileiro com distintos problemas e necessidades; as crescentes demandas por maior controle dos gastos em saúde e cobranças de organismos financiadores externos são citados por Carvalho et al. (2012) como origem de uma melhoria na organização e maior interesse pela qualificação as decisões tomadas no Ministério da Saúde (MS).

Neste intuito, por meio de um intenso debate envolvendo diversos órgãos realizado no início da década de 2000 evidenciou-se a necessidade de uma estrutura que assumisse as tarefas de articulação, apoio e difusão das ações de monitoramento e avaliação (Carvalho et al., 2012). Tal discussão resultou na criação de uma estrutura específica em 2006 para desempenhar estas atividades, hoje atribuídas ao Departamento de Monitoramento e Avaliação do SUS (DEMAS) vinculado à Secretaria Executiva da instituição desde 2013 (Brasil, 2013).

Apesar de reconhecer a recente criação do departamento e o estágio de transição organizacional que se encontrava, o Tribunal de Contas da União (TCU) destacou a desarticulação entre departamentos que deveriam estar envolvidos nas atividades de monitoramento e avaliação e a inexistência de uma política de avaliação no âmbito do Ministério (TCU, 2011).

Discorrendo sobre o processo pelo qual a DEMAS percorreu para implantar o MeA no MS, Carvalho et al. (2012) destaca a importância à institucionalização e definição das práticas e os processos de monitoramento e avaliação da gestão e ao vínculo com a aprovação do Relatório Anual de Gestão (RAG) em 2007 e 2008. O monitoramento do RAG nos anos de 2007, 2008 e 2009 demonstrou a fragilidade das informações disponíveis (em torno de $50 \%$ dos municípios e menos de $20 \%$ dos Estados não tinham aprovados seus RAG nos conselhos de saúde), resultando na criação de uma cooperação do Grupo de Trabalho da ABRASCO e o Instituto Materno-Infantil de Pernambuco (IMIP) para auxiliar no desenvolvimento de metodologias, para envolver atores acadêmicos e da pesquisa aplicada e para desenvolver linhas para a qualificação das equipes gestoras. Houve também o mapeamento das práticas de 
monitoramento e avaliação desenvolvidas pelos gestores estaduais e municipais, bem como identificar técnicos vinculados a estes processos em âmbito estadual e municipal.

Cabe destacar ainda a iniciativa da Organização Pan-Americana da Saúde (OPAS) para instituir meios de difusão das informações sobre a situação de saúde e suas tendências. Apesar de a OPAS atuar a décadas na disseminação de uma série de dados estatísticos e análises periódicas de âmbito continental, convivem com limitações relacionadas à qualidade e oportunidade dos dados aportados pelos países membros, principalmente nos países americanos em desenvolvimento (RIPSA, 2015a).

Para enfrentar esta dificuldade, em 1995 foi lançada a Iniciativa Regional de Dados Básicos em Saúde (IRDBS) com o objetivo de “apoiar esforços dos países membros em reunir dados e informações para caracterizar a situação de saúde no continente, bem como tornar esses dados disponíveis ao público em geral. Sua concepção baseia-se na seleção de um conjunto de indicadores, agrupados por categorias, que permite traçar um panorama geral da situação de saúde na Região. O trabalho empreendido tem motivado as esferas nacionais a aperfeiçoar seus sistemas e bases de dados e a produzir e divulgar informações, segundo critérios comuns" (RIPSA, 2015b).

\subsubsection{Secretaria do Tesouro Nacional (STN)}

Em 2007 o Ministério dos Transportes firmou com o BIRD o acordo de empréstimo no 7383 BR para subsidiar a implantação do Projeto Transporte Rodoviário (PREMEF), parte integrante do programa de redução dos custos logísticos brasileiros vigente à época (ANTT, 2008). Além da participação de órgãos públicos diretamente ligado à execução orçamentária (Departamento Nacional de Infraestrutura Terrestre - DNIT, Ministério dos Transportes e Agência Nacional de Transportes Terrestres - ANTT), a Secretaria do Tesouro Nacional (STN) foi incorporada ao acordo tendo em vista a crescente relevância dos investimentos públicos para a consecução das políticas fiscais e da necessidade de difusão das informações e conhecimentos gerados para os demais atores envolvidos no processo de investimento.

Segundo o Relatório $\mathrm{n}^{\text {o }} 201200864$ elaborado pela Controladoria Geral da União (CGU)(CGU, 2012), as iniciativas designadas à STN foram organizadas por meio do Projeto 
BRA/06/024, o qual visou modernizar os processos de seleção, implementação, monitoramento e avaliação de projetos de investimento a luz da adaptação das melhores práticas utilizadas no setor privado. O projeto vinculado à STN ocorreu entre 2006 e 2013 (UNDP, 2015), mas em 2011 sofreu significativas alterações que o descaracterizou, segundo os apontamentos da controladoria.

As justificativas apresentadas pela secretaria para a alteração no projeto enfatizaram que "as prioridades governamentais com relação ao monitoramento e avaliação da execução de projetos tomaram outros rumos que prescindiram da participação efetiva da Secretaria do Tesouro Nacional no desenvolvimento de um sistema com esse objetivo". Tal alteração resultou na inclusão de outros produtos e a descontinuidade aos inicialmente previstos e afetos à concepção e criação do SMA, levando à não contratação de empresas para elaboração do "Plano de Implantação" e para a implantação do sistema de monitoramento (CGU, 2012).

\subsubsection{Plano Plurianual do Governo Federal brasileiro (PPA)}

O modelo de eficiência nas políticas públicas proposto pela ideologia gerencialista ganhou força no Brasil a partir do final da década de 1990, mas que teve como importante impulso com a promulgação da Constituição Federal de 1988(Souza, 2006). Um importante instrumento para esta reforma foi instituído por meio dos Orçamentos Anuais e PPAs (Bresser-Pereira, 2000), os quais tinham por objetivo fixar gastos e orientar as iniciativas com foco nos resultados.

Tais intenções foram consolidadas na elaboração do PPA 2000-2003 que, ao combinar instrumentos de planejamento, orçamento e gerenciamento, representou uma importante mudança no Brasil para adotar o que vinha sendo adotado por diversos países. Entretanto, Calmon e Gusso (2002) atribuíram as dificuldades de monitoramento e avaliação anteriores àquela época às dificuldades econômicas e políticas que o pais atravessava. Ainda assim, os autores destacam significativos avanços, mas com pouca utilização das informações das avaliações pelo Congresso Nacional.

Garcia (2000) também contribui com uma análise sobre os avanços que ocorreram no final da década de 1990, mas destaca que os programas não foram desenhados para serem avaliados, o 
que contribui sobremaneira encontrar informações sobre seu desempenho e impacto.As diversas dificuldades daquela época, por exemplo, influíram o fomento do recém criado Sigplan com informações confiáveis, não ultrapassando mais de $40 \%$ de registros de avanços físicos e indicadores apurados (Calmon e Gusso, 2002).

Apesar dos avanços observados nos PPAs de 2000-2003, 2004-2007 e 2008-2011,percebe-se na literatura que permanecem problemas que impactam a obtenção, disseminação e apropriação das informações: baixa interação dos órgãos executores envolvidos, debilidades na mensuração de resultados e na capacitação dos recursos envolvidos no processo.

Em 2011 o TCU realizou um levantamento dos sistemas de monitoramento e avaliação presentes na administração direta pública federal, utilizando-se como prerrogativa a necessidade de conhecer a organização e o funcionamento dos aspectos operacionais referentes às atividades governamentais (Brasil, 2011). O levantamento realizado pelo tribunal contou com a resposta de 25 dos 31 órgãos responsáveis por programas e ações do PPA e constatou:

1. a elevada dependência destes órgão da metodologia e dos instrumentos de planejamento estabelecidos pelo MPOG, tendo em vista que 60\% (15) das instituições respondentes utilizam apenas estes indicadores para monitorar os programas e ações sob sua responsabilidade;

2. a limitação das UMAs - uma vez que possuem pouco conhecimento sobre os sistemas de monitoramento de metas físicas e os processos avaliativos;

3. a maior afinidade das atividades de monitoramento à gestão das políticas setoriais que aos macro objetivos definidos no PPA, úteis na mensuração do desempenho;

4. a incongruência epistemológica entre o MPOG e os subsistemas - resultado da falta de compartilhamento e compreensão dos conceitos;

5. a ausência de capacidades avaliativas nas instituições;

6. a falta de unicidade do sistema nacional - tendo em vista a falta de canais de comunicação entre as UMAs;

7. a desintegração dos sistemas de monitoramento e avaliação;

8. a incompatibilidade do desenho dos programas com o modelo de gestão; e

9. a fragilidade epistemológicas e na realização das avaliações. 
O recente trabalho de Serpa (2014) apresenta uma caracterização dos sistemas de avaliação de programas governamentais com o intuito de discutir como os mecanismos e instrumentos necessários para produzir informações sobre o desempenho e os resultados dos programas e políticas são estruturados e implementados.

A partir dos dados obtidos por meio de um questionário aplicado a 2.062 gestores das unidades da Administração Direta do Poder Executivo de 28 Ministérios, a autora conclui que: i) a capacidade avaliativa para produzir regulamente informações sobre as iniciativas públicas é restrita a nove órgão, e ii) há uma baixa institucionalização destas atividades, comprometidas por deficiências como insuficiência de recursos tecnológicos, financeiros e humanos. Entretanto, as informações produzidas - mesmo que insuficientes - são utilizadas para uma diversidade de propósitos.

\subsubsection{Países da América Latina}

As práticas utilizadas pela ONU e o Banco Mundial denotam o importante papel que a institucionalização representa para o sucesso de um SMA. Por este motivo, o trabalho de Grau e Ospina (2008) apresentado nesta subseção realiza uma análise deste aspecto em 12 países da América Latina e do Caribe, destacando os principais fatores que podem incidir na sua institucionalização e discorrendo sobre como se instituem capacidades de avaliação em um governo.

Grau e Ospina (2008) definiram institucionalização de um SMA como a capacidade de formalização de parcerias e consolidação de práticas obtidas por meio da valorização dos dados. Para permitir uma comparação, a autoras destacaram quatro características importantes: a diversificação funcional e instrumental, a coerência institucional, o uso da informação e a sustentabilidade.

O primeiro aspecto analisado pelas autoras - a diversificação funcional e instrumental - está relacionado à finalidade de um SMA. Conforme as autoras reconhecem, é difícil imaginar a existência de um SMA sem demanda, e o grau de institucionalização pode ser indicado pela construção de maiores graus de demanda. 
A diversificação da demanda pode ocorrer por meio de incentivos e de restrições, da confiabilidade da informação, do esforço continuado ou pela vinculação ao processo orçamentário, mas convergem de maneira geral para sua utilidade percebida (Grau \& Ospina, 2008). A exemplo dos incentivos para avaliação, a utilidade percebida representa a utilidade prática direta para diferentes finalidades - que no âmbito governamental, podem estar relacionadas à qualificação do processo decisório orçamentário, ao planejamento nacional ou setorial, a gestão dos serviços públicos e a prestação de contas. A diversificação funcional traz consigo a necessidade também de uma diversificação instrumental que, por seu turno, buscará organizar as informações segundo o objetivo e público a ser alcançado.

A diversificação de propósitos que estão envolvidas nestas considerações pode confrontar com outro elemento principal dos sistemas, a objetividade. Mas percebe-se que os seu foco é mantido quando observado pelo lado da busca por garantir um processo cíclico das informações disponíveis ao máximo de atores afins. Ainda assim, quanto mais sofisticado for um sistema para a diversificação dos propósitos, maior será sua utilidade, que pode ser potencializada pelas características do empreendedor operacional, principalmente.

No informe, Grau e Ospina (2008) perceberam a correspondência direta que os sistemas multifuncionais possuem com os níveis de institucionalização dos SMAs nos países analisados. O SMA do PPA brasileiro atua na interface entre o planejamento e o orçamento, combinando também as orientações mistas de política - reforçadas pelo sistema de metas presidenciais - e econômica. No Chile, a forte influência do patrocinador do sistema - o Ministério da Fazenda - sobre os demais setores públicos foi um importante fator para garantir a vocação multifuncional.

Em relação à utilidade prática, o estudo mostra que o propósito de determinados sistemas também influenciam na diversificação dos seus usuários. A necessidade de prestação de contas envolvidos nos sistemas de orientação política faz com que sejam criados módulos específicos para que alcance a sociedade, a exemplo do Sistema Nacional de Avaliação da Gestão e Resultados (SINERGIA), da Colômbia. 
Mas é a integração entre planejamento e orçamento que Grau e Ospina (2008) enfatizam como um importante demandante de um SMA, apresentando dois modelos de planejamento: centrado no próprio planejamento ou no orçamento. $\mathrm{O}$ modelo centrado no planejamento busca orientar o orçamento segundo prioridades nacionais de médio prazo, enquanto no modelo orçamentário sua preparação é o processo dominante, não condicionando o orçamento a um planejamento. Independente da orientação, é importante existir uma forma eficaz de conectar o planejamento com os orçamentos e a capacidade de decidir sobre os orçamentos à luz dos impactos esperados futuros. Esta ligação pode ser viabilizada pelos SMAs.

Grau e Ospina (2008) destacam também a necessidade de cooperação para permitir que o SMA contribuísse para transformar determinada gestão. Por isto, o maior grau de institucionalização dos SMAs foi avaliado por meio da coerência institucional, considerado como importantes fatores para sua utilidade a integração vertical e horizontal. A integração vertical busca aproximar as diversas instancias institucionais para que possam utilizar a informação e garantir a qualidade e utilidade do sistema. Unidades desintegradas são desestimuladas uma vez que não participam do processo, comprometendo a qualidade dos dados. O desempenho dos recursos envolvidos no nível operacional, por exemplo, tem sido cada vez mais reconhecido como elemento importante e que causam um efeito cascata até os objetivos estratégicos.

A integração transversal indicada por Grau e Ospina (2008) enfatiza a necessidade de sinergia entre a gestão de pessoas, de estatística, o planejamento e o orçamento. Apesar de o processo estatístico ser reconhecido como ferramenta para aprimoramento do processo de planejamento, esta integração é normalmente interrompida pela ausência da avaliação, a qual transforma a informação em conhecimento com a aplicação de técnicas específicas. Da mesma forma, a ausência de um maior controle e percepção global dos produtos gerados pelas unidades para as instituições dificulta a conscientização sobre a importância da avaliação.

Empiricamente, considera-se que a coerência institucional de um SMA está diretamente relacionada à sua utilidade e, consequentemente, seu grau de institucionalização. Grau e Ospina (2008) destacam que é de grande importância para a institucionalização de um SMA ambientes onde o resultado retroalimenta as instâncias gerenciais e contribui efetivamente 
para a melhoria dos programas e das organizações públicas - gerando a presença de um fluxo bidirecional de informações. Tal constatação foi obtida a partir do Sistema de Controle de Gestão liderado pela Direção de Orçamento do Chile, apesar de não ser evidente a participação dos dirigentes públicos na determinação das prioridades de monitoramento e avaliação e na definição dos indicadores de gestão. No Brasil, mesmo apresentando dificuldades, o SMA do PPA privilegia o componente de auto avaliação, aparentado uma maior apropriação das informações por diretores.

Em relação à identificação de metas e indicadores, as autoras destacam os malefícios da excessiva especialização de alguns sistemas como observado na Colômbia, Costa Rica, Nicarágua e naqueles voltados para o monitoramento de metas presidenciais do Brasil, do Chile e do Uruguai. Tal característica dificulta a apropriação do sistema por outras unidades e, consequentemente, o aprendizado gerencial. Para que então possa contribuir com a melhoria das políticas setoriais e também garantir sua sobrevivência, é importante a participação dos ministérios setoriais na identificação das metas e dos indicadores, bem como no processo de planejamento estratégico. Na Bolívia, a ausência de integração dos departamentos de planejamento setorial no funcionamento do sistema foi considerado como uma das principais causas do fracasso do Sistema de Acompanhamento e Avaliação da Gestão Pública por Resultado (SISER), visto a duplicação de funções e a geração de informações de pouca utilidade.

Os maiores déficits percebidos por Grau e Ospina (2008) na coerência institucional estão relacionados à integração transversal com outros processos do ciclo de gestão governamental. Estas lacunas têm sido preenchidas por meio de uma maior vinculação do MeA ao planejamento e à elaboração orçamentária, inserindo informações físicas e financeiras dos projetos de investimentos - a exemplo dos sistemas da Colômbia, do México e do Brasil. O escasso vínculo com o orçamento - conforme observado no Uruguai e em Honduras - sujeita as atividades de MeA a resultados pouco realistas e ritos monótonos.

A experiência do Peru demonstra a importância do envolvimento com instituições de estatísticas para a geração de informações das metas do orçamento por resultado, permitindo 
resolver simultaneamente o problema de informação de muitos setores com alguns ajustes na cobertura temática e geográfica das pesquisas.

Para que um SMA diversifique sua utilidade e se integre ao restante da estrutura organizacional, deve ser utilizado por diversos atores, existindo uma etapa que permita que a informação deixe de ser apenas potencial para ser de uso real. Quatro fatores que podem diminuir a brecha entre o uso real e potencial segundo as autoras: a geração de informação plausível, ser acessível, ser consumível e que produza consequências.

A baixa credibilidade da informação limita seu uso por usuários potenciais e torna o sistema auto referidos. Grau e Ospina (2008) atribuem esta baixa credibilidade aos inputs, à credibilidade dos gestores e a falta de incentivos para garantir maior credibilidade. $\mathrm{O}$ primeiro é resultado da falta de capacidade dos subsistemas que o compõe, a multiplicação de demandas para um mesmo fenômeno, e o escasso grau de maturidade gerencial, implicando em filtros pouco eficientes. O segundo resulta da dúvida na capacidade de seu gestor - neste caso o governo - criar um sistema onde regula sua própria avaliação ou o utiliza esporadicamente, a exemplo dos SMA presentes na Colômbia, em Honduras e no Peru. Segundo as autoras, no Brasil e no Chile há poucas (ou nenhuma) evidência de que os gerentes de metas pouco utilizam as informações, e no México os SMA agregam os dados a um nível de pouca utilidade para a gestão. O último aspecto está relacionado ao ciclo de eventos e à ausência da retroação, levando aos subsistemas a não vislumbrarem motivos para a geração de dados confiáveis uma vez que não usufruem dos benefícios proporcionados pelas análises das informações.

Nos doze países selecionados, Grau e Ospina (2008) perceberam que os sistemas mais antigos e consolidados se preocupam com o aprimoramento dos métodos e ferramentas (Brasil, Chile e México), dos indicadores (Colômbia) e com a credibilidade externa, incorporando auditorias ou mecanismos formais de validação dos dados (Chile, Brasil e Colômbia). Portanto, o exemplo destes quatro países indicam que as avaliações externas com metodologias reconhecidas e idôneas geram credibilidade tanto para os resultados que produzem como no ambiente onde estão inseridos. Nos departamentos estatísticos, o aumento da credibilidade 
está mais relacionada ao aprimoramento metodológico ou operacional, uma vez que geram um volume de informação muito superior ao retorno que os é útil.

Para as autoras, nos países onde os relatórios são obrigados a indicar as medidas de correção (México e Chile) existe uma maior probabilidade de que as informações geradas resultem em um impacto real em alguma instância da administração pública - especialmente quando há atores internacionais envolvidos (como na Nicarágua e Honduras). Em relação à apropriação das informações dos SMA pelo congresso, em geral quando ocorre são realizadas após o processo de negociação dos grupos políticos. Em alguns casos, a elaboração de longos relatórios desencoraja o seu uso.

O último atributo avaliado por Grau e Ospina (2008) para a institucionalização de um SMA é a sustentabilidade - associado pelas autoras à oferta perene de informações. Além da necessidade de demanda, a oferta adequada dos produtos de um SMA pode também contribuir como sua maior utilidade. Um ingrediente básico destacado anteriormente e também por Grau e Ospina (2008) é a confiança e sustentabilidade dos dados. O primeiro representa a credibilidade, a qualidade e a objetividade da informação garantidos pelas capacidades técnicas disponíveis internamente e nos atores participantes e os arranjos institucionais do SMA. Arranjos que privilegiem alternar entre a centralização e descentralização das atividades podem equilibrar melhor a qualidade do primeiro e a objetividade do segundo.

A sustentabilidade representa a necessidade de esforços continuados para uma maior eficiência do SMA. Por isto, a interação entre sistemas e com o ambiente depende de um elemento fundamental para o aprimoramento: tempo. A variável idade dos sistemas que usufruem das atividades de retroalimentação tem significativa importância para seu sucesso, sendo fundamental para vencer os primeiros anos sua utilidade. Adicionalmente, marcos formais também podem contribuir para garantir a sobrevida, em muitos casos estabelecidos em financiamentos que exigem uma unidade coordenadora e estabilidade de pessoal. 


\section{MÉTODO PARA DEFINIÇÃO DAS DIRETRIZES DE UM SMA DAS POLÍTICAS PÚBLICAS PARA A INFRAESTRUTURA FEDERAL DE TRANSPORTES}

\subsection{Descrição do método}

A literatura, as práticas e as experiências nacionais e internacionais discorrem sobre os aspectos genéricos para uma abordagem sistêmica e aplicáveis a qualquer área - e por isto foram denominadas como diretrizes gerais para um SMA. Para adequá-las ao setor de transportes foi realizada uma pesquisa Delphi com especialistas envolvidos com as políticas públicas para infraestrutura federal do setor. A Delphi é uma ferramenta utilizada para analisar estatisticamente dados qualitativos, concebida inicialmente como instrumento de previsões para fins militares e aplicado posteriormente em diversas outras áreas (RAND Corporation, n.d.).

A Figura 4.1 a seguir apresenta esquematicamente o caminho a ser percorrido na aplicação do método proposto.

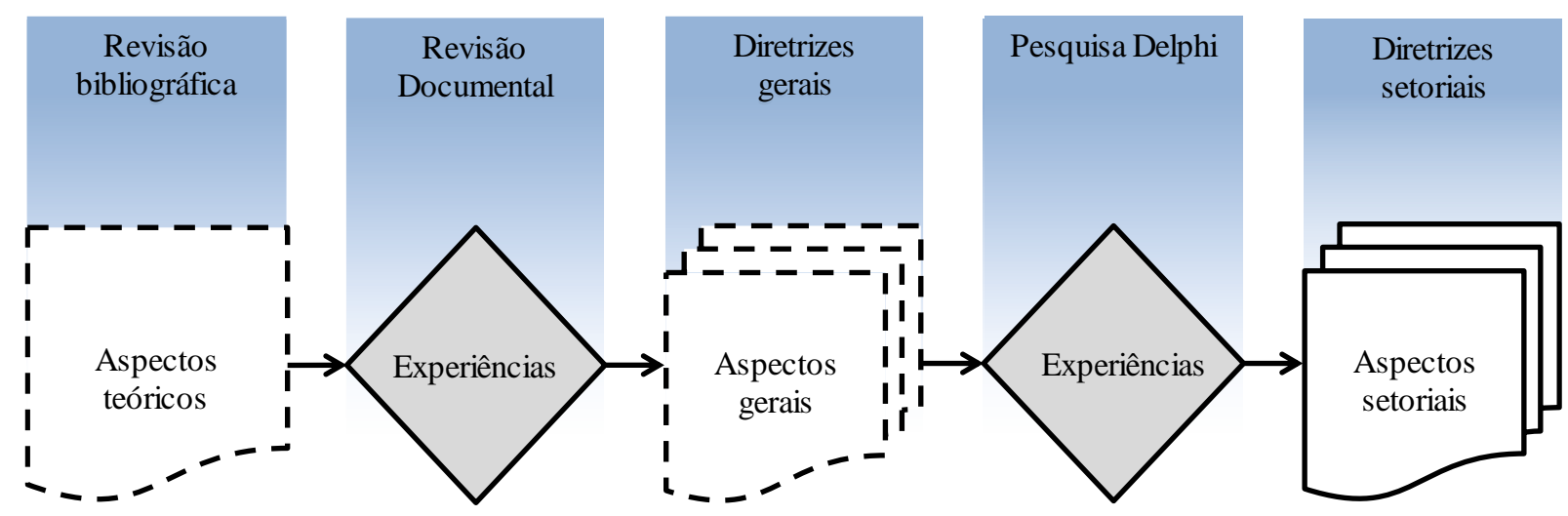

Figura 4.1- Apresentação esquemática do método.

Fonte: Elaborado pelo autor.

O método para definição das diretrizes de um SMA das políticas públicas para a infraestrutura federal de transportes é composto por cinco etapas: identificação das diretrizes gerais de um SMA, elaboração de um questionário, aplicação do questionário, análise dos dados e definição das diretrizes para o setor. A Figura 4.2 a seguir esquematiza as etapas deste método. 


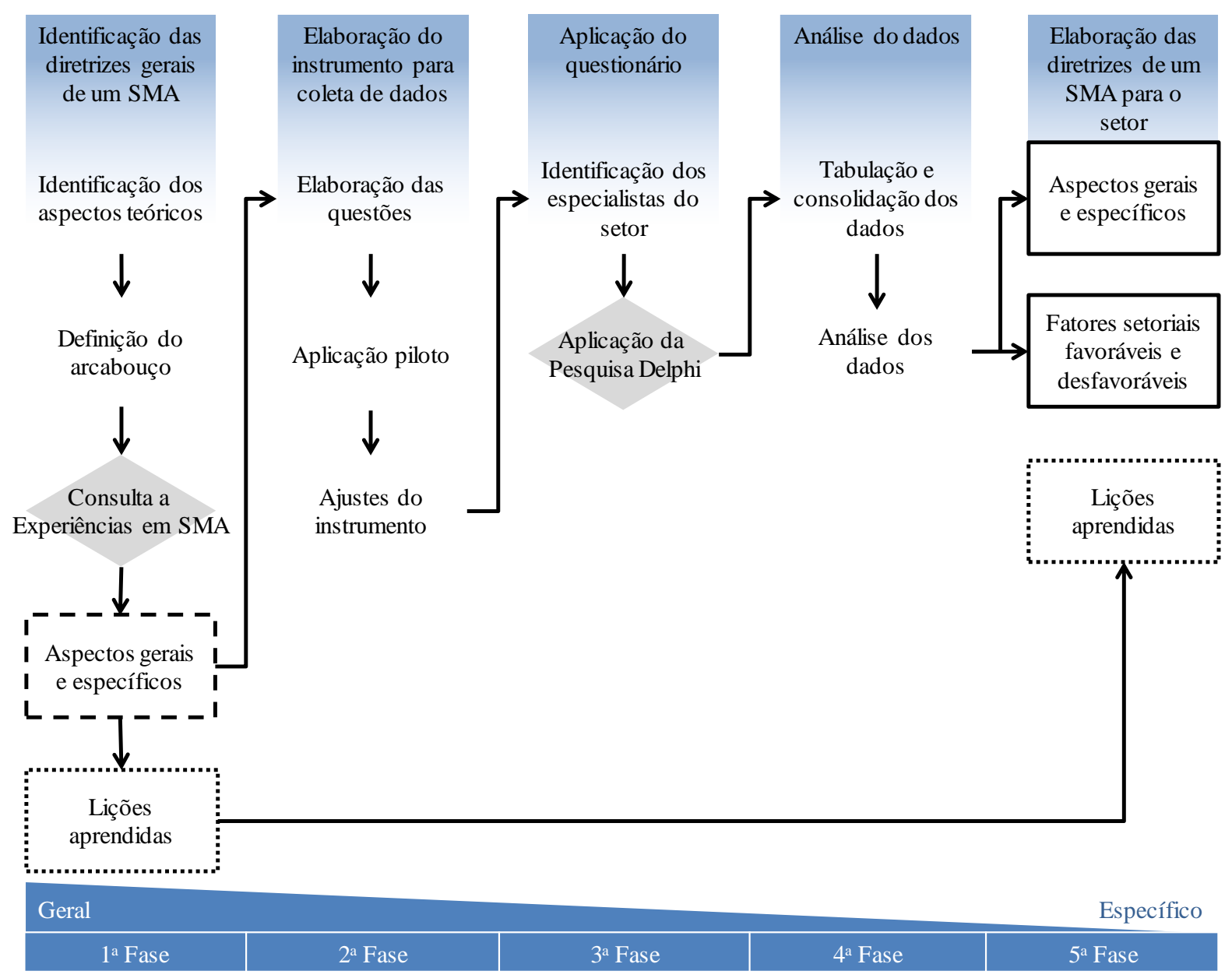

Figura 4.2-Apresentação detalhada das fases do método proposto.

Fonte: Elaborado pelo autor.

A $1^{\text {a }}$ etapa consiste na análise comparativa dos aspectos teóricos identificados na TGS e no ciclo de políticas públicas com as práticas recomendadas pelo Banco Mundial para compatibilizar termos e estabelecer um arcabouço comum. Em seguida, é realizada um revisão de manuais, normas e publicações que relatam experiências nacionais e internacionais com SMAs para identificar aspectos não destacados pela literatura e destacar oportunamente os fatores que impactaram favorável ou desfavoravelmente na criação e manutenção de um SMA de outros setores no Brasil, principalmente.

Para analisar estes documentos, Richardson e Peres (1985), Gil (2008) e Oliveira (2008) propõem, a partir de Bardin, três etapas: i) pré-análise; ii) análise do material ou codificação e iii) tratamento dos resultados - inferência e interpretação. 
A pré-análise documental permite o reconhecimento preliminar dos conteúdos por meio de uma leitura "superficial" dos materiais. A seleção do tipo de documentação para esta etapa envolve uma iteração entre o domínio do pesquisador sobre o assunto, pesquisas na internet e as fontes citadas nos próprios textos avaliados. Esta fase também contribui para a formulação das hipóteses e dos objetivos do trabalho e a elaboração dos indicadores a serem utilizados para quantificar a pesquisa. Por isso, mesmo a leitura sendo dita como superficial, deve ser suficiente para obter uma compreensão do tema abordado nos documentos e de como mensurá-lo em meio a distintas fontes de informação não padronizadas.

$\mathrm{Na}$ análise do material, os textos que terão uma análise mais rigorosa são selecionados, sem o prejuízo da inserção de outros que poderão complementar estas análises. Por meio de uma leitura mais aprofundada dos documentos, esta fase é considerada mais trabalhosa tendo em vista a realização dos processos de codificação, categorização e quantificação da informação disponível (Richardson e Peres, 1985).

Ao final da análise de conteúdo, a análise documental faz o tratamento dos resultados para classificar e agrupar as informações para uma abordagem quali-quantitativa e interpretação dos dados. Apesar de as análises dos resultados contarem com técnicas para auxiliar na interpretação dos dados, os citados autores reconhecem a importância que a codificação possui para o sucesso desse tipo de pesquisa.

Como resultado desta etapa, são definidas as diretrizes gerais de um SMA, formada por aspectos gerais e específicos e a relação dos aspectos favoráveis e desfavoráveis e respectivas ações desenvolvidas, denominadas de lições aprendidas.

A $2^{\mathrm{a}}$ etapa elabora o instrumento para a coleta de dados para definição das diretrizes de um SMA das políticas públicas para a infraestrutura de transportes. Uma sequência de formulários online (disponibilizado pela ferramenta Google Forms) apresentaram um questionário Delphi semiestruturado para permitir que os respondentes explicitem seus conhecimentos tácitos sobre o tema. 
Utilizando a escala do tipo Likert com cinco pontos, as respostas de cada pergunta são compulsórias e padronizadas para uniformizar o raciocínio ao longo da pesquisa. As opções de resposta permitiram que os respondentes informassem sobre o desconhecimento do tema, a inexistência ou nenhuma importância do aspecto em questão e outras três opções que representam o grau de presença ou importância (pouco, intermediário e muito presente ou importante). O Quadro 4.1 a seguir apresenta a correspondência entre as escalas utilizadas em cada tópico.

Quadro 4.1 - Correspondência das escalas de resposta dos tópicos 1 e 2.

\begin{tabular}{|l|l|c|}
\hline Tópico 1 & Tópico 2 & Pontos \\
\hline Desconheço & Desconheço & 0 \\
\hline Inexiste & Nenhuma Importância & 1 \\
\hline $\begin{array}{l}\text { Atende formalidades e/ou é incipiente, } \\
\text { desarticulada ou isolada; }\end{array}$ & Pouco importante & 2 \\
\hline Está num estágio intermediário de aplicação & Importância intermediária & 3 \\
\hline É amplamente utilizado & Muito importante & 4 \\
\hline
\end{tabular}

Fonte: Elaborado pelo autor.

Para cada pergunta, o instrumento de coleta de dados disponibilizou um campo textual livre para o registro voluntário de comentários, opiniões e para fomentar o diálogo consensual não identificado entre os respondentes.

Wright e Giovinazzo (2000) enfatizam que a Delphi deve utilizar uma linguagem homogênea e que contribua com o raciocínio orientado para o futuro. Por isto, recomenda-se que cada pergunta faça uma breve apresentação do componente em questão. Além disto, desde o início da pesquisa deve ser enfatizado aos participantes que as respostas devem refletir a percepção que possuem do problema em tela sobre a perspectiva das políticas públicas setoriais - e não da instituição que representam ou das convicções setoriais e pessoais.

Apesar das pesquisas Delphi buscarem o consenso, é possível que não alcancem tal objetivo. Dajani, Sincoff e Talley (1979) apresentam cinco resultados possíveis em uma pesquisa Delphi, oportunamente reunidos neste trabalho em dois grupos: o primeiro formado pelo 
consenso e pela maioria, e o segundo pela bipolaridade, pela pluralidade e pelo desacordo ou dissenso. No primeiro grupo, determinada opção de resposta reúne $50 \%$ ou mais dos respondentes - concentração esta maior no consenso. No segundo grupo, a bipolaridade representa a formação de dois grupos que prevalecem e concentram mais de $50 \%$ dos respondentes; e a pluralidade das respostas é obtida quando uma opção se destaca entre as demais, mas concentra $50 \%$ ou menos das opiniões - caso contrário conclui-se que não há consenso entre as respostas dos especialistas.

Dajani, Sincoff e Talley (1979) destacam que, exceto o consenso, os demais resultados devem ser submetidos a uma validação para finalizar ou realizar uma nova rodada da pesquisa. Os autores recomendam que o resultado indicado pela maioria em determinada questão seja submetido a uma simples aprovação ou não pelos demais respondentes para qualificar tal resultado; e que os resultados que representam a bipolaridade e a pluralidade das opiniões remetam à avaliação do perfil dos entrevistados para decidir sobre o término ou reformulação da pesquisa.

Entretanto, este estudo utiliza tal avaliação dos perfis apenas para analisar o resultado final da pesquisa - não sendo, portanto, parte integrante dos critérios de continuidade das rodadas para minimizar inferências qualitativas ao longo da coleta de dados. Assim, o consenso em determinada questão foi considerado nos casos onde uma única opção de resposta concentrar $70 \%$ ou mais das opiniões dos respondentes, e a maioria será representada por entre $50 \%$ ou $70 \%$ dos respondentes, conforme mostra a Figura 4.3 seguir. 


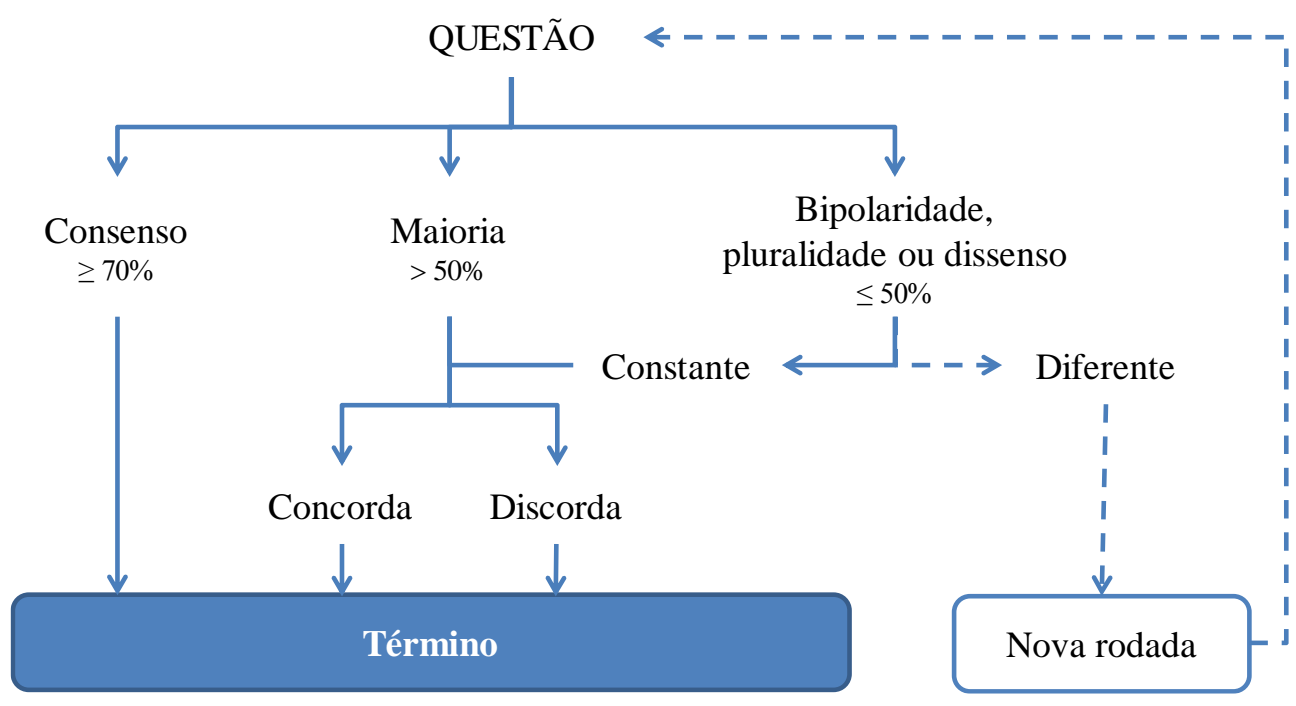

Figura 4.3 - Critérios para continuidade ou conclusão da pesquisa Delphi.

Fonte: Elaborado pelo autor.

As questões que não alcançarem o consenso foram revisadas para incorporar os comentários e as sugestões dos especialistas - caso necessário - e evitar a identificação dos respondentes nestes campos. Dá-se, então, início a uma nova rodada apresentando os resultados e comentários registrados na rodada anterior para as questões não consensuadas, conforme ilustra o apêndice A. Desta forma, cada sujeito poderá manter ou alterar sua opinião enviada anteriormente. Este processo se repete até se verificar que o resultado de cada pergunta se apresentem estatisticamente inalterados ao final de cada rodada.

Em relação ao momento para término do questionário Delphi, Der Gracht (2012) enfatiza que os critérios estabelecidos por diversos estudos para mensurar o consenso e a significância da variação das respostas entre rodadas de uma pesquisa Delphi apresentam fragilidades. Além do uso inadequado de métodos estatísticos destinados a amostras independentes e com distribuição normal, o autor conclui que há necessidade de se verificar a estabilidade das respostas antes de se concluir uma pesquisa Delphi.

Assim como Der Gracht (2012), Rayens e Hahn (2000) destacam a diversidade de métodos estatísticos utilizados para tal finalidade. Ambos os trabalhos enaltecem a eficiência da distância interquartílica para a comparação de distribuições. Wright e Giovinazzo (2000), por exemplo, sugerem que a estabilidade das respostas pode ser medida a partir das distâncias da 
mediana ao $1^{\circ}$ e ao $3^{\circ}$ quartil.Der Gracht (2012) sugere o uso do teste qui-quadrado $\left(\chi^{2}\right)$ para mensurar a relevância das alterações entre as respostas de duas rodadas.

Neste estudo, o valor representativo da amostra é representado pela mediana, o comportamento da distribuição da amostra em cada rodada será verificada pela distância interquartílica e o valor-p do teste $\chi^{2} e ́$ utilizado para verificar se as respostas de duas rodadas consecutivas de uma questão não consensuada são idênticas com um grau de confiança de 95\%. Rowe e Wright (1999) indicam que a maioria das pesquisas discutidas pelos autores é concluída com duas ou três rodadas - quando não há alterações e contribuições significativas nas respostas.Opcionalmente, os testes Mann-Whitney e Wilcoxon foram utilizados para avaliar se há diferença significativa entre grupos de repostas distintos.

A pesquisa deve ser aplicada previamente a uma amostra qualificada e diferente da pesquisa definitiva para verificar a necessidade de ajustes na estrutura do questionário, na usabilidade da ferramenta e no entendimento e clareza dos termos utilizados. A aplicação piloto permite também avaliar os processos de consolidação, de análise e testar a reaplicação das rodadas subsequentes e os modelos estatísticos que determinam o término da pesquisa.

$\mathrm{Na} 3^{\mathrm{a}}$ etapa se destina à aplicação da pesquisa Delphi e se inicia com a identificação de especialistas que atuam na infraestrutura federal de transportes. Assim como na pesquisa piloto, o universo da pesquisa Delphi são os grupos qualificados que atuam e contribuem diretamente para o sistema em questão. Galanc e Mikuś (1986) indicam que a pesquisa com sete ou mais respondentes traz resultados satisfatórios, ressalvando a ineficiência de grupos muito maiores. Por isto, o número de especialistas convidados tem por objetivo garantir sete ou mais respondentes por questão, independente do modal de atuação.

Cada respondente deve ser contatado para apresentar brevemente a pesquisa e questionar sobre o interesse para participar da pesquisa ou indicar outro especialista. O convite pode ser presencial, por telefone ou por e-mail, buscando registrar os dados de contato para participar do questionário Delphi. 
A aplicação da pesquisa Delphi começa com o encaminhamento de uma mensagem para o email fornecido durante a identificação dos respondentes, contendo o endereço para acesso ao questionário Delphi e o prazo para participar da enquete. Para alcançar o número de respostas desejado, o questionário ficou disponível 24 horas por dia.

No dia que anteceder o encerramento da rodada, um novo contato é realizado por e-mail e/ou telefone com os especialistas que ainda não preencheram o questionário, convidando-os novamente para participar da pesquisa. O prazo inicial da pesquisa foi de cinco dias úteis, contados a partir do envio do e-mail.Eventualmente, este prazo poderá ser prorrogado para garantir um numero adequado de respostas válidas por questão.

A consolidação e análise dos dados obtidos com a aplicação do questionário Delphi são realizadas na $4^{\mathrm{a}}$ etapa. As respostas foram registradas e tabuladas em uma planilha eletrônica também online (acessada pela ferramenta Google Sheets), e os testes estatísticos e a análise dos dados foram realizados utilizando o programa Excel (teste qui-quadrado e descrições estatísticas) e os suplementos Real Statistics (para Mann-Whitney) e Action (para Wilcoxon).

Foram consideradas válidas as respostas com pontuação entre 1 e 4 da escala do tipo Likert. Desta forma, as respostas com pontuação igual a 0 , declaradas como desconheço pelo respondente, não participaram das análise. O resultado de cada questão é representado pela mediana dos valores válidos e apresentado sob a forma de gráficos, quadros ou tabelas.

Assim como realizado na análise documental das experiências nacionais e internacionais, a avaliação dos comentários voluntários enviado pelos respondentes utiliza a técnica de análise de conteúdo para avaliar a necessidade de adequação as diretrizes gerais ao setor de infraestrutura federal; bem como identificar palavras chaves que os relacionassem aos aspectos específicos das diretrizes gerais. Neste último caso, a quantidade de inferências por aspecto específico e respondentes envolvidos são apresentados sob a forma um quadro.

Os dados são comparados entre si e com o perfil dos respondentes para discutir os resultados da pesquisa Delphi, apontando similaridades, divergências e os pontos favoráveis e desfavoráveis no setor para a criação de um SMA.Outras análises estatísticas e comparações 
complementares poderão ser definidas para subsidiar a discussão dos resultados a partir da observação direta dos dados. A percepção dos especializas sobre o estágio atual e a importância dos aspectos específicos apresentados sinaliza preliminarmente o grau de maturidade de uma abordagem sistêmica no setor de infraestrutura federal de transportes.

Com resultado da análise dos dados e dos comentários, a $5^{\text {a }}$ etapa define as diretrizes para um SMA das políticas públicas para a infraestrutura federal de transportes, realizando os ajustes necessários nas diretrizes gerais e acrescentando os fatores favoráveis e desfavoráveis no setor.

\subsection{Aplicação do método}

\subsubsection{Identificação das diretrizes gerais para um SMA}

Seguindo a recomendação de Bertalanffy (1975), para abordar a TGS em um ambiente organizacional foi utilizado o trabalho e Katz e Kahn (1978), o qual descreve nove aspectos específicos. A liderança foi adicionada como um décimo aspecto de um sistema tendo em vista o destaque dado por Katz e Kahn (1978). Da mesma forma, a discussão sobre o Ciclo de Políticas Públicas permitiu identificar importantes aspectos de uma abordagem sistêmica, entre eles o empreendedor político que possui atuação semelhante ao aspecto da liderança.

O Banco Mundial elenca doze componentes considerados relevantes para a criação de um SMA. Comparando individualmente cada componente aos aspectos específicos identificados na literatura, a programação física e financeira dos recursos para um SMA recomendado pelo banco, por exemplo, não foi identificada explicitamente; e a retroação não foi claramente identificada como um componente das recomendações do Banco Mundial. Já a liderança operacional está presente implicitamente nas recomendações do banco.

Os componentes apresentados pelo Banco Mundial e relacionados aos dados sobre os insumos, os processos, as saídas e seus impactos no ambiente (Coleta de dados sobre produtos e resultados, Rotinas de monitoramento, Bases de dados, Pesquisa e avaliação e Qualidade dos dados) estão associados aos aspectos gerais de ambiente (Fluxo de energia e o ciclo de eventos). 
Os aspectos específicos destacados na TGS e relacionados à instabilidades internas e a equifinidade associados à totalidade de um sistema estão representados pelos seguintes componentes da proposta do Banco Mundial: a estrutura institucional, a gestão do capital intelectual, o plano de MeA, as parcerias, a previsão físico-financeira dos recursos e a cultura e comunicação institucional. O décimo segundo componente do modelo propostos pelo banco - a finalidade dos SMAs - e a liderança operacional foram associadas ao aspecto geral de finalidade.

O Quadro 4.2 a seguir apresenta os principais aspectos identificados na literatura e nas práticas do Banco Mundial.

Quadro 4.2 -Comparação entre os aspectos de um SMA segundo a teoria e as práticas internacionais.

\begin{tabular}{|c|c|c|c|}
\hline \multirow[t]{2}{*}{ AG } & \multicolumn{2}{|r|}{ Teoria } & \multirow{2}{*}{$\begin{array}{c}\text { Práticas } \\
\text { Banco Mundial }\end{array}$} \\
\hline & TGS & CPP & \\
\hline$\frac{\stackrel{\oplus}{0}}{\frac{0}{0}}$ & O ciclo de eventos; & $\begin{array}{l}\text { Formação e implementação da agenda; } \\
\text { Os problemas, as soluções e a política, } \\
\text { percepção e definição de problemas; } \\
\text { governamental e das políticas públicas } \\
\text { As políticas públicas; }\end{array}$ & $\begin{array}{l}\text { Rotinas de monitoramento; } \\
\text { Coleta de dados sobre produtos } \\
\text { e resultados; } \\
\text { Bases de dados; } \\
\text { Qualidade dos dados; } \\
\text { Pesquisa e avaliação; }\end{array}$ \\
\hline 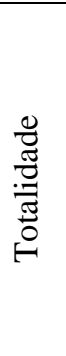 & $\begin{array}{l}\text { Instabilidades } \\
\text { Internas; } \\
\text { A equifinalidade; }\end{array}$ & $\begin{array}{l}\text { As instituições públicas; } \\
\text { A teoria dos programas; }\end{array}$ & $\begin{array}{l}\text { Estrutura institucional; } \\
\text { Gestão do capital intelectual; } \\
\text { Estabelecer e manter parcerias; } \\
\text { Plano de MeA; } \\
\text { Programação física e financeira; } \\
\text { Cultura organizacional de MeA; }\end{array}$ \\
\hline 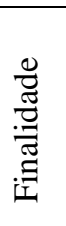 & $\begin{array}{l}\text { A diferenciação; } \\
\text { A retroação ou } \\
\text { feedback; } \\
\text { A lideranç; }\end{array}$ & $\begin{array}{l}\text { Atividades de monitoramento e de avaliação; } \\
\text { O empreendedor político; }\end{array}$ & Finalidade; \\
\hline
\end{tabular}

Fonte: Elaborado pelo autor.

As designações atribuídas aos aspectos gerias foram revistas para melhor se adaptarem ao ambiente institucional a que está vinculado um SMA. Enquanto os aspectos gerais de 
ambiente foram denominados de funcionais, a totalidade foi revista para aspecto geral organizacional. Apenas o aspecto geral de finalidade foi mantido, dado o claro entendimento que o termo transmite.

A similaridade entre dois componentes propostos pelo banco (a coleta de dados relacionados aos produtos e resultados por meio de pesquisas periódicas e a pesquisa e avaliação) permite o agrupamento destes em um único aspecto específico (pesquisa e avaliação). Estes e os demais componentes relacionados aos dados sobre os insumos, os processos, as saídas e seus impactos no ambiente (rotinas de monitoramento, base de dados útil e qualidade dos dados) podem ser agrupados em um aspecto geral que representa o fluxo de informação em um (sub) sistema de retroação, denominado de aspecto geral funcional.

Os aspectos específicos relacionados à totalidade de um sistema e a maioria dos componentes presentes na camada institucional do modelo proposto pelo Banco Mundial podem ser agrupados no aspecto geral organizacional. Neste grupo, o componente que reúne a cultura, a advocacy e a comunicação foi revisado. A advocacy descrita por (Görgens \& Kusek, 2009) demonstra que está mais relacionado às atividades de promoção e de integração, e por isto foi associada na proposta deste estudo aos patrocinadores e pelos empreendedores empresarias.

Os demais componentes (estímulo a parcerias e a finalidade) e aspectos (o ciclo de eventos, a finalidade e a liderança) apresentam forte proximidade com o aspecto geral de finalidade. Neste caso, o estímulo à parcerias corresponde à diversificação de finalidade de um sistema no ciclo de eventos, onde busca fomentar os supra sistemas e outros sistemas.

As atividades de retroação interna de um SMA podem ser atribuídas à liderança operacional, a qual atua sobre os demais aspectos específicos para aprimorar e especializar seu produtos, diferenciando-o, aprimorando-o e diversificando sua finalidade.

A organização dos aspectos de um abordagem sistêmica em gerais e específicos utilizou as funções primárias de cada componente. Entretanto, a forte interdependência entre eles faz com que participem regular e simultaneamente em mais de um aspecto geral. O ciclo de eventos, por exemplo, garante a interação de um sistema com o ambiente, mas também contribui para que este diversifique sua finalidade. E apesar do componente relacionado à 
parcerias estar associado pelo Banco Mundial à camada institucional, ele também possui fundamental participação para ampliar a finalidade do sistema. Uma vez que ambos possuem grande afinidade de objetivos, foram associados ao aspecto geral de finalidade.

O Quadro 4.3 a seguir apresenta os aspectos gerais e específicos para a criação de um SMA identificados na literatura e nas práticas do Banco Mundial.

Quadro 4.3 - Descrição dos aspectos específicos das diretrizes gerais para um SMA.

\begin{tabular}{|c|c|c|}
\hline Aspectos gerais & Aspecto específico & Descrição \\
\hline \multirow[t]{4}{*}{ Funcionais } & $\begin{array}{l}\text { Pesquisas e } \\
\text { avaliações }\end{array}$ & $\begin{array}{l}\text { Atividades de pesquisas periódicas ou por amostragens amplas do } \\
\text { ambiente em que se insere o produto, visando gerar dados sobre resultados } \\
\text { e generalizar conhecimentos para um propósito específico. }\end{array}$ \\
\hline & $\begin{array}{l}\text { Rotinas de } \\
\text { monitoramento }\end{array}$ & $\begin{array}{l}\text { Levantar dados quali-quantitativos sobre o andamento as etapas de um } \\
\text { processo (entrada, processamento e saída). }\end{array}$ \\
\hline & Base de dados útil & $\begin{array}{l}\text { Repositório de dados viabilizado por ferramentas para reunir os dados } \\
\text { coletados durante o monitoramento rotineiro, pesquisas esporádicas e } \\
\text { específicas. }\end{array}$ \\
\hline & $\begin{array}{l}\text { Qualidade dos } \\
\text { dados }\end{array}$ & $\begin{array}{l}\text { atividades desenvolvidas para aumentar a qualidade dos dados e fomentar } \\
\text { a capacidade das equipes, como melhores supervisão e auditoria. }\end{array}$ \\
\hline \multirow[t]{5}{*}{ Organizacionais } & $\begin{array}{l}\text { Estrutura } \\
\text { institucional }\end{array}$ & $\begin{array}{l}\text { Descrição da hierarquia, dos relacionamentos e do arranjo do trabalho, } \\
\text { indicando sua interação e disposição em um sistema }\end{array}$ \\
\hline & $\begin{array}{l}\text { Gestão do capital } \\
\text { intelectual }\end{array}$ & $\begin{array}{l}\text { Iniciativa para a retenção e o desenvolvimento das capacidades e } \\
\text { habilidades dos elementos de um sistema. }\end{array}$ \\
\hline & $\begin{array}{l}\text { Plano de MeA } \\
\text { integrado }\end{array}$ & $\begin{array}{l}\text { Detalhamento das atividades e dos produtos para integrar atores e ser } \\
\text { integrado com outros instrumentos e instâncias de planejamento. }\end{array}$ \\
\hline & $\begin{array}{l}\text { Previsão física- } \\
\text { financeira }\end{array}$ & $\begin{array}{l}\text { Detalhamento pormenorizado e previsão formal dos recursos necessários } \\
\text { para o sistema. }\end{array}$ \\
\hline & $\begin{array}{l}\text { Cultura } \\
\text { organizacional }\end{array}$ & $\begin{array}{l}\text { Seleção de crenças, suposições e valores que levam a uma maior ou menor } \\
\text { receptividade de um SMA na instituição. }\end{array}$ \\
\hline
\end{tabular}


Continuação do Quadro 4.3

\begin{tabular}{|l|l|l|}
\hline Aspectos gerais & Aspecto específico & Descrição \\
\hline Finalidade & Parcerias & $\begin{array}{l}\text { Arranjos que fortalecem o vinculo com os sub e supra sistemas por meio } \\
\text { do fluxo uni ou bidirecional de informações. }\end{array}$ \\
\cline { 2 - 3 } & Finalidade & Destinação do produto gerado pelo sistema. \\
\cline { 2 - 3 } & O empreendedor & $\begin{array}{l}\text { Indivíduos empenhados em um propósito, especialistas em determinada } \\
\text { questão, revestidos de autoridade e de habilidades para fomentar os demais } \\
\text { aspectos específicos, para defender ideias próprias ou de terceiros, para } \\
\text { manter conexões técnicas e políticas e para promover o SMA por meio da } \\
\text { diversificação, do seu uso e do seu constante aprimoramento. }\end{array}$ \\
\hline
\end{tabular}

Fonte: Elaborado pelo autor.

Oportunamente, a análise das experiências com SMA no Brasil e na América Latina indicam pontos favoráveis e desfavoráveis e as ações desencadeadas que podem subsidiar a criação e a manutenção de um SMA para as políticas públicas para a infraestrutura federal de transportes. Os Quadro 4.4 e 4.5 a seguir apresentam estas informações sob a forma de lições aprendidas. 
Quadro 4.4 - Aspectos favoráveis e ações necessárias segundo aspectos específicos.

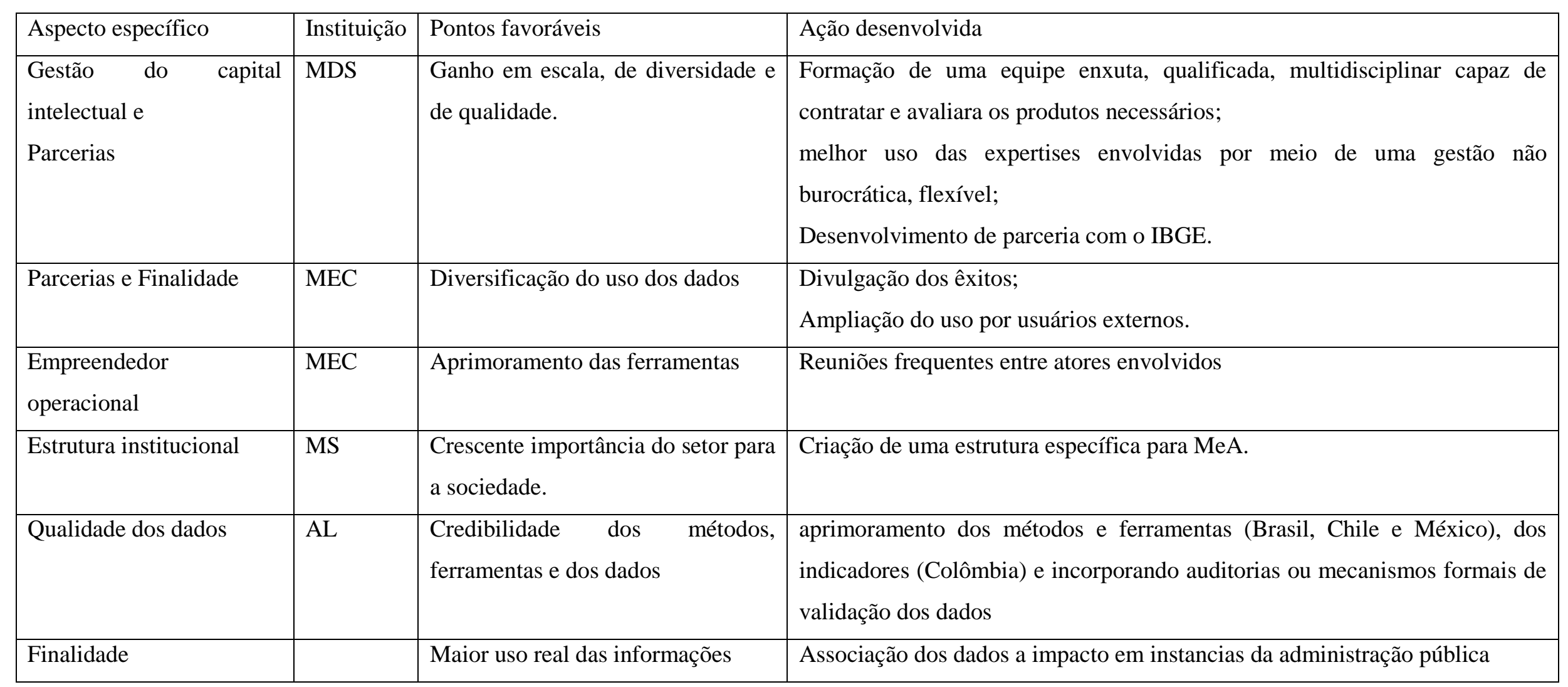

Fonte: Elaborado pelo autor. 
Quadro 4.5 - Aspectos desfavoráveis e ações necessárias segundo aspectos específicos.

\begin{tabular}{|c|c|c|c|}
\hline Aspecto específico em foco & Instituição & Pontos desfavoráveis & Ação necessária \\
\hline Base de dados útil & MDS & $\begin{array}{l}\text { Integração de dados e ferramentas } \\
\text { devido à diversidade de fontes e } \\
\text { falta de padrão dos formatos }\end{array}$ & Definição de indicadores segundo atributos. \\
\hline $\begin{array}{l}\text { Base de dados útil } \\
\text { Qualidade dos dados }\end{array}$ & MEC & $\begin{array}{l}\text { a falta de utilidade para os gestores } \\
\text { e a instabilidade das ferramentas }\end{array}$ & $\begin{array}{l}\text { Desenvolvimento de parceria para realizar estudos e pesquisas sobre } \\
\text { governança, planejamento e monitoramento de ações governamentais. }\end{array}$ \\
\hline Qualidade dos dados & MS & $\begin{array}{l}\text { Fragilidade nas informações } \\
\text { disponíveis }\end{array}$ & $\begin{array}{l}\text { Desenvolvimento de parcerias para auxiliar no desenvolvimento de } \\
\text { metodologias, para envolver atores acadêmicos e da pesquisa aplicada e para } \\
\text { atuar na qualificação das equipes gestoras. }\end{array}$ \\
\hline $\begin{array}{l}\text { Parcerias e } \\
\text { Pesquisa e avaliação }\end{array}$ & MS & $\begin{array}{l}\text { Desarticulação } \\
\text { departamentos; } \\
\text { inexistência de uma política de } \\
\text { avaliação }\end{array}$ & $\begin{array}{l}\text { Institucionalização; } \\
\text { definição das práticas e os processos de monitoramento e avaliação da gestão e } \\
\text { o vínculo com o RAG. }\end{array}$ \\
\hline $\begin{array}{l}\text { Finalidade e } \\
\text { Empreendedor operacional }\end{array}$ & STN & Mudança de governo & Não foram citadas ações de mitigação. \\
\hline $\begin{array}{l}\text { Parcerias, } \\
\text { Qualidade dos dados e } \\
\text { Gestão do capital intelectual }\end{array}$ & PPA & $\begin{array}{l}\text { Baixos registro de avanços físicos e } \\
\text { apuração de indicadores }\end{array}$ & Não foram citadas ações de mitigação. \\
\hline \multirow[t]{2}{*}{ Finalidade } & AL & Vocação multifuncional do SMA; & Atuação marcante do patrocinador no Chile; \\
\hline & $\mathrm{AL}$ & Necessidade de prestação de contas & Criação de módulos específicos para que alcance a sociedade na Colômbia \\
\hline Estrutura institucional & $\mathrm{AL}$ & Coerência institucional & Fluxo bidirecional de informações no Chile e no Brasil \\
\hline
\end{tabular}


Continuação do Quadro 8

\begin{tabular}{|c|c|c|c|}
\hline Aspecto específico em foco & Instituição & Pontos desfavoráveis & Ação necessária \\
\hline Diferenciação & $\mathrm{AL}$ & $\begin{array}{l}\text { Excessiva especialização na } \\
\text { Colômbia, Costa Rica e Nicarágua }\end{array}$ & $\begin{array}{l}\text { participação dos ministérios setoriais na identificação das metas e dos } \\
\text { indicadores, bem como no processo de planejamento estratégico }\end{array}$ \\
\hline \multirow[t]{2}{*}{ Parcerias } & $\mathrm{AL}$ & $\begin{array}{l}\text { Ausência de integração dos } \\
\text { departamentos de planejamento } \\
\text { setorial na Bolívia }\end{array}$ & maior vinculação do MeA ao planejamento e à elaboração orçamentária \\
\hline & $\mathrm{AL}$ & $\begin{array}{l}\text { Problemas de informações em } \\
\text { muitos setores no Peru }\end{array}$ & envolvimento com instituições de estatísticas \\
\hline \multirow[t]{2}{*}{ Finalidade } & AL & $\begin{array}{l}\text { escasso vínculo com o orçamento } \\
\text { no Uruguai e em Honduras }\end{array}$ & Não foram citadas ações de mitigação. \\
\hline & $\mathrm{AL}$ & $\begin{array}{l}\text { Limitada utilização dos dados na } \\
\text { Colômbia, em Honduras, no Peru, } \\
\text { no Brasil, no Chile e no México }\end{array}$ & Não foram citadas ações de mitigação. \\
\hline
\end{tabular}

Fonte: Elaborado pelo autor. 


\subsubsection{Elaboração do questionário Delphi}

A pesquisa Delphi foi concebida sob a forma de sete seções. A primeira seção faz uma breve apresentação do presente trabalho, dos objetivos deste estudo e da pesquisa Delphi e apresenta,a partir da segunda rodada, os resultados da rodada anterior. A segunda seção coleta informações sobre o perfil dos respondentes - como por exemplo o cargo, a formação, vínculo, modal de atuação, e-mail para contato e o tempo de experiência na área. A seção três se destina ao nivelamento do conhecimento necessário para participar da Delphi, buscando unificar termos e conceitos entre os especialistas.

As seções quatro, cinco e seis discorrem sobre os aspectos funcional, organizacional e de finalidade de um sistema, respectivamente; cada qual organizado em dois tópicos. O primeiro tópico questiona os respondentes sobre o estágio atual individual de cada um dos aspectos considerado relevante para definir as diretrizes de um SMA para políticas de infraestrutura de transportes. Assim, para cada aspecto específico é representado por meio de perguntas individuais. O segundo tópico é composto por apenas uma pergunta que investiga a percepção dos respondentes sobre a importância dos aspectos em questão. Em ambos os tópicos, cada pergunta apresentará um campo de resposta textual livre para permitir que os respondentes enviem comentários sobre o aspecto em questão em busca de um diálogo e o consenso em determinada resposta. Um exemplo das questões aplicadas está apresentado no apêndice A.

A sétima e última seção do instrumento permitiu que os especialistas registrassem observações gerais sobre o tema ou a pesquisa por meio de um campo de resposta textual livre. Todas as respostas e comentários enviados pelos respondentes também foram encaminhados para os respectivos endereços eletrônicos informado na seção dois, por meio de uma programação gratuita (FormEmailer) incorporada às planilhas eletrônicas.

Para validar estes procedimentos e as ferramentas utilizadas, uma aplicação piloto foi realizada com a participação de 10 dos 20doutorandos ou doutores convidados que ingressaram na área de planejamento do Programa de Pós-graduação em Transportes (PPGT) da Universidade de Brasília (UnB) desde 2010. Oportunamente, todo o procedimento descrito anteriormente foi executado, permitindo identificar que o período em que foi realizado (janeiro de 2015) comprometeu a participação dos respondentes tendo em vista a 
concentração de atividades de lazer e descanso; fazendo-se necessário flexibilizar as datas de realização das rodadas para compatibilizar com a agenda dos respondentes.

Como sugestão de um dos respondentes da pesquisa piloto, a linguagem utilizada na escala do tipo Likert foi adequada para uniformizar a probabilidade de seleção entre as opções e enfatizar o caráter gradual da opinião. Adicionalmente, o contato realizado com os especialistas por telefone mostrou a necessidade de incluir no questionário um campo textual livre para cada questão desde a primeira rodada. Desta forma, tem-se a oportunidade de coletar informações relevantes sobre todos os aspectos - e não só aquele em dissenso - e de fomentar o diálogo entre os especialistas logo na segunda rodada.

\subsubsection{Aplicação da pesquisa Delphi}

O universo da pesquisa Delphi são os grupos que atuam e contribuem diretamente para o planejamento e a execução das políticas públicas para infraestrutura federal de transporte. A definição do tamanho da amostra deste universo respeitou as orientações bibliográficas sobre a pesquisa Delphi.

A seleção dos sujeitos da pesquisa resultou de um mapeamento das instituições relevantes que atuam diretamente na formulação e implementação das políticas públicas para a infraestrutura de transportes; identificando em suas estruturas a instância mais adequada à uma visão holística sobre o setor. Normalmente, é representada pelos departamentos de planejamento ou de pesquisa, ou outro com uma visão ampla da instituição e do setor, a exemplo das secretarias executivas. Adicionalmente, outras instituições ou associações foram selecionadas tendo em vistas publicações relevantes para o planejamento recente da infraestrutura de transportes.

Tal mapeamento iniciou com o levantamento dos órgãos envolvidos no fornecimento de informações realizado pelo Estudo e Revisão dos Mecanismos Técnicos e Institucionais de Perenização do Plano Nacional de Logística e Transportes (PNLT) (MT, 2010). A relação de instituições presente neste trabalho foi atualizada para incluir outras que surgiram ou que publicaram trabalhos relevantes para o setor. 
Para garantir que os especialistas indicados apresentem uma visão holística da infraestrutura de transportes, foram estabelecidos os seguintes critérios: pesquisadores na área ou que desempenham ou tenham desempenhado algum cargo de gestor ou de direção nos últimos cinco anos no setor público ou privado que atuam diretamente com a infraestrutura federal de transportes; preferencialmente pós-graduados e com dez anos ou mais de experiência na área.

Uma relação de 51especialistas em 37 instituições públicas e privadas foram identificados. Entre os dias 05 de janeiro e 02 de fevereiro de 2015 foi possível contatar 31 especialistas por telefone e e-mail e outros 20 apenas por e-mail. Em ambos os casos o presente trabalho e os propósitos da Delphi foram apresentados, solicitado a confirmação da sua participação ou a indicação de um profissional com o perfil desejado para participar da pesquisa.

No dia 02 de fevereiro, um e-mail foi enviado a todos os selecionados contendo a apresentação, o endereço eletrônico para acesso e o prazo desejado para participarem da pesquisa.A $1^{\text {a }}$ rodada da Delphi foi realizada entre os dias 02 e 06 de fevereiro, registrando 31,4\% de participação - 16 dos 51 convidados enviaram suas contribuições pelo formulário. Entretanto, um respondente informou desconhecer 11 dos 15 assuntos da pesquisa, motivo pelo qual foi excluído da análise dos dados.

Como o consenso das opiniões dos especialistas na $1^{\text {a }}$ rodada foi registrado em apenas quatro questões (coleta de dados, parcerias, finalidade e o grau de importância dos aspectos gerais funcionais), uma $2^{\mathrm{a}}$ rodada foi aplicada aos 15 participantes entre os dias 06 e 23 de fevereiro de 2015. O questionário elaborado para $2^{\mathrm{a}}$ rodada foi composto por onze perguntas: oito destinadas a qualificar a resposta da maioria para serem encerradas e três reaplicadas integralmente dado o dissenso registrado entre os especialistas. Com a qualificação das respostas da maioria dos especialistas e os consensos registrados nas três questões reaplicadas integralmente, a pesquisa Delphi pode ser encerrada na $2^{\mathrm{a}}$ rodada.

Desta forma, o encerramento da pesquisa ocorreu de forma direta, sem a necessidade de verificações estatísticas para decidir sobre a continuidade da pesquisa.Os resultados da aplicação do questionário Delphi e a análise dos dados são apresentados no item 5 a seguir. 


\section{APRESENTAÇÃO E ANÁLISE DOS DADOS}

A primeira rodada da pesquisa Delphi obteve $29,4 \%$ de respostas válidas com a presença de especialistas que atuam em 13 instituições, conforme apresenta o Quadro 5.1. Para permitir a comparação dos resultados da pesquisa Delphi com o perfil dos respondentes, a segunda coluna agrupa cada instituição participante segundo o tipo de atividade.

Quadro 5.1 - Relação de instituições presentes na pesquisa Delphi e grupos de atividade (quantidade de respondentes).

\begin{tabular}{|c|c|}
\hline Nome da instituição participante & Grupo de atividade \\
\hline Agência Nacional de Aviação Civil - ANAC (2) & \multirow[t]{5}{*}{ Executor (7) } \\
\hline Agência Nacional de Transportes Terrestres - ANTT (1) & \\
\hline Companhia Docas do Estado de São Paulo - CODESP (1) & \\
\hline Ministério da Fazenda (2) & \\
\hline Ministério dos Transportes (1) & \\
\hline Confederação Nacional da Indústria - CNI (1) & \multirow[t]{3}{*}{ Ator setorial (3) } \\
\hline Confederação Nacional do Transporte - CNT (1) & \\
\hline Sindicato Nacional da Indústria da Construção Pesada - Sinicon (1) & \\
\hline Controladoria Geral da União - CGU (1) & \multirow[t]{2}{*}{ Fiscalizador (2) } \\
\hline Tribunal de Contas da União - TCU (1) & \\
\hline $\begin{array}{l}\text { Fundação Coordenação de Projetos, Pesquisas e Estudos } \\
\text { Tecnológicos - COPPETEC (1) }\end{array}$ & \multirow[t]{3}{*}{ Pesquisador (3) } \\
\hline Fundação Dom Cabral - FDC (1) & \\
\hline Instituto de Pesquisa Econômica Aplicada - Ipea (1) & \\
\hline
\end{tabular}

Fonte: Elaborado pelo autor.

Um número menor de especialistas enviaram respostas válidas na segunda rodada (10). Tal fato pode ser reflexo da ausência de estímulos para participar da pesquisa Delphi, permitindo que os especialistas priorizem outras atividades relacionadas a uma rotina mais evidente de resultados. Entretanto, a participação por áreas de atuação foi semelhante ao registrado na $1^{\text {a }}$ rodada, conforme se nota no Gráfico 5.1. Prevaleceram aqueles que atuam em rodovias e ferrovias, mas com um percentual significativo de respondentes que atuam também nas infraestruturas de portos, aeroportos e hidrovias. 


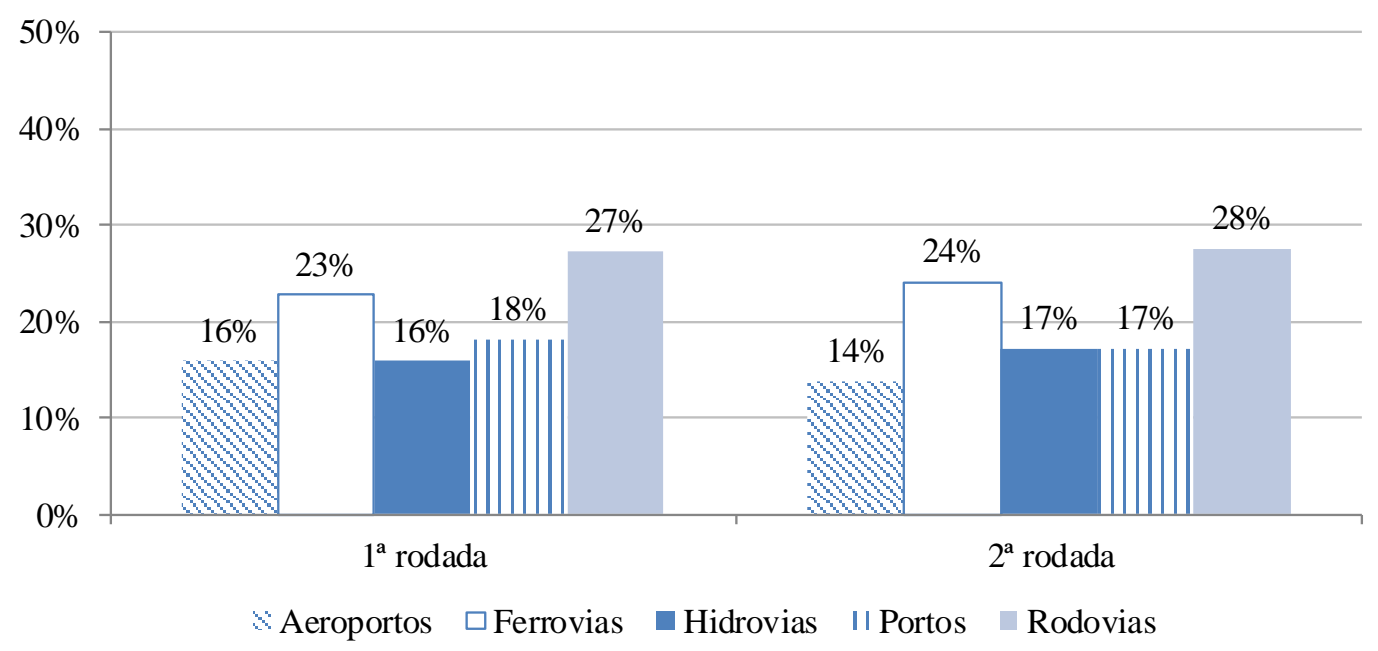

Gráfico 5.1 - Área de atuação dos especialistas respondentes.

Fonte: Elaborado pelo autor.

Prevaleceram também nas duas rodadas da Delphi os respondentes que, à época da pesquisa, ocupavam cargo de Coordenador, gerente, diretor ou presidente, conforme mostra o Gráfico 5.2 a seguir. No mesmo gráfico percebe-se que um maior percentual de respondentes com algum cargo de chefia (coordenador, gerente, diretor ou presidente) participou da $2^{\mathrm{a}}$ rodada.

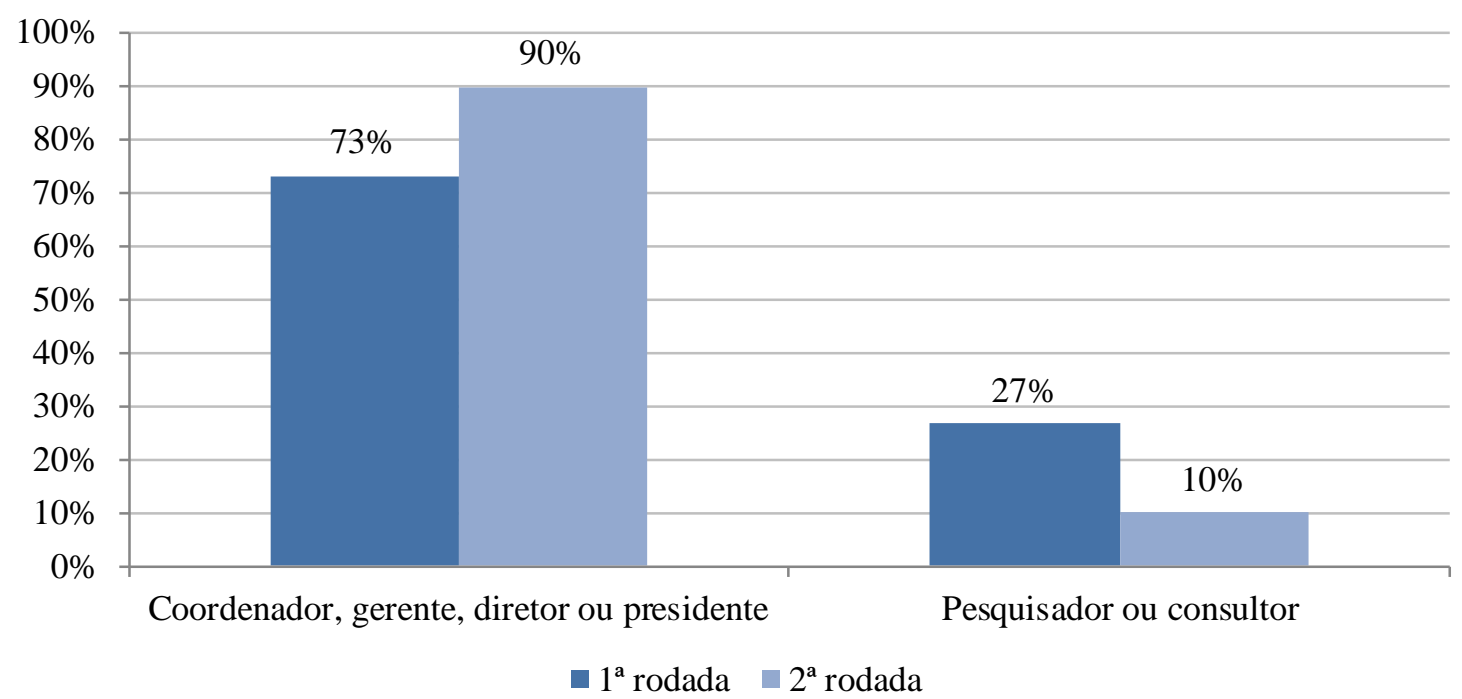

Gráfico 5.2 - Perfil dos especialistas respondentes segundo os cargos ocupados. Fonte: Elaborado pelo autor. 
Além da qualificação dos cargos ocupados, o Gráfico 5.3 a seguir mostra que a segunda rodada foi respondida por um maior percentual de pós-graduados: enquanto na primeira rodada $60 \%$ dos respondentes declararam ser mestre ou doutor, na segunda este percentual foi de $70 \%$. Em ambas as rodadas, cerca de $80 \%$ dos respondentes informaram possui 10 anos de experiência na área, conforme apresenta o Gráfico 2. Adicionalmente, todos os respondentes do tipo "Especialistas" informaram possuir 10 anos ou mais de experiência na área, indicando possuir um significativo conhecimento prático da área.

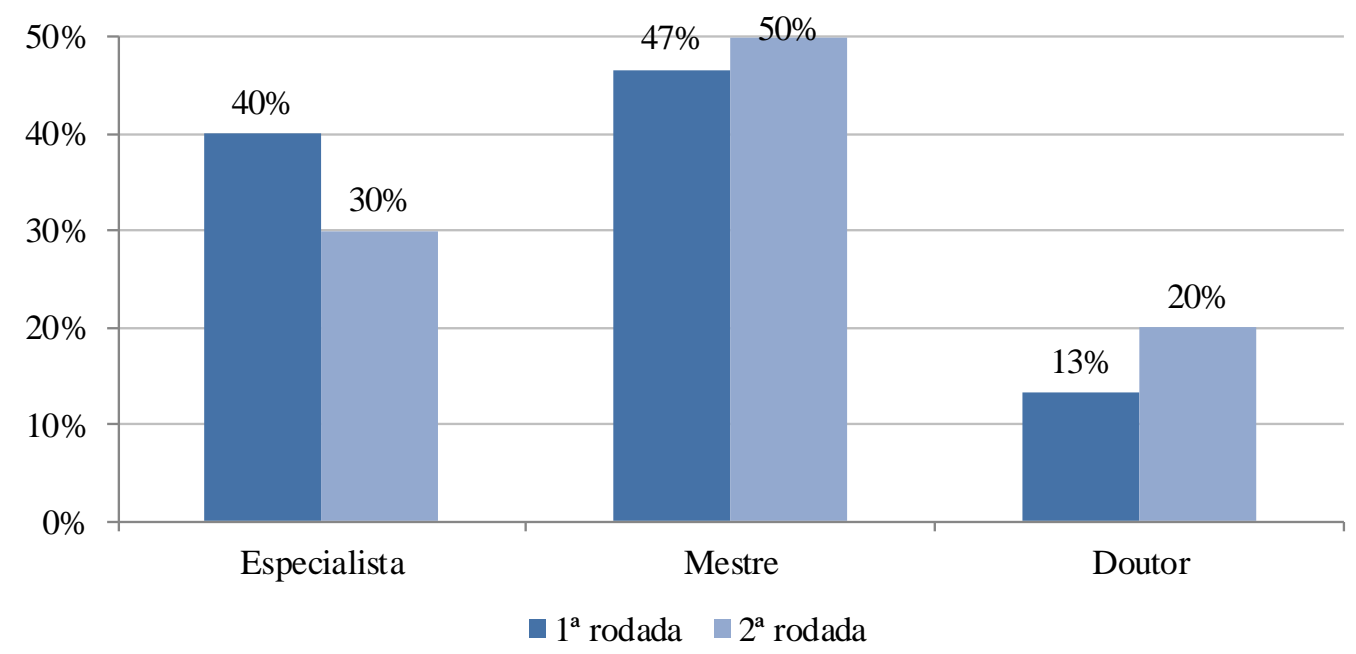

Gráfico 5.3 - Percentual de especialistas respondentes segundo a formação.

Fonte: Elaborado pelo autor.

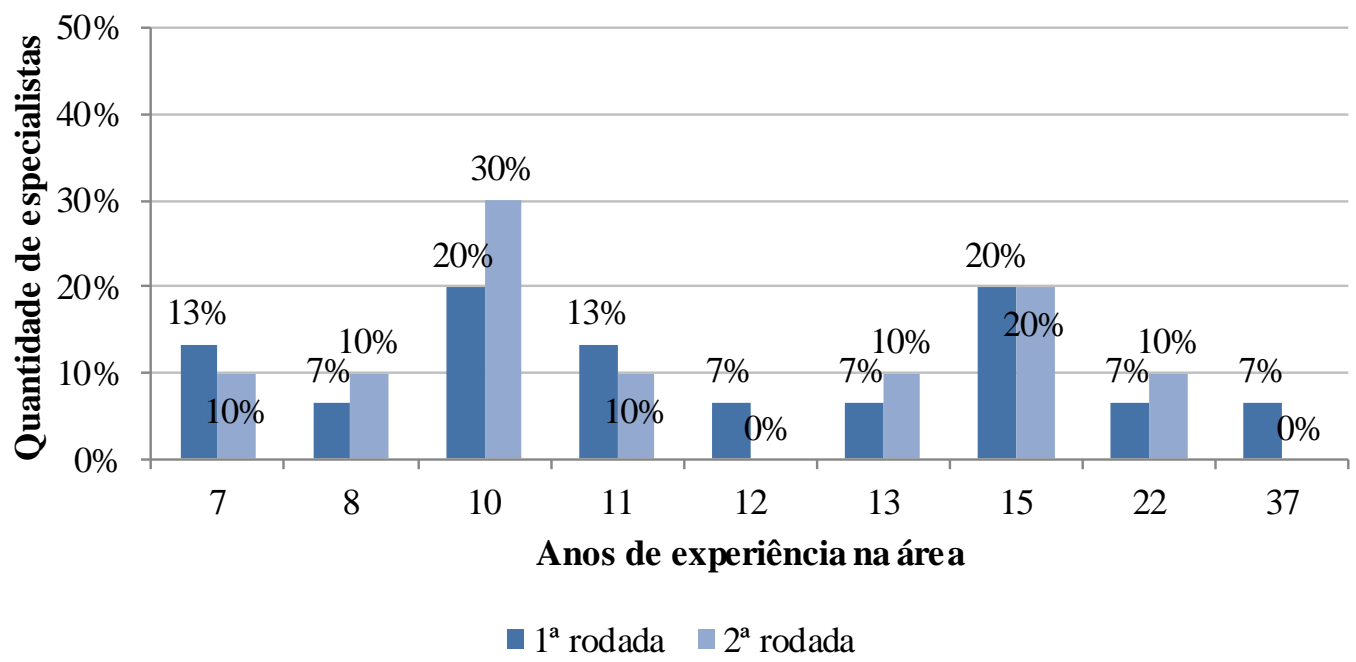

Gráfico 5.4 - Percentual de especialistas respondentes segundo a quantidade de anos de experiência na área.

Fonte: Elaborado pelo autor. 
Apesar do menor número de respondentes na segunda rodada da pesquisa Delphi, todos os aspectos específicos registraram sete ou mais respostas válidas. O Gráfico 5.5 apresenta a quantidade de opiniões válidas enviadas por aspecto específico e por tópico que representaram o resultado final da pesquisa.

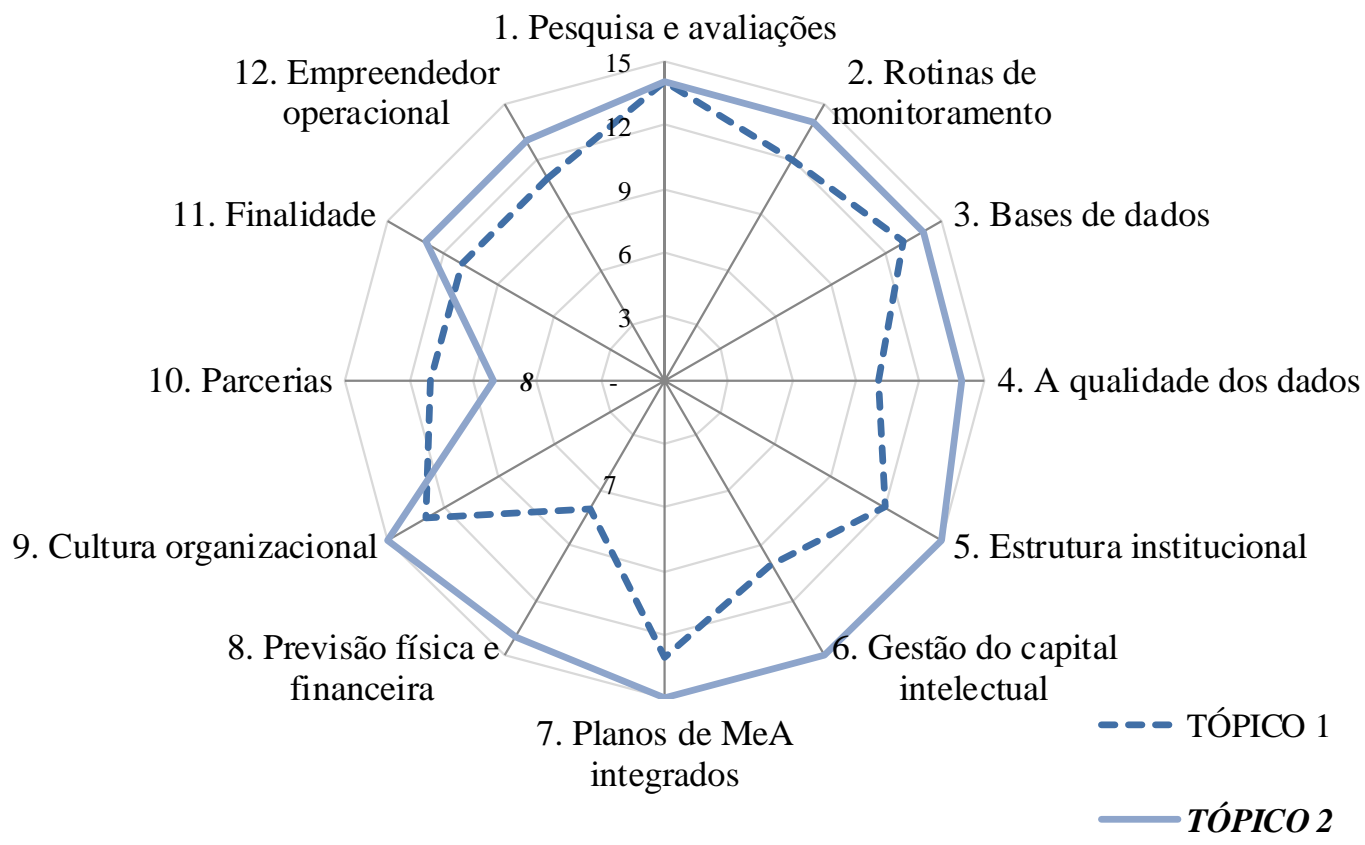

Gráfico 5.5 - Quantidade de opiniões válidas por aspecto específico e tópico.

Fonte: Elaborado pelo autor.

Segundo a opinião dos respondentes sobre o estágio atual dos aspectos específicos no setor (Tópico 1), todos atendem apenas formalidades e/ou são incipientes, desarticulados ou isolados -conforme mostra o Gráfico 5.6 -, confirmando a primeira hipótese deste trabalho (H1).

O mesmo gráfico mostra que em dois aspectos funcionais (aspectos 2 e 3) e em um organizacional (aspecto 5), todos os especialistas que participaram da $2^{\mathrm{a}}$ rodada concordaram com o resultado da maioria. Além disso, percebe-se o elevado grau de consenso registrado sobre um aspecto funcional (aspecto 4) e a pequena diferença entre duas opiniões, a qual pode ter refletido no baixo o grau de concordância com a maioria de um aspecto finalístico (aspecto 12). Entre os cinco aspectos que registraram o consenso entre os especialistas, quatro (aspectos 1, 8, 10 e 11) apresentaram percentuais próximos (cerca de 72\%) e um (aspecto 4) se destacou pelo elevado percentual registrado (90\%). 


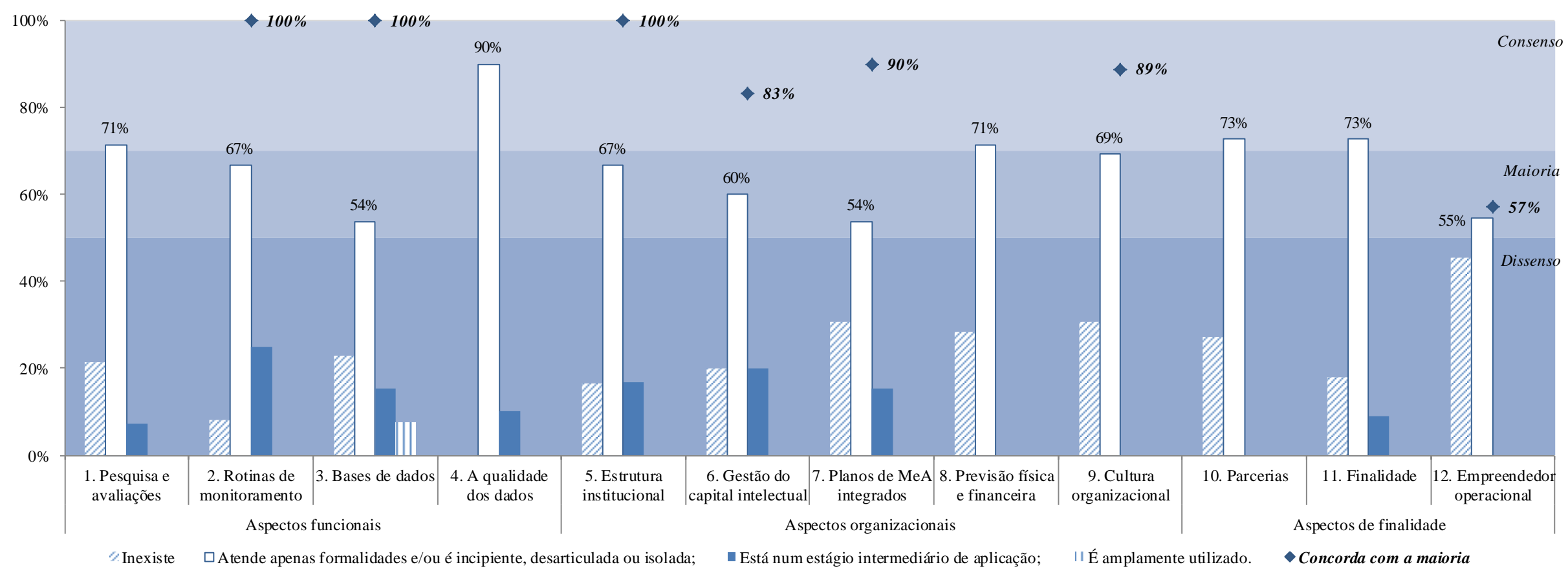

Gráfico 5.6 - Estágio atual dos aspectos específicos de um SMA no setor de infraestrutura federal de transportes.

Fonte: Elaborado pelo autor. 
O elevado percentual de respondentes que sinalizaram a inexistência do empreendedor operacional demonstra que, atualmente, ele é o mais precário. $\mathrm{O}$ valor médio das respostas encontrado para este aspecto específico $(1,545)$ é o menor valor entre os demais, conforme apresenta o Gráfico 5.7a seguir.

2. Rotinas de monitoramento

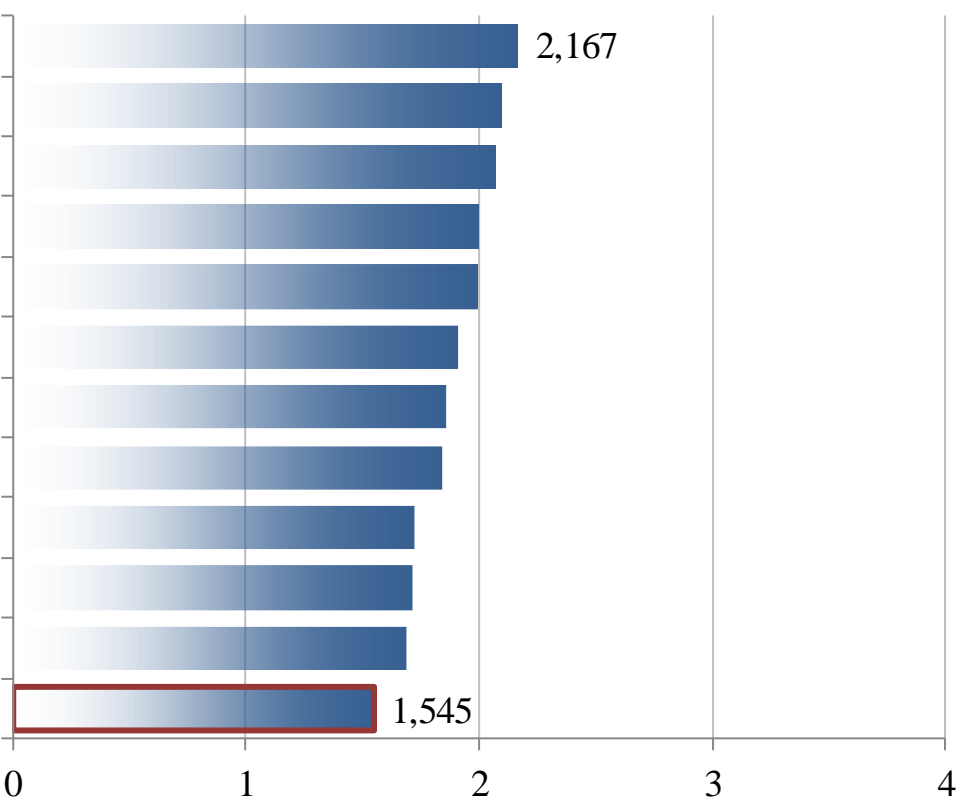

4. A qualidade dos dados

3. Bases de dados

5. Estrutura institucional

6. Gestão do capital intelectual

11. Finalidade

1. Pesquisa e avaliações

7. Planos de MeA integrados

10. Parcerias

8. Previsão física e financeira

9. Cultura organizacional

12. Empreendedor operacional 0

Legenda:

$\begin{array}{cl}\text { Eixo horizontal } & \text { Descrição } \\ 0 & \text { Desconheço } \\ 1 & \text { Inexiste } \\ 2 & \text { Atende apenas formalidades e/ou é incipiente, desarticulada ou isolada; } \\ 3 & \text { Está num estágio intermediário de aplicação; } \\ 4 & \text { É amplamente utilizado. }\end{array}$

Gráfico 5.7 - Valor médio da opinião dos especialistas sobre o estágio atual dos aspectos específicos de um SMA no setor de infraestrutura federal de transportes.

Fonte: Elaborado pelo autor.

A pergunta do Tópico 2 em cada aspecto geral questionou os respondentes sobre a importância dos respectivos aspectos que o compõe para o setor. O Gráfico 5.8mostra que enquanto três aspectos foram indicados como de importância intermediária (aspectos 6,8 e 10), os demais foram declarados pelos especialistas como muito importantes. Segundo o mesmo gráfico, houve consenso sobre a elevada importância dos aspectos funcionais (aspectos 1, 2, 3 e 4), e a importância dos aspectos organizacionais foi alternada entre 
intermediária e muito importante e decidida pela opinião da maioria. Os aspectos finalísticos registraram o maior percentual de consenso (aspecto 10) e de concordância com a opinião da maioria (aspecto 11).

Estes resultados também se repetem quando se verifica a mediana das respostas. Conforme mostra o Legenda:

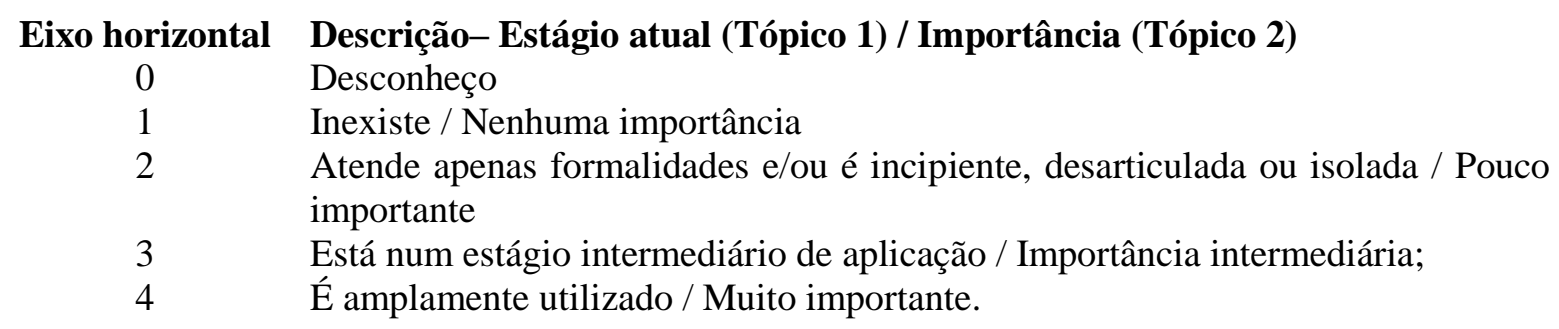

Gráfico 5.9, a mediana encontrada para o Tópico 1 (estágio atual) mostra que, segundo os especialistas respondentes, todos os aspectos atualmente atendem apenas formalidades e/ou são incipientes, desarticulados ou isolados (mediana 2). Para o Tópico 2 (grau de importância), há a formação de dois grupos de respostas, indicando que três aspectos específicos são de importância intermediária (aspectos 6, 8 e 10, com mediana 3) e os demais muito importante (com mediana 4).

Percebe-se, portanto, que o aspecto da liderança (12. Empreendedor operacional) possui importância equivalente aos demais previstos pela literatura e práticas internacionais, confirmando a segunda hipótese deste trabalho (H2). 


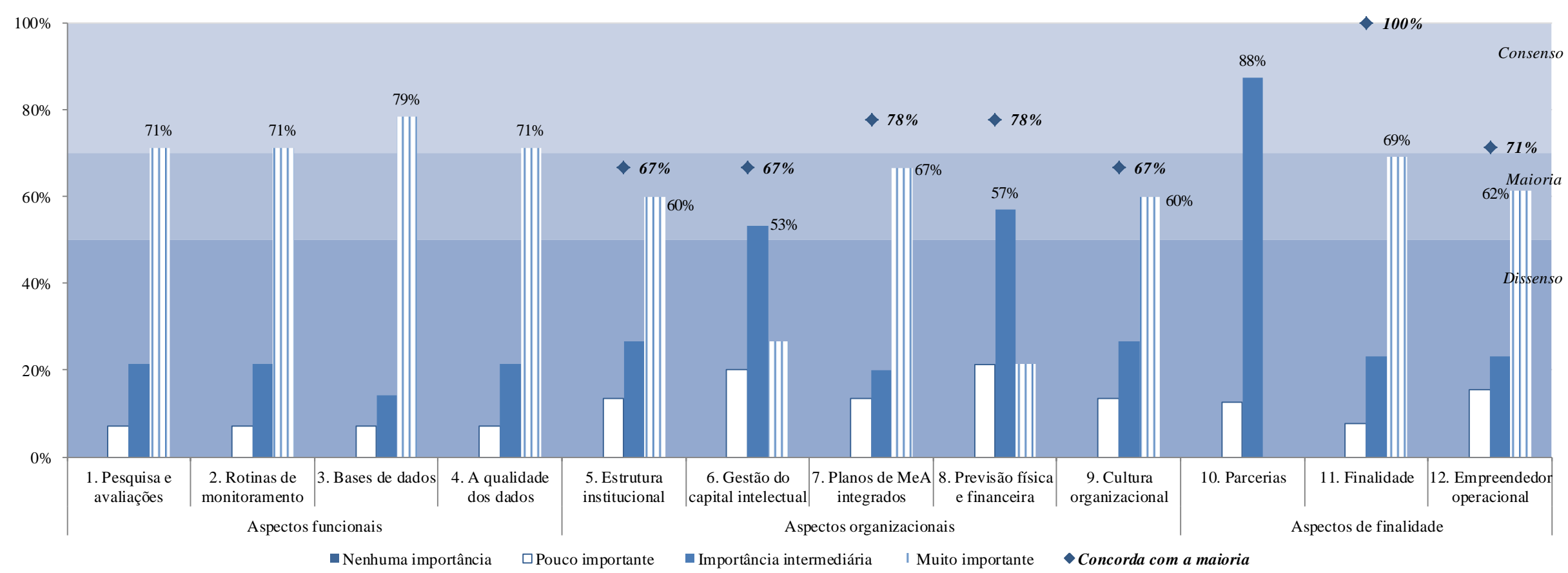

Gráfico 5.8 - Grau de importância dos aspectos específicos de um SMA para o setor de infraestrutura federal de transportes. Fonte: Elaborado pelo autor. 


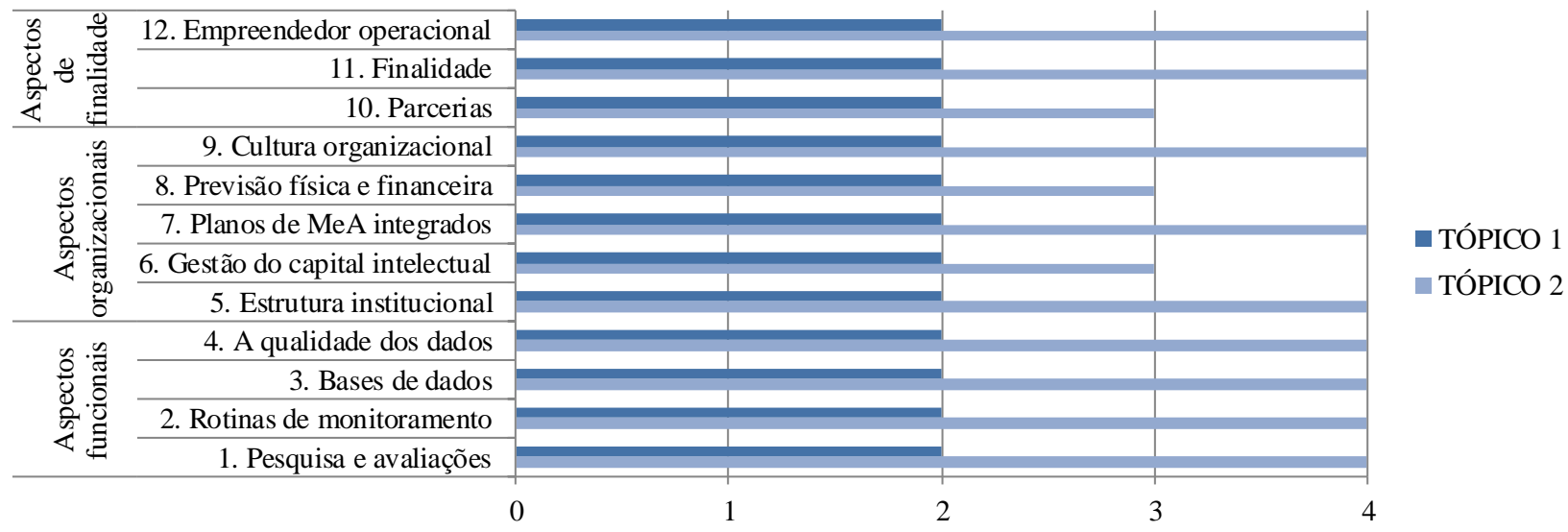

Legenda:

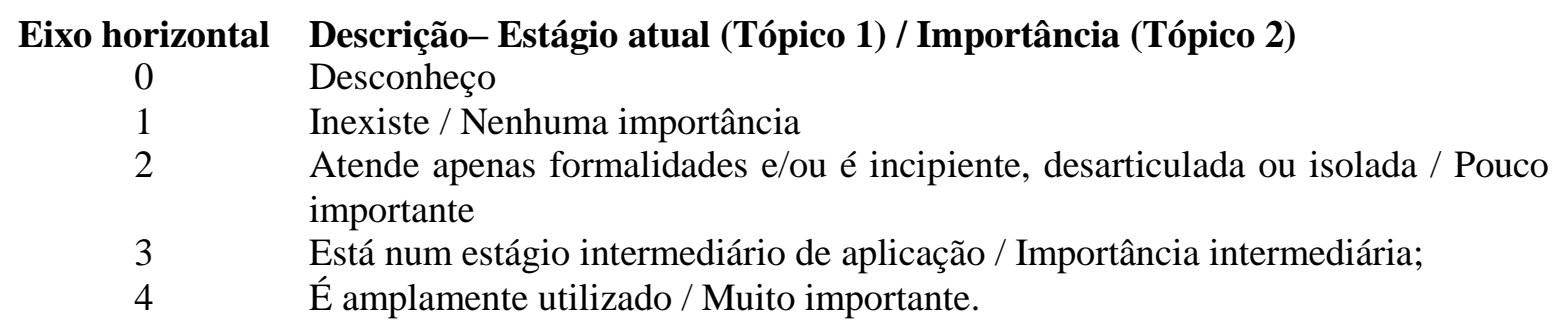

Gráfico 5.9 - Mediana das respostas dos especialistas sobre o estágio atual e grau de importância dos aspectos específicos de um SMA para o setor de infraestrutura federal de transportes.

Fonte: Elaborado pelo autor.

Foi possível avaliar se há diferença significativa das respostas entre os dois grupos de opiniões formadas sobre o grau de importância dos aspectos específicos. Os testes de normalidade Kolmogorov-Smirnov e Shapiro-Wilk confirmam que os dados de ambos os grupos não possuem uma distribuição normal (Valor-p<0,05). Com isto, foram realizados testes estatísticos do tipo não paramétricos (Wilcoxon e Mann-Whitney) para verificar se há diferença entre as respostas. A Tabela 5.1 a seguir apresenta os valores encontrados.

Tabela 5.1- Similaridade entre os grupos de respostas com importância intermediária e muito importante.

\begin{tabular}{|l|c|c|}
\hline Teste & Wilcoxon & Mann-Whitney \\
\hline Tipo de amostra & Dependente & Independente \\
\hline Valor-p & $1,189 \mathrm{E}-06$ & $1,176 \mathrm{E}-06$ \\
\hline
\end{tabular}

Fonte: Elaborado pelo autor. 
Ao estabelecer que a hipótese inicial (h0) do teste considera que as amostras são diferentes para um grau de confiança de $95 \%$, percebe-se que os resultados apresentados na tabela 1 acima confirmam que há diferença entre os dois grupos de respostas (Valor-p<0,05).

Adicionalmente, optou-se por verificar a força do relacionamento linear entre o grau de importância dos aspectos específicos, o grupo de atividade e a quantidade de modais de atuação dos especialistas. Os dados disponível indicam que:

1. Há uma correlação linear fraca e positiva do aspecto 6 com a instituição e a quantidade de modais que os respondentes atuam (respectivamente 0,5755 e 0,5041), sinalizando principalmente que os executores das políticas públicas e atores setoriais tendem a atribuir um grau de importância menor (3) a este aspecto específico que aqueles que atuam na fiscalização e pesquisa (4);

2. O tempos de atuação e o grau de importância do aspecto 8 possuem forte correlação linear negativa $(-0,7222)$, indicando que os respondentes com maiores tempos de atuação atribuíram uma menor importância a este aspecto específico (3).

Segundo Bertalanffy (1975), Katz e Kahn (1978) e Görgens e Kusek (2009), os componentes de um sistema são interdependentes e, por isto, apresentem o mesmo grau de importância. Uma vez que os especialistas do setor de infraestrutura de transportes atribuíram graus de importância distintos entre os aspectos específicos, entende-se que o conceito da interdependência dos elementos para uma abordagem sistêmica carece de maior consolidação entre os especialistas consultados.

Conforme comentado, além dos resultados compulsórios analisados anteriormente, os especialistas enviaram voluntariamente comentários sobre os aspectos específicos. $\mathrm{Na} 1^{\mathrm{a}}$ rodada, $67 \%$ (10) dos respondentes enviaram 70 comentários válidos, registrando uma média de 3,7 registros por respondente. Destacaram a participação de um especialista - que enviou comentários válidos para 12 das 15 perguntas do questionário - e a ausência de comentários sobre o grau de importância dos aspectos específicos relacionados ao aspectos gerais organizacional e de finalidade (questões 14 e 15). Entre os demais aspectos específicos, o maior número de comentários foi observado entre os aspectos gerais funcionais, onde $33 \%$ das questões (5) concentraram 59\% dos comentários desta rodada. 
$\mathrm{Na} 2^{\mathrm{a}}$ rodada, $50 \%$ (5) dos respondentes enviaram 76 comentários - perfazendo uma média de 6,3 comentários por respondente. Entre eles, 88\% (67) registros foram réplicas aos comentários registrados na $1^{\mathrm{a}}$ rodada e os demais $12 \%$ (9) novos comentários gerais aos aspectos em questão. Apesar da média maior que a $1^{\text {a }}$ rodada, o envio de $92 \%$ dos comentários registrados por apenas dois respondentes compromete o valor médio encontrado para a $2^{\mathrm{a}}$ rodada. Assim como na primeira rodada, os maiores números de comentários válidos - sejam eles réplicas ou gerais - também foram registrados nos aspectos gerais funcionais, que concentraram $62 \%$ dos comentários válidos.

O uso do campo textual livre trouxe também a oportunidade de coletar informações importantes sobre o tema para o setor de infraestrutura federal de transportes. A análise destes comentários permitiu verificar quais os aspectos específicos são mais citados espontaneamente como impactantes nas políticas públicas da infraestrutura federal de transportes, segundo a opinião dos especialistas respondentes.

Entre os 146 comentários, foi possível associar 64 (43,8\%) aos aspectos específicos para um SMA. Estes comentários foram enviados por dez especialistas distintos e estão apresentados no item B do apêndice e consolidados no Quadro 5.2 -a seguir.

Quadro 5.2 -Quantidade de respondentes e citações indiretas atribuídos a cada aspecto específico das diretrizes gerais.

\begin{tabular}{|l|l|c|c|}
\hline Aspecto geral & Aspecto Específico & Respondentes & Citações \\
\hline Funcional & 1. Pesquisa e avaliação & 1 & 1 \\
\cline { 2 - 4 } & 2. Rotinas de monitoramento & 4 & 4 \\
\cline { 2 - 4 } & 3. Bases de dados & 4 & 4 \\
\cline { 2 - 4 } & 4. Qualidade dos dados & 3 & 8 \\
\hline Organizacional & 5. Estrutura institucional & 5 & 4 \\
\cline { 2 - 4 } & 6. Gestão de recursos & 5 & 8 \\
\cline { 2 - 4 } & 7. Planos de MeA integrados & 1 & 7 \\
\cline { 2 - 4 } & 8. Envolvimento dos gestores financeiros e de RH & 4 & 30 \\
\cline { 2 - 4 } & 9. Cultura favorável ao MeA & 8 & 7 \\
\hline Finalidade & 10. Parcerias & 3 & 12 \\
\cline { 2 - 4 } & 11. Finalidade & 4 & 3 \\
\cline { 2 - 4 } & 12. Empreendedor operacional & 5 & 8 \\
\hline
\end{tabular}

Fonte: Elaborado pelo autor. 
No Quadro 5.2, enquanto a primeira e a segunda coluna apresentam os aspectos gerais e específicos das diretrizes preliminares gerais, a terceira coluna apresenta o número de respondentes distintos responsáveis pelos comentários relacionados ao aspecto específico em questão. Esta informação contribui para impedir que o elevado número de comentários enviados por uma pequena quantidade de respondentes, conforme constatado, faça prevalecer a opinião de poucos especialistas. A quarta coluna apresenta o número de citações indiretas identificadas nos comentários enviados pelos especialistas.

O total de citações apresentado no Quadro 5.2 -mostra que todos os aspectos específicos foram inferidos pelos respondentes ao menos uma vez. Mas se destacaram os comentários recorrentes sobre a falta de integração, de articulação e de coordenação das atividades do setor, que resultou no maior destaque dos aspectos específicos relacionados ao estímulo às parceiras e ao empreendedor operacional. O primeiro foi identificado em 30 comentários e se destacou também pela elevada quantidade de especialistas distintos que se referiram indiretamente à necessidade de parcerias (8). Já o segundo está presente em um grande número de comentários (12) e foi citado por uma quantidade intermediária de especialistas distintos (4).

As citações relacionadas a estes dois aspectos específicos estão presentes em 65\% (39) dos 64 comentários que expressaram as dificuldades do setor segundo a opinião dos especialistas participantes. Entretanto, a opinião compulsória dos respondentes sobre o estímulo às parceiras contradiz a espontânea.

Ao serem questionados sobre o grau de importância que a parceria representa para um SMA efetivo (item 2.10do aspecto específico de finalidade), na $1^{\text {a }}$ rodada 14 especialistas enviaram respostas válidas, onde $36 \%$ informaram que as parcerias são muito importante, $50 \%$ de importância intermediária e 14\% pouco importante, conforme apresenta o Gráfico 5.10. Este resultado demonstra que houve dissenso entre os respondentes na $1^{\mathrm{a}}$ rodada da Delphi, provocando a reaplicação integral da questão acrescida da apresentação do resultado desta rodada por meio de um gráfico semelhante e apresentado no Gráfico 5.10. 


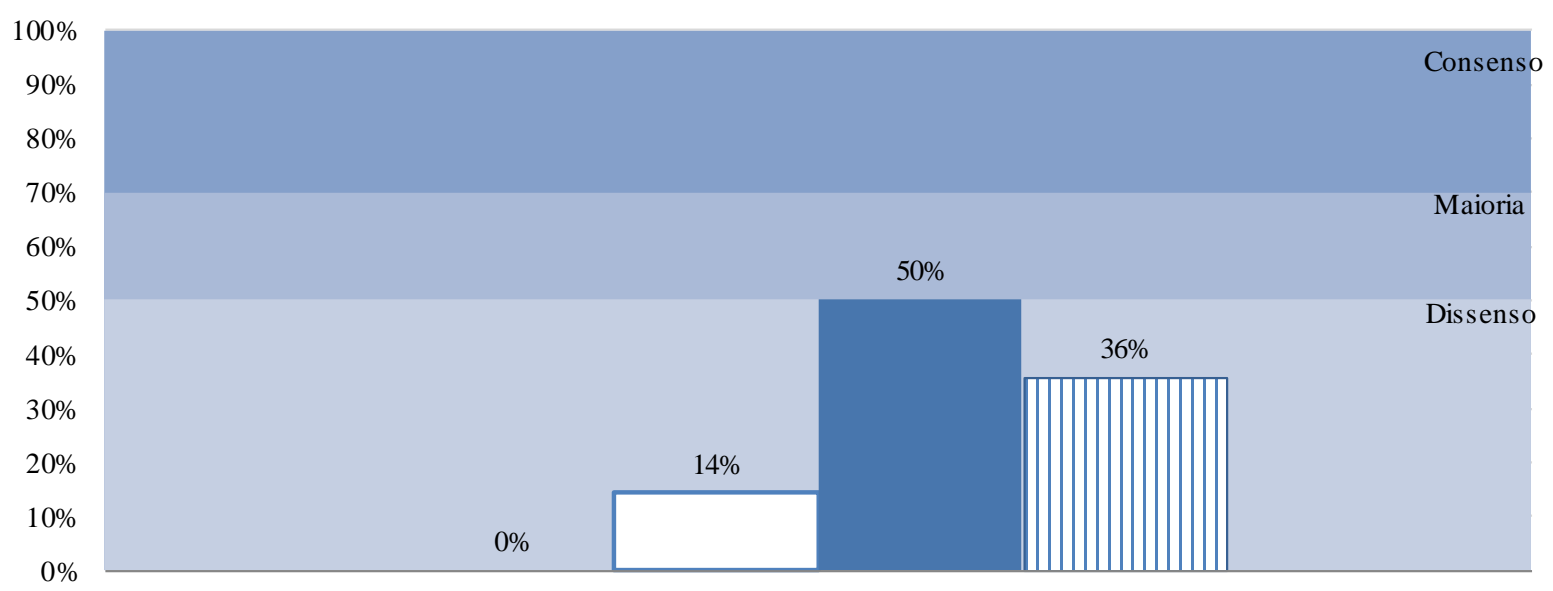

10. Estímulos a parcerias

Nenhuma importância $\square$ Pouco importante $\quad$ Importância intermediária $\square$ Muito importante

Gráfico 5.10 - Resultado da questão 10 na $1^{\mathrm{a}}$ rodada.

Fonte: Elaborado pelo autor.

$\mathrm{Na} 2^{\mathrm{a}}$ rodada, entre os dez especialistas respondentes, metade (5) revisaram suas respostas em relação a rodada anterior. Apesar de dois especialistas indicarem algum grau de importância ao aspecto específico da parceria na $1^{\mathrm{a}}$ rodada (especificamente, pouco e muito importante), os mesmo informaram na rodada seguinte desconhecer sobre o tema. Desta forma, os outros oito respondentes foram responsáveis pelas respostas válidas na $2^{\mathrm{a}}$ rodada, onde $88 \%$ informaram que o aspecto em questão possui grau de importância intermediária e 12\% classificaram-no como pouco importante.

Rowe e Wright (1999) alertam sobre os casos onde os respondentes alteram suas respostas para seguir um comportamento do grupo, resultando em um consenso formal entre os painelistas. Percebe-se este comportamento nas questões reaplicadas integralmente, onde o resultado da segunda rodada convergiu para a opção que se destacou na rodada anterior. De certa forma, tal comportamento é esperado em uma pesquisa Delphi uma vez que as sucessivas rodadas buscam a revisão da opinião dos especialistas. Mas apesar de os especialistas consensuarem formalmente sobre a importância intermediária das parcerias para o setor, o significativo número de comentários voluntários sobre os problemas relacionados à este aspecto específico inferem o reconhecimento e importância que ele representa para os especialistas do setor. 
O segundo destaque observados nos comentários indica que o empreendedor operacional foi lembrado espontaneamente por um número significativo de especialistas distintos, maior que outros quatro aspectos específicos (Pesquisa e avaliação, Qualidade dos dados, Envolvimento dos gestores financeiros e de RH e Finalidade).

Tal constatação contribui para ratificar a precariedade e relevância que o aspecto da liderança operacional (12. Empreendedor operacional) possui para o setor. Os comentários a seguir ilustram comentários relacionados aos aspectos específicos da parceria e do empreendedor operacional.

2. O setor público federal de infraestrutura de transportes fomenta, atualmente, a criação de rotinas de monitoramento dos insumos (os projetos) e dos processos (recursos envolvidos)?

2.3. Há alguns setores que desenvolvem algumas boas práticas, de maneira pontual, no entanto são ações isoladas.

2.3.1 Concordo com o comentário 3.

2.3.2. "Existem ações isoladas, de fato falta uma coordenação. O Ministério dos Transportes tem buscado fazer esta coordenação, porém exige patrocínio do gestor máximo dos órgãos e em especial do MPOG."

2.9. Pode melhorar, com informatização dos processos e coordenação mais clara $e$ definição de linhas de comando claras.

7. O setor público federal de infraestrutura de transportes, atualmente: Incentiva a elaboração de planos de monitoramento e avaliação e os integra com outras instâncias e instrumentos de planejamento?

7.5. Pouca capacidade de articulação interna para a integração multimodal. 


\section{DIRETRIZES DE UM SMA DAS POLÍTICAS PÚBLICAS PARA A INFRAESTRUTURA FEDERAL DE TRANSPORTES}

A ausência de comentários e questionamentos na Delphi sobre as diretrizes preliminares gerais mostra que eles são suficientes e adequadas para o setor de infraestrutura de transportes. Desta forma, as diretrizes de um SMA das políticas públicas para a infraestrutura federal de transportes são representadas pelos doze aspectos específicos descritos anteriores, apresentados nos quadros12e 13 a seguir.

Os comentários presentes nos trabalhos que relatam as experiências em outras áreas, somados ao resultado da análise dos comentários enviados pelos especialistas são fontes ricas de informações complementares à implementação das diretrizes definitivas de um SMA efetivos para o setor. Enquanto as experiências em outras áreas indicam as dificuldades encontradas e as iniciativas desenvolvidas para mitigá-las, o maior número de citações indiretas aos aspectos específicos pode orientar no direcionamento dos esforços. Os quadros 3.12, 3.13 e 3.14 a seguir apresentam estas informações.

Quadro 6.1 - Descrição dos aspectos gerais das diretrizes definitivas.

\begin{tabular}{|l|l|}
\hline Aspecto geral & Descrição \\
\hline Funcionais & $\begin{array}{l}\text { São os aspectos relacionados aos fatores energéticos de um sistema, como } \\
\text { seu caráter cíclico, sua estabilidade e o consumo de matéria, energia ou } \\
\text { informação. }\end{array}$ \\
\hline Organizacionais & $\begin{array}{l}\text { São os aspectos que garantem a adequada interação dos seus elementos } \\
\text { para transformar os insumos nos produtos desejados em meio aos } \\
\text { constrangimento que são impostos pelo ambiente. }\end{array}$ \\
\hline Finalidade & $\begin{array}{l}\text { São os aspectos que levam à criação, manutenção e evolução de um } \\
\text { sistema. }\end{array}$ \\
\hline
\end{tabular}

Fonte: Elaborado pelo autor. 
Quadro 6.2 - Descrição dos aspectos específicos das diretrizes preliminares gerais.

\begin{tabular}{|c|c|c|}
\hline $\begin{array}{l}\text { Aspectos } \\
\text { gerais }\end{array}$ & $\begin{array}{l}\text { Aspecto } \\
\text { específico }\end{array}$ & Descrição \\
\hline \multirow[t]{4}{*}{ Funcionais } & $\begin{array}{l}\text { Pesquisas e } \\
\text { avaliações }\end{array}$ & $\begin{array}{l}\text { Atividades de pesquisas periódicas ou por amostragens amplas do } \\
\text { ambiente em que se insere o produto, visando gerar dados sobre } \\
\text { resultados e generalizar conhecimentos para um propósito específico. }\end{array}$ \\
\hline & $\begin{array}{l}\text { Rotinas de } \\
\text { monitoramento }\end{array}$ & $\begin{array}{l}\text { Levantar dados quali-quantitativos sobre o andamento as etapas de um } \\
\text { processo (entrada, processamento e saída). }\end{array}$ \\
\hline & $\begin{array}{l}\text { Base de dados } \\
\text { útil }\end{array}$ & $\begin{array}{l}\text { Repositório de dados viabilizado por ferramentas para reunir os dados } \\
\text { coletados durante o monitoramento rotineiro, pesquisas esporádicas e } \\
\text { específicas. }\end{array}$ \\
\hline & $\begin{array}{l}\text { Qualidade dos } \\
\text { dados }\end{array}$ & $\begin{array}{l}\text { atividades desenvolvidas para aumentar a qualidade dos dados e } \\
\text { fomentar a capacidade das equipes, como melhores supervisão e } \\
\text { auditoria. }\end{array}$ \\
\hline \multirow[t]{5}{*}{ Organizacionais } & $\begin{array}{l}\text { Estrutura } \\
\text { institucional }\end{array}$ & $\begin{array}{l}\text { Descrição da hierarquia, dos relacionamentos e do arranjo do trabalho, } \\
\text { indicando sua interação e disposição em um sistema }\end{array}$ \\
\hline & $\begin{array}{l}\text { Gestão do capital } \\
\text { intelectual }\end{array}$ & $\begin{array}{l}\text { Iniciativa para a retenção e o desenvolvimento das capacidades e } \\
\text { habilidades dos elementos de um sistema. }\end{array}$ \\
\hline & $\begin{array}{l}\text { Plano de MeA } \\
\text { integrado }\end{array}$ & $\begin{array}{l}\text { Detalhamento das atividades e dos produtos para integrar atores e ser } \\
\text { integrado com outros instrumentos e instâncias de planejamento. }\end{array}$ \\
\hline & $\begin{array}{l}\text { Previsão física- } \\
\text { financeira }\end{array}$ & $\begin{array}{l}\text { Detalhamento pormenorizado e previsão formal dos recursos } \\
\text { necessários para o sistema. }\end{array}$ \\
\hline & $\begin{array}{l}\text { Cultura } \\
\text { organizacional }\end{array}$ & $\begin{array}{l}\text { Seleção de crenças, suposições e valores que levam a uma maior ou } \\
\text { menor receptividade de um SMA na instituição. }\end{array}$ \\
\hline \multirow[t]{3}{*}{ Finalidade } & Parcerias & $\begin{array}{l}\text { Arranjos que fortalecem o vinculo com os sub e supra sistemas por } \\
\text { meio do fluxo uni ou bidirecional de informações. }\end{array}$ \\
\hline & Finalidade & Destinação do produto gerado pelo sistema. \\
\hline & $\begin{array}{l}\text { O empreendedor } \\
\text { operacional }\end{array}$ & $\begin{array}{l}\text { Indivíduos empenhados em um propósito, especialistas em } \\
\text { determinada questão, revestidos de autoridade e de habilidades para } \\
\text { fomentar os demais aspectos específicos, para defender ideias próprias } \\
\text { ou de terceiros, para manter conexões técnicas e políticas e para } \\
\text { promover o SMA por meio da diversificação, do seu uso e do seu } \\
\text { constante aprimoramento. }\end{array}$ \\
\hline
\end{tabular}

Fonte: Elaborado pelo autor. 
Quadro 6.3 - Aspectos favoráveis e ações necessárias segundo aspectos específicos.

\begin{tabular}{|c|c|c|c|}
\hline Aspecto específico & Instituição & Pontos favoráveis & Ação desenvolvida \\
\hline $\begin{array}{l}\text { Gestão do capital } \\
\text { intelectual e } \\
\text { Parcerias }\end{array}$ & MDS & $\begin{array}{l}\text { Ganho em escala, de } \\
\text { diversidade e de qualidade. }\end{array}$ & $\begin{array}{l}\text { Formação de uma equipe enxuta, qualificada, multidisciplinar capaz } \\
\text { de contratar e avaliara os produtos necessários; } \\
\text { melhor uso das expertises envolvidas por meio de uma gestão não } \\
\text { burocrática, flexível; } \\
\text { Desenvolvimento de parceria com o IBGE. }\end{array}$ \\
\hline $\begin{array}{l}\text { Empreendedor } \\
\text { operacional }\end{array}$ & MEC & Aprimoramento das ferramentas & Reuniões frequentes entre atores envolvidos \\
\hline Estrutura institucional & MS & $\begin{array}{l}\text { Crescente importância do setor } \\
\text { para a sociedade. }\end{array}$ & Criação de uma estrutura específica para MeA. \\
\hline Finalidade & & Maior uso real das informações & $\begin{array}{l}\text { Associação dos dados a impacto em instancias da administração } \\
\text { pública }\end{array}$ \\
\hline
\end{tabular}

Fonte: Elaborado pelo autor. 
Quadro 6.4 - Aspectos desfavoráveis e ações necessárias segundo aspectos específicos.

\begin{tabular}{|c|c|c|c|}
\hline Aspecto específico & Instituição & Pontos desfavoráveis & Ação necessária \\
\hline Base de dados útil & MDS & $\begin{array}{l}\text { Integração de dados e ferramentas } \\
\text { devido à diversidade de fontes e } \\
\text { falta de padrão dos formatos }\end{array}$ & Definição de indicadores segundo atributos. \\
\hline $\begin{array}{l}\text { Base de dados útil } \\
\text { Qualidade dos dados }\end{array}$ & MEC & $\begin{array}{l}\text { A falta de utilidade para os } \\
\text { gestores e a instabilidade das } \\
\text { ferramentas }\end{array}$ & $\begin{array}{l}\text { Desenvolvimento de parceria para realizar estudos e pesquisas sobre } \\
\text { governança, planejamento e monitoramento de ações governamentais. }\end{array}$ \\
\hline $\begin{array}{l}\text { Parcerias e } \\
\text { Pesquisa e avaliação }\end{array}$ & MS & $\begin{array}{l}\text { Desarticulação entre } \\
\text { departamentos; } \\
\text { Inexistência de uma política de } \\
\text { avaliação }\end{array}$ & $\begin{array}{l}\text { Institucionalização; } \\
\text { definição das práticas e os processos de monitoramento e avaliação da } \\
\text { gestão e } \\
\text { o vínculo com o RAG. }\end{array}$ \\
\hline $\begin{array}{l}\text { Parcerias, } \\
\text { Qualidade dos dados e } \\
\text { Gestão do capital } \\
\text { intelectual }\end{array}$ & PPA & $\begin{array}{l}\text { Baixo registro de avanços físicos } \\
\text { e apuração de indicadores }\end{array}$ & Não foram citadas ações de mitigação. \\
\hline
\end{tabular}


Continuação do Quadro 6.4

\begin{tabular}{|c|c|c|c|}
\hline Aspecto específico & Instituição & Pontos desfavoráveis & Ação necessária \\
\hline \multirow[t]{2}{*}{ Finalidade } & AL & Vocação multifuncional do SMA; & Atuação marcante do patrocinador no Chile; \\
\hline & $\mathrm{AL}$ & $\begin{array}{l}\text { Necessidade de prestação de } \\
\text { contas }\end{array}$ & Criação de módulos específicos para que alcance a sociedade na Colômbia \\
\hline Estrutura institucional & $\mathrm{AL}$ & Coerência institucional & Fluxo bidirecional de informações no Chile e no Brasil \\
\hline Diferenciação & $\mathrm{AL}$ & 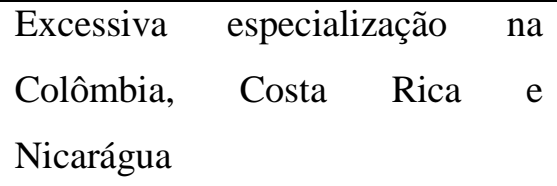 & $\begin{array}{l}\text { participação dos ministérios setoriais na identificação das metas e dos } \\
\text { indicadores, bem como no processo de planejamento estratégico }\end{array}$ \\
\hline \multirow[t]{2}{*}{ Parcerias } & $\mathrm{AL}$ & $\begin{array}{l}\text { Ausência de integração dos } \\
\text { departamentos de planejamento } \\
\text { setorial na Bolívia }\end{array}$ & maior vinculação do MeA ao planejamento e à elaboração orçamentária \\
\hline & $\mathrm{AL}$ & $\begin{array}{l}\text { Problemas de informações em } \\
\text { muitos setores no Peru }\end{array}$ & envolvimento com instituições de estatísticas \\
\hline Finalidade & $\mathrm{AL}$ & $\begin{array}{l}\text { Limitada utilização dos dados na } \\
\text { Colômbia, em Honduras, no Peru, } \\
\text { no Brasil, no Chile e no México }\end{array}$ & Não foram citadas ações de mitigação. \\
\hline
\end{tabular}

Fonte: Elaborado pelo autor. 
Quadro 6.5 - Quantidade de respondentes e citações indiretas sobre as dificuldades presente nos comentários enviados pelos especialistas respondentes.

\begin{tabular}{|l|l|c|c|}
\hline Aspecto geral & Aspecto Específico & Respondentes & Citações \\
\hline Funcional & 1. Pesquisa e avaliação & 1 & 1 \\
\cline { 2 - 4 } & 2. Rotinas de monitoramento & 4 & 4 \\
\cline { 2 - 4 } & 3. Bases de dados & 4 & 4 \\
\cline { 2 - 4 } & 4. Qualidade dos dados & 3 & 3 \\
\hline Organizacional & 5. Estrutura institucional & 5 & 8 \\
\cline { 2 - 4 } & 6. Gestão de recursos & 5 & 4 \\
\cline { 2 - 4 } & 7. Planos de MeA integrados & 1 & 7 \\
\cline { 2 - 4 } & 8. Envolvimento dos gestores financeiros e de RH & 4 & 7 \\
\cline { 2 - 4 } & 9. Cultura favorável ao MeA & 8 & 7 \\
\hline Finalidade & 10. Parcerias & 3 & 12 \\
\cline { 2 - 4 } & 11. Finalidade & 4 & 7 \\
\cline { 2 - 4 } & 12. Empreendedor operacional & & 4 \\
\hline
\end{tabular}

Fonte: Elaborado pelo autor. 


\section{CONCLUSÕES}

Apesar de ter à disposição técnicas e estudos para se aprimorar, o setor de transportes encontra dificuldades para gerar, se apropriar e disseminar informações correlatas. Identificar quais são os aspectos necessários para que estas informações fomentem uma abordagem sistêmica dos transportes é, portanto, fato importante para contribuir na superação destas dificuldades. A proposta deste trabalho foi a de contribuir para este entendimento, explorando a Teoria Geral dos Sistemas para o adequado e tempestivo provisionamento destes ativos.

Atendendo o objetivo geral deste estudo, foram propostos doze aspectos específicos para a criação de um SMA efetivo das políticas pública federais para a infraestrutura de transporte no Brasil, agrupados em três aspectos gerais de uma abordagem sistêmica dos problemas: a interação com o ambiente, sua estrutura e sua finalidade.

Mediante a aplicação de uma pesquisa Delphi com especialistas que atuam no setor de infraestrutura de transportes, foi possível confirmar as duas hipóteses deste trabalho. Segundo os respondentes, todos os dozes aspectos específicos indicados por este trabalho para a criação e manutenção de um SMA efetivo das suas políticas públicas de um o setor de infraestrutura de transportes atendem formalidades e/ou são incipientes, desarticulados ou isolados.

Além disto,os diferentes graus de importância atribuídos a três aspectos específicos e o desencontro dos resultados compulsórios e espontâneos corroboram para ilustrar a necessidade de consolidar o entendimento sobre abordagens sistêmicas no setor de infraestrutura federal de transportes.Tais constatações contribuem para demonstrar a fragilidade de etapas importantes para o sucesso da implementação e o aprimoramento do ciclo de políticas públicas para o setor de infraestrutura federal de transportes.

A revisão da teoria antecipou a relevância que a liderança operacional possui para um sistema, mas que é pouco destacado nas práticas e experiências internacionais com SMA e foi fundamental no sucesso ou fracasso da criação de iniciativas semelhantes no país. Denominada como empreendedores operacionais, este aspecto específico reflete para um SMA a atuação dos empreendedores políticos na elaboração da agenda pública. Um 
empreendedor operacional se diferencia dos patrocinadores ou stakeholders na medida em que acumula atribuições para dedicar exclusivamente para "fazer um SMA funcionar".

Os especialistas que atuam na infraestrutura federal de transportes reconheceram compulsoriamente a liderança operacional com igual importância aos demais aspectos específicos para a criação de um SMA. Nos comentários voluntários, a recorrente citação dos especialista sobre a falta de integração, de coordenação e de articulação corroboraram para demonstrar a precariedade e a importância deste aspecto específico no setor. Portanto, o fortalecimento de um empreendedor operacional é o diferencial que os SMA das políticas públicas para a infraestrutura federal de transportes devem apresentar para serem criados e serem efetivos.

\subsection{Limitações e recomendações}

Ao longo da pesquisa, as ferramentas on-line e os critérios utilizados para coleta e análise dos dados foram satisfatórios para o objetivo do estudo. $\mathrm{O}$ acréscimo dos campos para comentários associados aos textos de nivelamento e de descrição dos componentes trouxe uma maior complexidade para a consolidação dos dados e podem ter inibido a participação dos respondentes.

A ausência de artifícios para garantir o envolvimento efetivo dos sujeitos até o final da enquete, a necessidade de um perfil mínimo que garantisse uma visão holística do setor e o período em que a Delphi foi realizada - feriados, férias e em época de mudança de governo trouxeram ao estudo uma dificuldade para cumprir com o cronograma previamente estabelecido e formar uma amostra ampla o suficiente para atender os requisitos desejados até o final da pesquisa: sete ou mais respondentes, com expertise e visões holística e multimodal sobre a infraestrutura federal de transportes. Por isto, priorizou-se o cargo ocupado em detrimento ao tempo de experiência dos respondentes, reduzindo este de dez para sete anos.

Recomenda-se como atividade e pesquisa futuras a aplicação das diretrizes propostas a cada modal de transportes, contribuindo para fortalecer o ciclo de políticas públicas e para consolidar e aprimorar o entendimento de uma abordagem sistêmica no setor de infraestrutura federal de transportes. 


\section{REFERÊNCIAS BIBLIOGRÁFICAS}

Almeida, C. F., Gularte, J. G., De Oliveira Ferreira, E., De Oliveira, A. R. G., e Yamashita, Y. (2009). Metodologia de Caracterização do Transporte Rodoviário Interestadual Semiurbano de Passageiros: O Caso do Distrito Federal e Entorno. Apresentado em Anais do XXV ANPET-Congresso de Pesquisa e Ensino em Transportes, Vitória, ES, Brasil.

ANTT. (2008). Relatório Gestão ANTT 2008. Brasília, DF: Ministério dos Transportes.

Bamberger, J. M., Rugh, J., e Mabry, L. S. (2006). RealWorld evaluation: Working under budget, time, data, and political constraints. Sage publications.

Banister, D., e Berechman, J. (2003). Transport investment and economic development. Routledge.

Barbieri, I. (2000). Entropia e neguentropia como medidas de organizações de sistemas socioculturais de natureza cibernético-dialética. Departamento de Ciências da Educação da Faculdade de Ciências e Letras- UNESP, Araraquara.

Bojović, N. J. (2002). A general system theory approach to rail freight car fleet sizing. European Journal of Operational Research, 136(1), 136-172.

Brasil. (2013). Decreto no 8065 de 07 de Agosto de 2013.

Bresser-Pereira, L. C. (2000). A reforma gerencial do Estado de 1995. Moderna, 55, 72.

Calmon, K. M. N., e Gusso, D. A. (2002). A experiência de avaliação do Plano Plurianual (PPA) do Governo Federal no Brasil. Planejamento e Políticas Públicas, (25). Disponível em http://www.ipea.gov.br/ppp/index.php/PPP/article/view/61, Acessado em 23 de maio de 2014.

Capella, A. C. N. (2007). Perspectivas teóricas sobre o processo de formulação de políticas públicas. Políticas públicas no Brasil. Rio de Janeiro: Fiocruz, 1, 87-124.

Carvalho, A. L. B. de, Sousa, M. F. de, Shimizu, H. E., Senra, I. M. V. B., e Oliveira, K. C. de. (2012). A gestão do SUS e as práticas de monitoramento e avaliação: possibilidades e desafios para a construção de uma agenda estratégica.

Cassiolato, M., e Gueresi, S. (2010). Como Elaborar Modelo Lógico: roteiro para formular programas e organizar avaliação. Nota Técnica, (6).

CGU. (2012). Relatório de Auditoria $n^{o} 201200864$ (No. 201200864). Brasília, DF: Controladoria-Geral da União.

Chen, H.-T. (2005). Practical program evaluation: Assessing and improving planning, implementation, and effectiveness. Sage.

Chiavenato, I. (2003). Introdução à teoria geral da administração. Elsevier Brasil.

Correia, D. E. R., e Yamashita, Y. (2004). Metodologia para identificação da qualidade da informação para planejamento de transportes. Artigo / Article. Disponível http://repositorio.unb.br/handle/10482/13478, Acessado em 24 de maio de 2014.

Dahua, L. Q. L. M. Y. (2010). Application of System Theory in Urban Transport Hub Design [J]. Urban Rapid Rail Transit, 4, 014.

Dajani, J. S., Sincoff, M. Z., e Talley, W. K. (1979). Stability and agreement criteria for the termination of Delphi studies. Technological forecasting and social change, 13(1), 83-90. 
DNIT. Resolução ${ }^{\circ} 10$, de 31 de janeiro de 2007 - regimento interno do DNIT (2007).

Do Vale, C. C. (2013). Teoria geral do sistema: histórico e correlações com a geografia e com o estudo da paisagem. ENTRE-LUGAR, 3(6), 85-108.

Dye, T. R. (2013). Understanding public policy (14th ed.). Prentice Hall Englewood Cliffs, NJ.

Easton, D. (1957). An approach to the analysis of political systems. World politics, 9(03), 383-400.

Ekwall, D., e Lantz, B. (2013). Seasonality of cargo theft at transport chain locations. International Journal of Physical Distribution e Logistics Management, 43(9), 728-746.

Faludi, A. (1973). The "systems view" and planning theory. Socio-Economic Planning Sciences, 7(1), 67-77.

Ferreira, A. B. de H. (2010). Novo dicionário eletrônico Aurélio. Editora Positivo.

Frattini, S. (1993). Sistemas de informação de marketing: bases conceituais, descrição de caso e proposta de abordagens para uma utilização efetiva. Fundação Getúlio Vargas.

Frey, K. (2009). Políticas públicas: um debate conceitual e reflexões referentes à prática da análise de políticas públicas no Brasil. Planejamento e Políticas Públicas, O(21). Disponível em http://www.ipea.gov.br/ppp/index.php/PPP/article/view/89, Acessado em 07 de maio de 2014.

Galanc, T., e Mikuś, J. (1986). The choice of an optimum group of experts. Technological Forecasting and Social Change, 30(3), 245-250.

Galindo, E. P. (2009). Análise Comparativa do Entendimento do Transporte como Objeto do Planejamento. (Dissertação de Mestrado em Transportes). Unb, Brasília, DF.

Garcia, R. C. (2000). Reorganização do processo de planejamento do Governo Federal: o PPA 2000-2003.

Gil, A. C. (2010). Métodos e técnicas de pesquisa social. In Métodos e Técnicas De Pesquisa Social. Atlas.

Görgens, M., e Kusek, J. Z. (2009). Making monitoring and evaluation systems work: a capacity development toolkit. Washington, DC: World Bank.

Grau, N. C., e Ospina, S. (2008). Fortalecimiento de los sistemas de monitoreo y evaluación (MeE) en América Latina: informe comparativo de 12 países (Vol. 12). Banco Mundial.

Halim, R. A., Tavasszy, L. A., e Seck, M. D. (2012). Modeling the global freight transportation system: A multilevel modeling perspective. In Simulation Conference (WSC), Proceedings of the 2012 Winter (pp. 1-13). IEEE.

Hughes, B. P., Anund, A., e Falkmer, T. (2015). System theory and safety models in Swedish, UK, Dutch and Australian road safety strategies. Accident Analysis e Prevention, 74, 271-278.

Hutchinson, B. G. (1979). Princípios de planejamento dos sistemas de transporte urbano. Guanabara Dois.

Jann, W., e Wegrich, K. (2007). 4 Theories of the Policy Cycle. Handbook of public policy analysis, 43.

Katz, D., e Kahn, R. L. (1978). The social psychology of organizations. Wiley e Sons.

Kusek, J. Z., e Rist, R. C. (2004). Ten steps to a results-based monitoring and evaluation system: a handbook for development practitioners. World Bank Publications.

Larsson, P., Dekker, S. W., e Tingvall, C. (2010). The need for a systems theory approach to road safety. Safety science, 48(9), 1167-1174.

Lhullier, L. A. (1978). Os objetivos do cpga/UFRGS e a situação de seus egressos no mercado de trabalho. 
Magalhães, M. T. Q., Silveira, L. S. da C., Pereira, E., Silva, H. A. da, Andrade, T. M. de, Yamashita, Y., e Aragão, J. J. G. de. (2007). Teleological Framework for Transport Planning and Evaluation: a Tool in the Seek For Integrated and Meaningful Solutions for Better Results.

Manheim, M. L. (1979). Fundamentals of Transportation systems analysis; Volume 1: Basic concepts.

Monobe, T. (1998). Enfoque sistêmico na administração de investimentos. Caderno de Estudos, (17), 01-24.

Morais, A. C. de. (2013). Projetos de infraestrutura de transportes : inserção efetiva na agenda governamental (Tese / Thesis). Universidade de Brasília, UnB, Brasília, DF.

MT. (2007). Metodologia integrada de suporte ao planejamento, acompanhamento e avaliação dos programas nacionais de transportes: relatório síntese. Brasília, DF: Secretaria de Gestão de Programas de Transportes.

MT. (2010). Estudo e revisão dos mecanismos técnicos e institucionais de perenização do PNLT (No. 9) (p. 78). Brasília, DF: Ministério dos Transportes e da Defesa.

Nieto-Parra, S., Oliveira, M., e Tibocha, A. (2013). The politics of transport infrastructure policies in Colombia.

Prodanov, C. C., e Freitas, E. C. de. (2013). Metodologia do trabalho científico: métodos e técnicas da pesquisa e do trabalho acadêmico (2 ed.). Novo Hamburgo: Feevale.

RAND Corporation. (n.d.). Delphi Method | RAND. Disponível em http://www.rand.org/topics/delphimethod.html. Acessado em 15 outubro 2014.

Rayens, M. K., e Hahn, E. J. (2000). Building consensus using the policy Delphi method. Policy, politics, e nursing practice, 1(4), 308-315.

Richardson, R. J., e Peres, J. A. (1985). Pesquisa social: métodos e técnicas. Atlas São Paulo.

RIPSA, (2015a). BVS RIPSA. Retrieved March 4, 2015, from http://www.ripsa.org.br/vhl/opasoms/

RIPSA, (2015b). Iniciativa RIPSA Nacional. Disponível em http://www.ripsa.org.br/ba/vhl/indicadores-e-dadosbasicos-ripsa-nacional/iniciativa-ripsa-nacional/, Acessado em 4 de março de 2015.

Rocha, P. E. N. de M., Kessel, L., Cabral, C., Cunha, O. M. da, Oliveira, J. E. B. de, e Neves, S. M. C. M. (n.d.). Sistema Integrado de Planejamento, Orçamento e Finanças do Ministério da Educação (Simec). Apresentado emConcurso Inovação na Gestão Pública Federal. Disponível em http://inovacao.enap.gov.br/index.php?option=com_docmanetask=doc_viewegid=288, acessado em 31 de outubro de 2014.

Rowe, G., e Wright, G. (1999). The Delphi technique as a forecasting tool: issues and analysis. International journal of forecasting, 15(4), 353-375.

Rua, M. das G. (2009). Políticas públicas. Florianópolis: Departamento de Ciências da Administração/UFSC.

Santos, A. R. dos. (2012). Monitoramento e avaliação de programas no setor público: a experiência do PPA do Governo Federal no período 2000-2011. (Monografia). Instituto Serzedello Corrêa, Brasília, DF.

Serpa, S. M. H. C. (2014). Uma leitura dos usos da avaliação na administração pública no Brasil a partir da caracterização dos sistemas de avaliação de programas governamentais. (Tese (Doutorado)). Universidade de Brasília, UnB, Brasília, DF.

Siegel, G. (1971). A unidade do método sistêmico. Revista de Administração Pública, 5(1), 7-a.

Silva, E. L. da, e Menezes, E. M. (2011). Metodologia da pesquisa e elaboração de dissertação. rev. atual. Florianópolis: Laboratório de Ensino a Distância da UFSC. 
Silva, F. G. F. da. (2009). Metodologia para identificar as informações necessárias para definição de políticas públicas do transporte rodoviário interestadual de passageiros: caso da regulação tarifária. Universidade de Brasília, UnB, Brasília, DF.

Souza, C. (2006). Políticas públicas: uma revisão da literatura. Sociologias, 8(16), 20-45.

Tavasszy, L. A., Ivanova, O., e Halim, R. A. (2015). Modelling Global Container Freight Transport Demand. In Handbook of Ocean Container Transport Logistics (pp. 451-475). Springer.

TCU. (2011). Relatório de Levantamento dos Sistemas de Monitoramento e Avaliação dos Órgãos da Administração Direta do Poder Executivo. (No. TC 032.287/2010 -0). Brasília, DF: Tribunal de Contas da União.

TCU. (2012). Auditoria Operacional na Gestão das Obras do Departamento Nacional de Infraestrutura de Transportes (Dnit) (No. TC 032.446/2011-0). Brasília, DF: Tribunal de Contas da União.

Tedesco, G. M. I. (2010). Metodologia para a elaboração do diagnóstico de um sistema de transportes.

Uhlmann, G. W. (2002). Teoria geral dos sistemas: do atomismo ao sistemismo, uma abordagem sintética das principais vertentes contemporâneas desta proto-teoria. Centro Interdisciplinar de Semiótica da Cultura e da Mídia. São Paulo: USP.

UN. (2014). United Nations. Disponível em http://www.un.org/en/, acessado em 10 de outubro de 2014.

UNDP, (2009). Handbook on Planning, Monitoring and Evaluating for Development Results. New York, USA: United Nations. Disponível em http://www.undp.org/eo/handbook, Acessado em 10 de outubro de 2014.

UNDP, U. N. D. P. (2015). Data | United Nations Development Programme. UNDP Open Data. Disponível em https://data.undp.org/dataset/Projects-in-Brazil/gfpp-g6t4/alt, acessado em 4 de março de 2015.

UNICEF. (2007). Programme Policy and Procedure Manual. UNICEF.

Vaitsman, J., Rodrigues, R. W., e Paes-Sousa, R. (2006). O Sistema de Avaliação e Monitoramento das Políticas e Programas Sociais: a experiência do Ministério do. Unesco.

Vergara, S. C. (1997). Projetos e relatórios de pesquisa em administração. Atlas.

Von Bertalanffy, L. (1975). Teoria geral dos sistemas. Alemanha: vozes.

Von Der Gracht, H. A. (2012). Consensus measurement in Delphi studies: review and implications for future quality assurance. Technological Forecasting and Social Change, 79(8), 1525-1536.

Wholey, J. S., Hatry, H. P., e Newcomer, K. E. (2010). Handbook of practical program evaluation (Vol. 19). John Wiley e Sons.

World Bank. (2014). History.Disponível em http://www.worldbank.org/en/about/history. Acessado em 17 de dezembro de 2014.

Wright, J. T., e Giovinazzo, R. A. (2000). Delphi: uma ferramenta de apoio ao planejamento prospectivo. Caderno de pesquisas em administração, 1(12), 54-65. 


\section{APÊNDICES}




\section{A DIRETRIZES GERAIS PARA UM SMA}

Quadro A.1 - Descrição dos aspectos específicos das diretrizes preliminares gerais.

\begin{tabular}{|c|c|c|}
\hline Aspectos gerais & Aspecto específico & Descrição \\
\hline \multirow[t]{4}{*}{ Funcionais } & $\begin{array}{l}\text { Pesquisas e } \\
\text { avaliações }\end{array}$ & $\begin{array}{l}\text { Atividades de pesquisas periódicas ou por amostragens amplas do } \\
\text { ambiente em que se insere o produto, visando gerar dados sobre resultados } \\
\text { e generalizar conhecimentos para um propósito específico. }\end{array}$ \\
\hline & $\begin{array}{l}\text { Rotinas de } \\
\text { monitoramento }\end{array}$ & $\begin{array}{l}\text { Levantar dados quali-quantitativos sobre o andamento as etapas de um } \\
\text { processo (entrada, processamento e saída). }\end{array}$ \\
\hline & Base de dados útil & $\begin{array}{l}\text { Repositório de dados viabilizado por ferramentas para reunir os dados } \\
\text { coletados durante o monitoramento rotineiro, pesquisas esporádicas e } \\
\text { específicas. }\end{array}$ \\
\hline & $\begin{array}{l}\text { Qualidade dos } \\
\text { dados }\end{array}$ & $\begin{array}{l}\text { atividades desenvolvidas para aumentar a qualidade dos dados e fomentar } \\
\text { a capacidade das equipes, como melhores supervisão e auditoria. }\end{array}$ \\
\hline \multirow[t]{5}{*}{ Organizacionais } & $\begin{array}{l}\text { Estrutura } \\
\text { institucional }\end{array}$ & $\begin{array}{l}\text { Descrição da hierarquia, dos relacionamentos e do arranjo do trabalho, } \\
\text { indicando sua interação e disposição em um sistema }\end{array}$ \\
\hline & $\begin{array}{l}\text { Gestão do capital } \\
\text { intelectual }\end{array}$ & $\begin{array}{l}\text { Iniciativa para a retenção e o desenvolvimento das capacidades e } \\
\text { habilidades dos elementos de um sistema. }\end{array}$ \\
\hline & $\begin{array}{l}\text { Plano de MeA } \\
\text { integrado }\end{array}$ & $\begin{array}{l}\text { Detalhamento das atividades e dos produtos para integrar atores e ser } \\
\text { integrado com outros instrumentos e instâncias de planejamento. }\end{array}$ \\
\hline & $\begin{array}{l}\text { Previsão física- } \\
\text { financeira }\end{array}$ & $\begin{array}{l}\text { Detalhamento pormenorizado e previsão formal dos recursos necessários } \\
\text { para o sistema. }\end{array}$ \\
\hline & $\begin{array}{l}\text { Cultura } \\
\text { organizacional }\end{array}$ & $\begin{array}{l}\text { Seleção de crenças, suposições e valores que levam a uma maior ou menor } \\
\text { receptividade de um SMA na instituição. }\end{array}$ \\
\hline \multirow[t]{3}{*}{ Finalidade } & Parcerias & $\begin{array}{l}\text { Arranjos que fortalecem o vinculo com os sub e supra sistemas por meio } \\
\text { do fluxo uni ou bidirecional de informações. }\end{array}$ \\
\hline & Finalidade & Destinação do produto gerado pelo sistema. \\
\hline & $\begin{array}{l}\text { O empreendedor } \\
\text { operacional }\end{array}$ & $\begin{array}{l}\text { Indivíduos empenhados em um propósito, especialistas em determinada } \\
\text { questão, revestidos de autoridade e de habilidades para fomentar os demais } \\
\text { aspectos específicos, para defender ideias próprias ou de terceiros, para } \\
\text { manter conexões técnicas e políticas e para promover o SMA por meio da } \\
\text { diversificação, do seu uso e do seu constante aprimoramento. }\end{array}$ \\
\hline
\end{tabular}

Fonte: Elaborado pelo autor.

Oportunamente, a análise das lições aprendidas no Brasil e na América Latina indicam pontos favoráveis e desfavoráveis e as ações desencadeadas que podem subsidiar a criação e a manutenção de um SMA para as políticas públicas para a infraestrutura federal de transportes. Os Quadros A.2 e A.3 apresentam estas informações. 
Quadro A.2 - Aspectos favoráveis e ações necessárias segundo aspectos específicos.

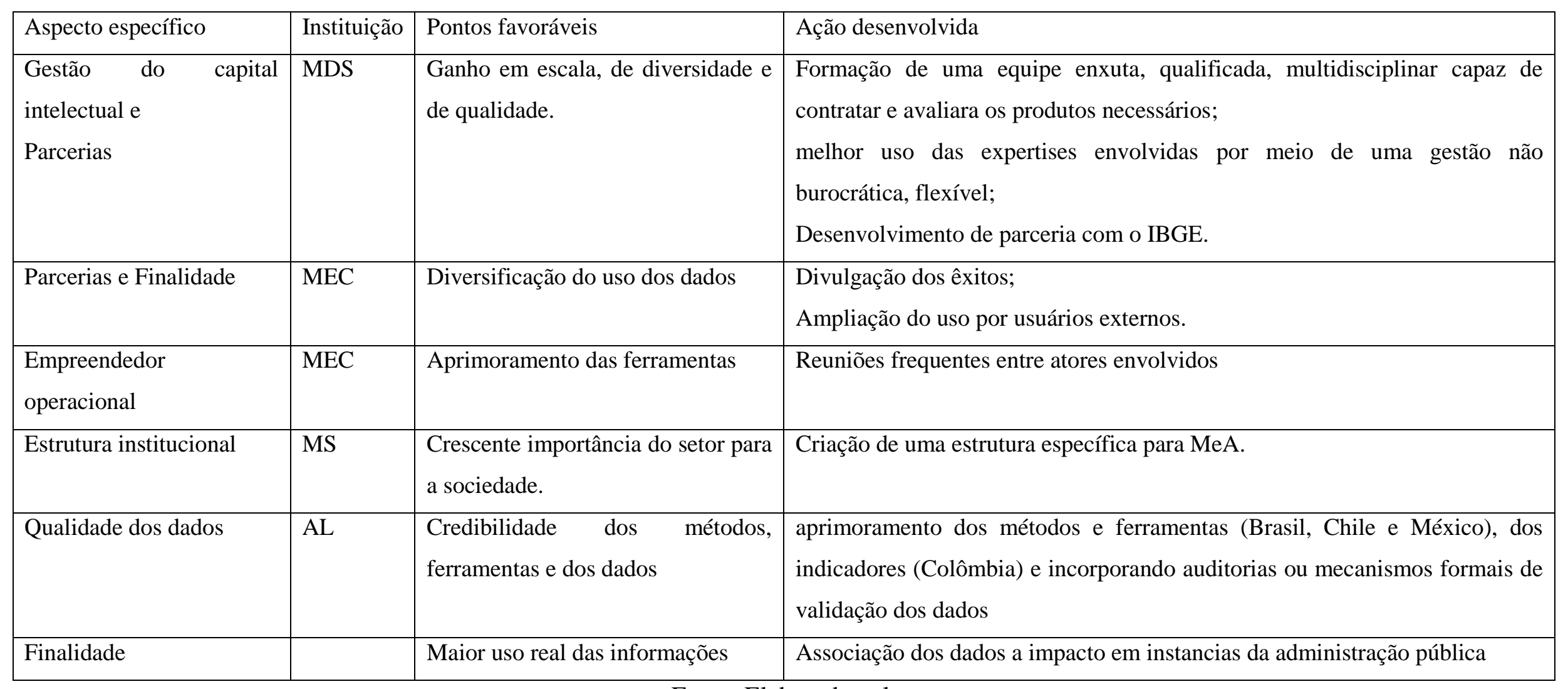

Fonte: Elaborado pelo autor. 
Quadro A.3 - Aspectos desfavoráveis e ações necessárias segundo aspectos específicos.

\begin{tabular}{|c|c|c|c|}
\hline Aspecto específico em foco & Instituição & Pontos desfavoráveis & Ação necessária \\
\hline Base de dados útil & MDS & $\begin{array}{l}\text { Integração de dados e ferramentas } \\
\text { devido à diversidade de fontes e } \\
\text { falta de padrão dos formatos }\end{array}$ & Definição de indicadores segundo atributos. \\
\hline $\begin{array}{l}\text { Base de dados útil } \\
\text { Qualidade dos dados }\end{array}$ & MEC & $\begin{array}{l}\text { a falta de utilidade para os gestores } \\
\text { e a instabilidade das ferramentas }\end{array}$ & $\begin{array}{l}\text { Desenvolvimento de parceria para realizar estudos e pesquisas sobre } \\
\text { governança, planejamento e monitoramento de ações governamentais. }\end{array}$ \\
\hline Qualidade dos dados & MS & $\begin{array}{l}\text { Fragilidade nas informações } \\
\text { disponíveis }\end{array}$ & $\begin{array}{l}\text { Desenvolvimento de parcerias para auxiliar no desenvolvimento de } \\
\text { metodologias, para envolver atores acadêmicos e da pesquisa aplicada e para } \\
\text { atuar na qualificação das equipes gestoras. }\end{array}$ \\
\hline $\begin{array}{l}\text { Parcerias e } \\
\text { Pesquisa e avaliação }\end{array}$ & MS & $\begin{array}{l}\text { Desarticulação } \\
\text { departamentos; } \\
\text { inexistência de uma política de } \\
\text { avaliação }\end{array}$ & $\begin{array}{l}\text { Institucionalização; } \\
\text { definição das práticas e os processos de monitoramento e avaliação da gestão e } \\
\text { o vínculo com o RAG. }\end{array}$ \\
\hline $\begin{array}{l}\text { Finalidade e } \\
\text { Empreendedor operacional }\end{array}$ & STN & Mudança de governo & Não foram citadas ações de mitigação. \\
\hline $\begin{array}{l}\text { Parcerias, } \\
\text { Qualidade dos dados e } \\
\text { Gestão do capital intelectual }\end{array}$ & PPA & $\begin{array}{l}\text { Baixos registro de avanços físicos e } \\
\text { apuração de indicadores }\end{array}$ & Não foram citadas ações de mitigação. \\
\hline \multirow[t]{2}{*}{ Finalidade } & $\mathrm{AL}$ & Vocação multifuncional do SMA; & Atuação marcante do patrocinador no Chile; \\
\hline & $\mathrm{AL}$ & Necessidade de prestação de contas & Criação de módulos específicos para que alcance a sociedade na Colômbia \\
\hline Estrutura institucional & $\mathrm{AL}$ & Coerência institucional & Fluxo bidirecional de informações no Chile e no Brasil \\
\hline
\end{tabular}


Continuação do Quadro 8

\begin{tabular}{|c|c|c|c|}
\hline Aspecto específico em foco & Instituição & Pontos desfavoráveis & Ação necessária \\
\hline Diferenciação & $\mathrm{AL}$ & $\begin{array}{l}\text { Excessiva especialização na } \\
\text { Colômbia, Costa Rica e Nicarágua }\end{array}$ & $\begin{array}{l}\text { participação dos ministérios setoriais na identificação das metas e dos } \\
\text { indicadores, bem como no processo de planejamento estratégico }\end{array}$ \\
\hline \multirow[t]{2}{*}{ Parcerias } & AL & $\begin{array}{l}\text { Ausência de integração dos } \\
\text { departamentos de planejamento } \\
\text { setorial na Bolívia }\end{array}$ & maior vinculação do MeA ao planejamento e à elaboração orçamentária \\
\hline & $\mathrm{AL}$ & $\begin{array}{l}\text { Problemas de informações em } \\
\text { muitos setores no Peru }\end{array}$ & envolvimento com instituições de estatísticas \\
\hline \multirow[t]{2}{*}{ Finalidade } & AL & $\begin{array}{l}\text { escasso vínculo com o orçamento } \\
\text { no Uruguai e em Honduras }\end{array}$ & Não foram citadas ações de mitigação. \\
\hline & $\mathrm{AL}$ & $\begin{array}{l}\text { Limitada utilização dos dados na } \\
\text { Colômbia, em Honduras, no Peru, } \\
\text { no Brasil, no Chile e no México }\end{array}$ & Não foram citadas ações de mitigação. \\
\hline
\end{tabular}

Fonte: Elaborado pelo autor. 


\section{B EXEMPLOS DEFORMULÁRIOS UTILIZADOS NA PESQUISA DELPHI}

O questionário Delphi foi composto por sete seções, conforme apresenta a Figura B.1.

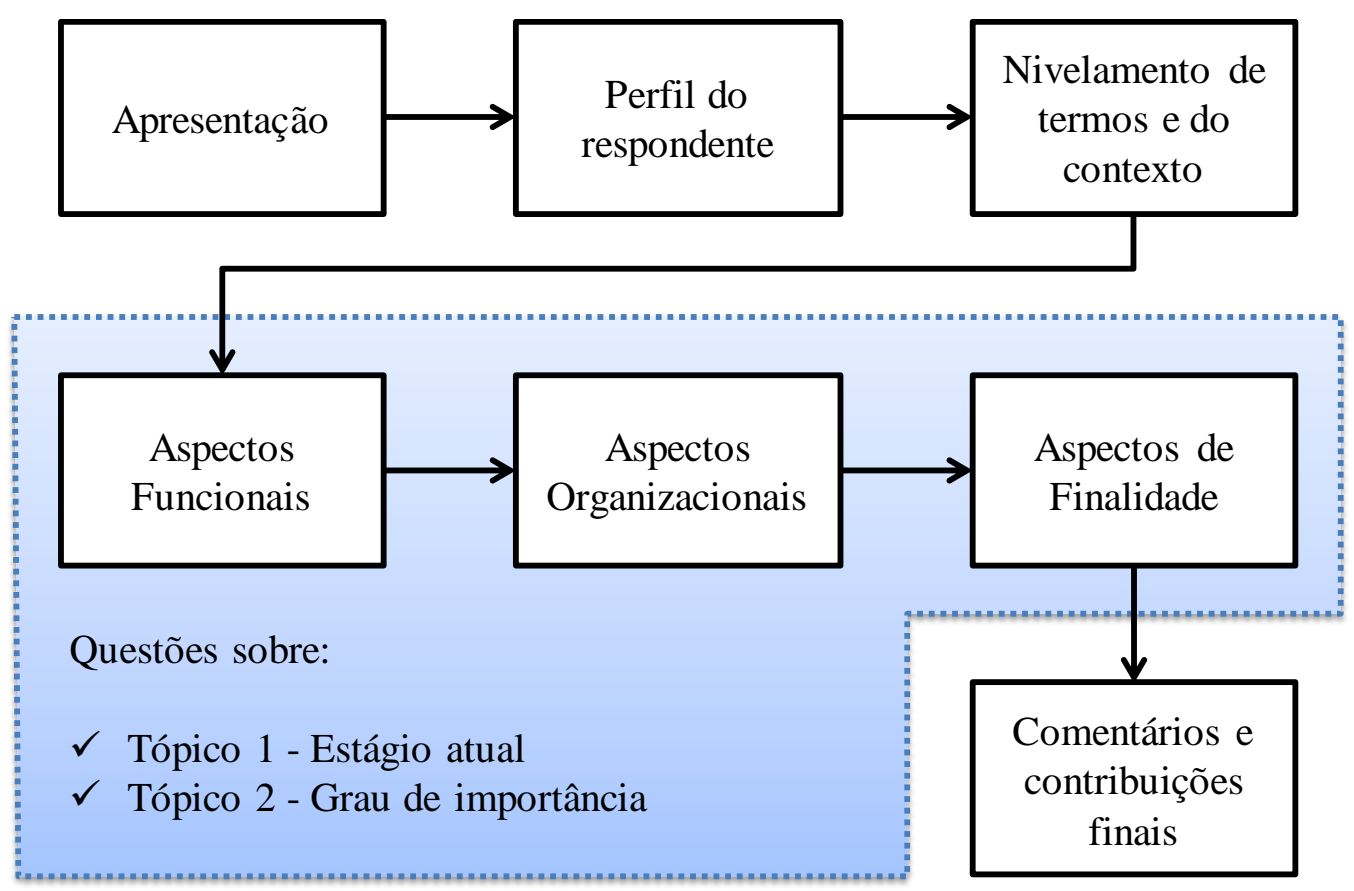

Figura B.1 - Seções da pesquisa Delphi.

Fonte: Elaborado pelo autor.

A seguir, são apresentados exemplos das questões aplicadas na $1^{\mathrm{a}}$ e $2^{\mathrm{a}}$ rodadas. 


\section{Aspectos de Finalidade}

Os aspectos de finalidade estão relacionados aos principais fatores para a construção, a manutenção e o sucesso de um sistema - como sua promoção, integração e requisição por instâncias externas relevantes, principal destinatário dos produtos gerados pelo SMA

\section{Tópico 1 - Estágio atual}

As questões deste tópico buscam informações sobre o estágio atual dos componentes propostos pelo estudo para viabilizar e manter uma abordagem sistêmic a das polític as públic as voltadas para a infraestrutura de transportes.

As opções para resposta são:

0 - Desconheço:

1 - Inexiste

2 - Atende apenas formalidades e/ou é incipiente, desarticulada ou isolada;

3 - Está num estágio intermediário de aplic ação;

4 - E amplamente utilizado.

O setor público federal de infraestrutura de transportes, atualmente:

12. Fomenta o desenvolvimento de empreendedores operacionais de um SMA?"

O empreendedor operacional de um SMA é um agente revestido de autoridade para promover a interlocução, integração e

viabilização de um SMA com outras instâncias.

$\begin{array}{lllll}0 & 1 & 2 & 3 & 4\end{array}$

Desconheço $\bigcirc$ É amplamente utilizado

Comentários para a questão 1.12

\section{Tópico 2 - Grau de importância}

Este tópico tem por objetivo verificar a importância que cada componente proposto pelo estudo possui para a criação de um SMA das polític as públicas voltadas para a infraestrutura de transportes.

Sua resposta não deve considerar o grau de complexidade que possuem no contexto atual, mas sim a importância que representa Tal informação sobre a complexidade deverá ser levantada para elaborar planos específicos de implantação para cada modal de transportes

Qual o atual grau de importância destes componentes para a criação e manutenção de um SMA para o setor público federal de infraestrutura de transportes?

Desconheço $\begin{gathered}\text { Nenhuma } \\ \text { importância }\end{gathered}$ Pouco importante $\begin{gathered}\text { Importância } \\ \text { intermediária }\end{gathered} \quad$ Muito importante

$\begin{aligned} & \text { 10. Estímulos a } \\ & \text { parcerias }\end{aligned}$
$\begin{aligned} & \text { 11. Finalidade } \\ & \begin{array}{l}\text { 12. Empreendedor } \\ \text { operacional }\end{array}\end{aligned}$

Comentários para os itens 2.10, 2.11, e 2.12

Figura B.2 - Exemplo de questões dos Tópicos 1 e 2 aplicadas na $1^{\text {a }}$ rodada da pesquisa Delphi.

Fonte: Elaborado pelo autor. 


\section{Aspectos de Finalidade}

Os aspectos de finalidade estão relacionados aos principais fatores externos para a construção, a manutenção e o sucesso de um sistema - como sua promoção, integração e requisição por instâncias externas relevantes, principal destinatário dos produtos gerados pelo SMA.

\section{Tópico 1 - Estágio atual}

As questões deste tópico buscam informaç̃es sobre o estágio atual dos componentes propostos pelo estudo para viabilizar e manter uma abordagem sistêmica das polític as públic as voltadas para a infraestrutura de transportes.

As opções para resposta são:

Para validação da resposta da maioria (sublinhada no gráfico que apresenta o resultado anterior):

0 - Desconheço

1 - Concordo com o resultado;

2 - Discordo do resultado

Para as questões reaplic adas:

0 - Desconheço,

1 - Inexiste;

2 - Atende apenas formalidades e/ou é incipiente, desarticulada ou isolada;

3 - Está num estágio intermediário de aplic ação;

4 - É amplamente utilizado.

O setor público federal de infraestrutura de transportes, atualmente:

1.12. Fomenta o desenvolvimento de empreendedores operacionais de um SMA?

O empreendedor operacional de um SMA é um agente revestido de autoridade para promover a interlocução, integração $e$

viabilização de um SMA com outras instâncias.

Desconheço

Concordo com o resultado

Discordo do resultado

\section{Resultado anterior da questão 1.12}

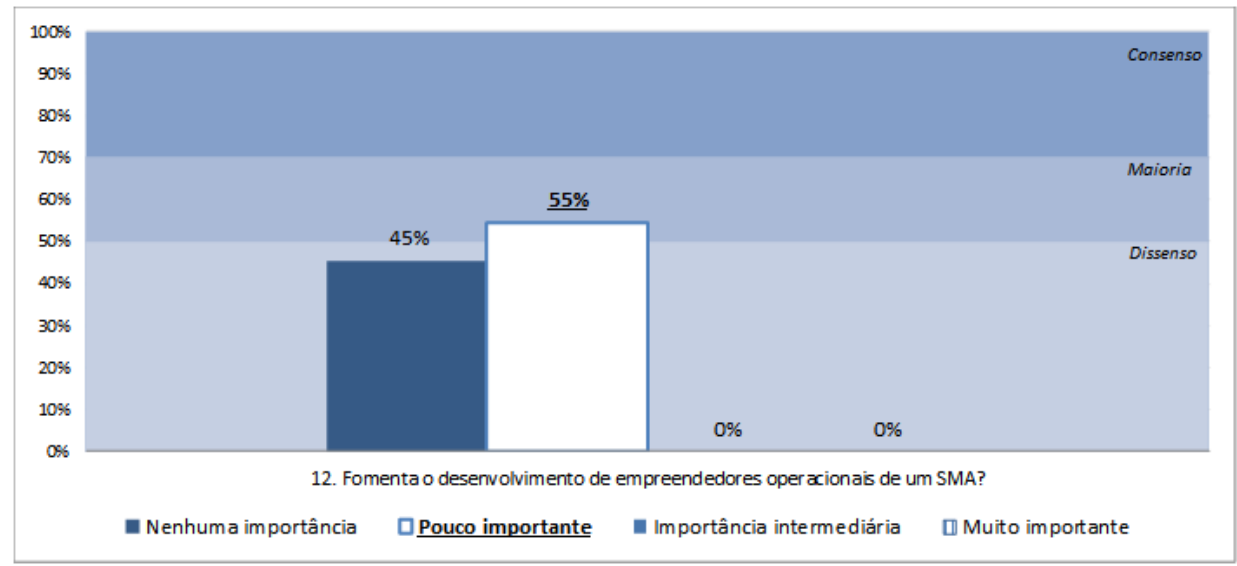

Comentário 1 sobre a questão 1.12

"O desenvolvimento de empreendedores de um SMA, quando realizado, parte da iniciativa dos próprios empreendedores ou de alguma política interna de alguma organização." Utilize o campo abaixo para comentar.

Figura B.3 - Exemplo de questão do Tópico 1 aplicada na 2a rodada da pesquisa Delphi para qualificação do resultado anterior e para a crítica dos especialistas sobre os comentários.

Fonte: Elaborado pelo autor. 


\section{Tópico 2 - Grau de importância}

Este tópico tem por objetivo verificar a importância que cada componente proposto pelo estudo possui para a criação de um SMA das políticas públicas voltadas para a infraestrutura de transportes.

Sua resposta não deve considerar o grau de complexidade que possuem no contexto atual, mas sim a importância que representa. Tal informação sobre a complexidade deverá ser levantada para elaborar planos específicos de implantação para cada modal de transportes.

Qual o atual grau de importância destes componentes para a criação e manutenção de um SMA para o setor público federal de infraestrutura de transportes?

$$
\text { Desconheço } \quad \begin{gathered}
\text { Nenhuma } \\
\text { importância }
\end{gathered} \text { Pouco importante } \quad \begin{gathered}
\text { Importância } \\
\text { intermediária }
\end{gathered} \text { Muito importante }
$$

10. Estímulos a
parcerias

\section{Resultado anterior da questão 2.10}

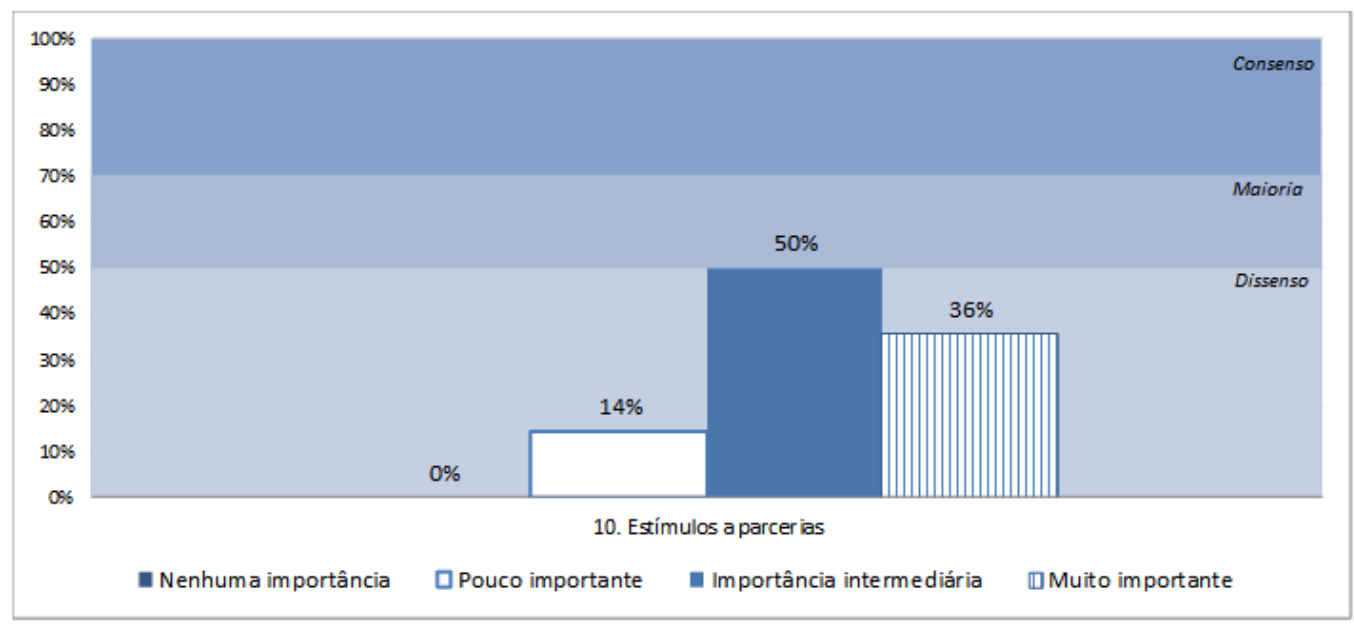

Figura B.4 - Exemplo de questão do Tópico 2 reaplicadas integralmente na 2a rodada da pesquisa Delphi.

Fonte: Elaborado pelo autor. 


\section{Comentários e contribuições finais}

$2^{\mathrm{a}}$ rodada

Comentários e contribuições finais 1

"Não há clareza no papel das instituições e órgãos de Governo. Há carência de dados e de avaliações ex-post. Existem iniciativas isoladas para criação de pequenas bases de dado e para a sistematização de avaliações mais simples." Utilize o campo abaixo para comentar.

Figura B.5 - Exemplo da sétima seção da $2^{\mathrm{a}}$ rodada da pesquisa Delphi para os especialistas registrarem comentários sobre a rodada e os comentários enviados na $1^{\mathrm{a}}$ rodada.

Fonte: Elaborado pelo autor. 


\section{COMENTÁRIOS ENVIADOS PELOS ESPECIALISTAS}

A numeração dos comentários enviados pelos especialistas utiliza a seguinte estrutura:

Item Q.: Número da questão apresentada ao respondente;

Item Q.C.: Número do comentário enviado na primeira rodada para a questão Q;

Item Q.C.R.: Número da réplica enviada na segunda rodada para o comentário $\mathrm{C}$ da questão Q;

Assim, o item 2.1.2 apresenta a segunda réplica enviada na segunda rodada para o comentário 1 da primeira rodada da questão 2. As palavras destacadas em itálico destacam a ênfase dada pelos especialistas que foi considerada para identificar as citações indiretas dos aspectos específicos propostos neste trabalho. 


\section{C.1 Tópico 1 - Estágio atual dos aspectos específicos}

1. O setor público federal de infraestrutura de transportes fomenta, atualmente: Práticas para a coleta de dados sobre os produtos (os ativos) e os resultados alcançados por meio de pesquisa e avaliações?

1.1. Com exceção do desempenho das atividades institucionais da Empresa de Planejamento e Logística - EPL, que pressupõe amplo acesso a bases de dados empíricos atinentes ao setor de transportes, de um modo geral todos os demais dados do Poder Executivo não fomentam de forma institucional a coleta de dados sobre produtos e os resultados alcançados por meio de pesquisa e avaliações.

1.2. "- não existem levantamentos sistemáticos; - exemplo: nos processos de concessão rodoviária em 2014 foram contratados estudos específicos para medição do tráfego das rodovias que seriam duplicadas; não havia estudo anterior, sistemático; a decisão de duplicar antecedeu a medição de tráfego; o estudo visava balizar a referência de tarifa - para o processo de concessão de trechos ferroviários (greenfield) não foi divulgado nenhum estudo de tráfego; o modelo escolhido atribui o risco de demanda para o governo federal (Valec) - nas rodovias e ferrovias há trechos concorrentes".

1.3. Há uma desarticulação no governo quanto ao setor do transporte. Há alguns setores que desenvolvem algumas boas práticas, de maneira pontual, no entanto são ações isoladas.

1.4. "O Ministério dos Transportes possui um sistema de avaliação e um sistema de monitoramento das políticas públicas, porém esta incipiente e desarticulado. um dos motivo pode ser a rotatividade dos gestores no departamento responsável."

1.5. Não há uma rotina de monitoramento dos ativos no setor público que tenha dado a resposta necessário ao sistema de gestão e auditoria dos produtos entregues aos órgãos do governo. Poderíamos até considerar que para os modais mais organizados e com maior atuação do setor privado (ferroviário e aéreo), o "estágio intermediário de aplicação" tenha sido alcançado. Todavia, em virtude da matriz de transporte desbalanceada que perdura no Brasil, e, apesar do setor aquaviário ter ampla atuação do setor privado, a burocracia do Estado ainda interfere muito nesse setor. Então, recaímos na sobrecarga do modal rodoviário que começa a ampliar a gestão por concessão, porém, com atraso de décadas a ser superado.

1.6. Para nós pesquisadores é impossível pesquisar o setor público. 
1.7. A implementação varia conforme a capacidade técnica dos técnicos em cargo de decisão/influência, não são institucionais nem amplamente garantidas.

1.8. Pesquisas ocorrem por modo de transportes, por projeto, para aferição de elementos ex ante, raramente ex post.

1.9. "A ANTT, por exemplo, realiza a pesquisa de satisfação dos usuários. A última pesquisa foi aplicada pelo Instituto Análise entre março e junho de 2014, em todo território nacional, com o objetivo de conhecer as opiniões e expectativas dos usuários, a fim de aprimorar o planejamento das ações regulatórias e fiscalizatórias da Agência. EPL - Iniciou pesquisa de Origem e Destino sobre cargas e passageiros em território nacional. EPL - Realizou pesquisa de Origem e Destino rodoviária."

1.10. O setor de infraestrutura de transportes é desarticulado com as demais áreas de governo e apresenta pouca interação federativa com estados e municípios. Não são feitas avaliações sistemáticas e periódicas de suas funcionalidades.

2. O setor público federal de infraestrutura de transportes fomenta, atualmente: A criação de rotinas de monitoramento dos insumos (os projetos) e dos processos (recursos envolvidos)?

\section{1. "PAC"}

2.1.1. Existe monitoramento do PAC, o Ministério do Planejamento inclusive criou uma Secretaria especialmente para este monitoramento e avaliação, SEPAC.

2.1.2. O autor deste comentário referiu-se à existência de rotinas de monitoramento no PAC, o que me leva a concordar com a alternativa 2 "'atende formalidades e/ou é incipiente".

2.2. Quando estas atividades existem, de um modo geral são praticadas de forma isolada e não padronizada com os demais órgãos envolvidos.

2.2.1. "Existem. São de certa forma padronizadas com os demais órgão. Não existe uma sistematização da obtenção dessas informações. O processo de obtenção das informações ainda é confuso e incipiente. "

2.2.2. "concordo, o comentário reforça a opção ""atende formalidades e/ou é incipiente" 
2.3. Há alguns setores que desenvolvem algumas boas práticas, de maneira pontual, no entanto são ações isoladas.

2.3.1. Concordo com o comentário 3 .

2.3.2. "Existem ações isoladas, de fato falta uma coordenação. O Ministério dos Transportes tem buscado fazer esta coordenação, porém exige patrocínio do gestor máximo dos órgãos e em especial do MPOG."

2.3.3. o comentário reforça a opção "atende formalidades e/ou é incipiente"

2.4. "Hoje é feito o monitoramento de todos os empreendimento de transportes no PAC Programa de Aceleração do Crescimento do Governo Federal. Porém esta em faze de implantação a utilização destas informações de monitoramento no Planejamento de Políticas Públicas."

2.4.1. Não diria que esta em fazer de implantação. Esta implantado só não esta informatizado. E nem tem expectativa para tal.

2.5. A política de transparência e dados abertos com a lei de acesso da informação que dá direitos a qualquer cidadão ou organização acompanhar os processos e questionar os insumos aplicados nos projetos geridos pelo governo, tem começado a dar resultados, instituindo a cultura do monitoramento coletivo, principalmente em grupos de representação de algumas sociedades civis organizadas e investidos internacionais interessados.

2.5.1. Isto não quer dizer que haja rotinas de monitoramento dos insumos e dos processos.

2.5.2. "Concordo plenamente. A LAI - Lei de Acesso a Informação tem contribuído para este monitoramento por meio da sociedade."

2.5.3. concordo com o comentário como expectativa em relação a uma tendência; a cultura de monitoramento coletivo ainda é incipiente

2.5.4. "Concordo que a maioria reconheça apenas os programas monitorados que são divulgados, mas existem rotinas de obtenção de dados e integração de informações para tomada de decisão que ficam apenas no nível estratégico do governo, com acesso restrito a maioria dos interessados. Toda via, vejo como a falta de cultura do acompanhamento público, ainda a ser consolidada no país e, 
que também, depende da evolução dos instrumentos de apresentação e divulgação dos resultados monitorados."

2.6. Muitos ligados a programas de governos específicos, como o PAC, para acompanhamento de obras, mas efetuados em diversas frentes distintas, por mais de uma instituição e com conflito de dados e resultados.

2.6.1. Sim! Falta coordenação por meio da SEPAC.

2.6.2. "o comentário reforça a opção ""atende formalidades e/ou é incipiente""'"

2.7. Com base no acompanhamento da gestão do MT e suas unidades vinculadas, é possível citar que o monitoramento existe, mas ainda precisa ser aperfeiçoado.

2.7.1. o comentário reforça a opção "atende formalidades e/ou é incipiente"

2.8. Há rotinas de monitoramento porém estão dissociadas da avaliação dos resultados alcançados.

2.8.1. O comentário reforça a opção "atende formalidades e/ou é incipiente"

Comentários gerais para a questão 1.2

2.9. Pode melhorar, com informatização dos processos e coordenação mais clara e definição de linhas de comando claras.

2.10. "Todos os comentários repassados se referem ao PAC, o que sugere que é o único sistema onde há algum tipo (ou tentativa) de monitoramento. Esta constatação está em linha com a opção ""atende formalidades e/ou é incipiente""'"

3. O setor público federal de infraestrutura de transportes fomenta, atualmente: A criação de bases com os dados que dispõe (banco de dados)?

3.1. Há alguns setores que desenvolvem algumas boas práticas, de maneira pontual, no entanto são ações isoladas.

3.1.1. "A SPI/MPOG tem investido fortemente nos últimos anos na necessidade de padrão e interoperabilidade do banco de dados dentro do Governo Federal. Diria 
que tem iniciativas como a INDE decreto 6.666/2012 e a INDA que vem sendo conduzidas pelo MPOG. Porém, falta patrocínio dos Gestores dos Ministérios."

3.1.2. "Na primeira rodada preenchi a alternativa 0 ""desconheço"" para esta questão. O comentário refere-se a práticas pontuais, o que razoável de se supor, e reforça a opção ""atende formalidades e/ou é incipiente""

3.2. "A SPNT - Secretaria de Política Nacional de Transportes possui hoje um Departamento de Informações em Transportes, sendo responsável por: I - orientar, implementar e avaliar as atividades de coleta de processamento de dados, análise estatística, elaboração dos indicadores e divulgação de informações de transportes e de setores intervenientes necessários ao processo de consolidação do Plano Nacional de Logística e Transportes; II - orientar, implementar e avaliar a manutenção e a atualização da coleta de dados, das estatísticas e indicadores de transportes relevantes para o processo de planejamento da Política Nacional de Transportes de curto, médio e longo prazo; III - promover o desenvolvimento e a manutenção do repositório de dados georreferenciados e metadados para o planejamento de transportes, de maneira compartilhada entre o Ministério e seus órgãos vinculados; IV - integrar os sistemas de informações geográficas e os de informações gerenciais ao planejamento de transportes; V - planejar e implementar a estratégia de aperfeiçoamento e ampliação dos dados, das estatísticas e dos indicadores de transportes; e VI - orientar e coordenar estudos e pesquisas necessários ao desenvolvimento de sistemas de modelagem de transportes e à avaliação econômico-financeira de projetos de infraestrutura de transportes. "

3.2.1. A SPNT acompanha apenas os sistemas de transportes terrestres, quando consegue acompanhar. O setor de transportes no Brasil é desarticulado em diversos ministérios, sem que haja uma política efetiva de coordenação.

3.2.2. "O comentário relata a atribuição de uma unidade do organograma da SPNT. Denota um propósito (positivo!), mas não esclarece o estágio de implantação das atividades. Suponho que as atividades estatutárias do Departamento de Informações estão ""num estágio intermediário de aplicação"". O autor do comentário poderia esclarecer se é este o caso." 
3.3. A pesar de bons exemplos na esfera federal como a INDE e o SNV baseada em fundamentos legais, a desarticulação entre federação, estados e municípios, tem impossibilitado o real e preciso dimensionamento de informações nacionais.

3.3.1. De fato, falta integração nas esferas de governo com relação ao planejamento.

3.3.2. o comentário reforça a opção "atende formalidades e/ou é incipiente"

3.4. tentamos fazer pesquisas e desistimos por falta de dados

3.4.1. "As pesquisas são justamente para se obter os dados! Lembro o ciclo da informação: Dados - Informações - Conhecimento - Inteligência"

3.4.2. o comentário reforça a opção "atende formalidades e/ou é incipiente"

3.5. Grande esforços isolados, mas que vem avançando de forma significativa, contudo, ainda não articulados plenamente.

3.5.1. "Falta articulação. Seria do Ministério dos Transportes e do MPOG."

3.5.2. o comentário reforça a opção "atende formalidades e/ou é incipiente"

3.6. Existe uma base de dados na ANTAQ e na ANTT

3.6.1. "Existem bases de dados em todos os órgãos de transporte. A questão é, estão interoperáveis? O MT tem uma iniciativa que esta fazendo esta integração com relação aos dados espaciais, atendendo do o decreto da INDE 6.666/2012"

3.6.2. "desconheço."

3.7. "As bases de dados decorrentes das pesquisas promovidas pela EPL serão utilizadas, por exemplo, para a elaboração do futuro Plano Nacional de Logística Integrada (PNLI), o que pressupõe a utilização de ferramentas para reunião dos dados."

3.7.1. "estágio intermediário de aplicação".

3.8. As funcionalidades das infraestruturas de transportes são pouco conhecidas e os serviços associados com baixo grau de informações públicas.

3.8.1. Concordo

Comentários gerais para a questão 1.3 
3.9. comentário 1 (3.1) resume os demais.

4. O setor público federal de infraestrutura de transportes fomenta, atualmente: A qualidade dos dados que dispõe?

4.1. O governo, de forma pontual, fomenta a coleta de dados, no entanto não há uma política para que a qualidade desses dados e nem uma estrutura de supervisão e discussão dos dados que, eventualmente, são apresentados.

4.1.1. "Existem sim pesquisas no setor de transportes. Posso citar rapidamente: Pesquisa Nacional de Tráfego de 2011 - Pesquisa classificatória, de O/D de todo território Nacional com apoio do Exército. 120 pontos de coleta. (MT/DNIT) Pesquisa de Trafego de 2014 - Pesquisa classificatória, de O/D de todo território Nacional. 200 pontos de coleta. (EPL) - Plano Nacional de contagem de tráfego PNCT - em andamento - DNIT - Pesquisas de Embarcadores - pesquisa nos aeroportos Nacionais. - EPL - poderia citar outras 5. Falta coordenação $e$ publicidade."

4.1.2. "minha opção na 1a rodada foi a 2: ""atende formalidades e/ou é incipiente"".concordo com este comentário"

4.2. A qualidade do dado é fundamental para o processo de planejamento e tem sido fomentado a capacitação das equipes do Ministério tanto para a coleta como para o tratamento destes dados que posteriormente se tornam informação e em seguida conhecimento para o setor de transportes.

4.3. Nos últimos três anos o aporte de equipes melhor formadas e preparadas tem apresentado melhoras nos resultados e modernização de processos, com tudo, a resposta dos sistemas de monitoramento ainda não conseguem suplantar a velocidade dos sistema produtivo.

4.3.1. "Correto, temos melhoras nos últimos anos significativas. Destaco os quadros que os cargo dos órgãos do setor de transportes em geral tem sido ocupados por técnicos." 
4.4. Ora com muita qualidade, ora com deficiências, raramente articuladas de forma integrada, carência de procedimentos de continuidade, podendo, em alguns casos serem contraditórias, mas que no geral, mostram um avanço em relação ao últimos 10 anos.

\subsubsection{Falta articulação.}

4.5. Basicamente, parte significativa de pesquisas no âmbito do MT está a cargo da EPL, a qual deve zelar pela qualidade dos dados das pesquisas contratadas, de maneira a que o produto desses dados se reflita num PNLI fidedigno à realidade brasileira.

4.6. O setor de transportes carece de base de dados pública, periódica e de qualidade.

4.6.1. Sim, melhor coordenação!

4.6.2. de acordo

Comentários gerais para a questão 1.4

4.7. os comentários relatam esforços de implantação e expectativa de que em algum momento a qualidade dos dados estará num patamar que permitirá a sua efetiva utilização como informação e conhecimento.

5. O setor público federal de infraestrutura de transportes, atualmente: Apresenta um arranjo institucional capaz de permitir atividades de retroação?

5.1. "Existem arranjos institucionais específicos para atividades de fiscalização. Por exemplo: na ANTT. Mas não percebo vinculação entre essas atividades e o estabelecimento de políticas públicas."

5.1.1. "Fiscalização só a ANTT - Agencia Reguladora para tal. Existe sim vínculos claros entre o Ministério dos Transportes e suas Vinculadas. O MT tem três secretarias finalísticas que tem vínculos claros com as vinculadas: - SEGES SFAT - SPNT Sendo os vínculos: SEGES - VALEC, DNIT e CODOMAR; SFAT - ANTT e SPNT - EPL"

5.1.2. "o comentário é meu; estou de acordo.. em outras palavras, acho que os arranjos institucionais existentes são subutilizados (ver os ""comentários gerais"" para esta questão 1.5 , abaixo)" 
5.2. O Ministério dos Transportes no Brasil é limitado a implantar políticas e ações apenas para o transporte terrestre. O setor de infraestrutura de transportes inclui ainda os ministérios dos portos e da aviação civil, além do Ministério da Defesa no tocante ao controle do espaço aéreo e autoridade marítima brasileira. Esse arranjo institucional dificulta a coordenação de ações voltadas ao setor de transportes como um todo. Eventualmente alguma ação de sucesso realizada para um setor pode ser, posteriormente, utilizada como case em outro, mas são ações muito pontuais.

5.2.1. DE fato, esta estrutura desfragmentada do transporte terrestre como s demais dificulta a integração.

5.2.2. "É verdade, mas em áreas de competência do Ministério dos Transportes as políticas também não parecem integradas (ex: propostas de PMI para estudos separados de rodovias e ferrovias na mesma área geográfica, como no norte do MT e PA) ver comentário 4, abaixo"

5.3. Existem iniciativas em alguns setores, porém não esta estabelecido na Instituição.

\subsubsection{Correto}

5.3.2. em geral as "iniciativas em alguns setores" antecedem a formalização do arranjo institucional

5.4. A compartimentalização e a especializaçãodificultam a ação de integração de instituições que concorrem por agendas próprias dos modais.

5.4.1. este não é apenas um problema de arranjo institucional; é um problema de gestão!

Comentários gerais para a questão 1.5

5.5. "Uma questão que permeia o problema institucional (o ""arranjo"") é a sistemática de designação para os cargos, em que os critérios políticos (indicações para os altos escalões) prevalecem sobre os critérios de competência. Não há arranjo institucional que funcione se não houver pessoas qualificadas (e respeitadas e valorizadas pelos superiores) nas funções de alta gerência." 
6. $O$ setor público federal de infraestrutura de transportes, atualmente: Apresenta políticas de gestão dos recursos humanos envolvidos na retroação?

6.1. Certamente deve haver uma política de RH para dar suporte às atividades, mas desconheço.

\subsubsection{Existe no MT mas é isolada dos demais.}

6.2. "O setor público federal brasileiro possui recursos e políticas que o torna atrativo para o desenvolvimento intelectual, tais como bons salários e diferenciais trabalhistas. Um indicador dessa atratividade são os concursos públicos, cada vez mais concorridos. Nota-se no entanto, uma carência de políticas de gestão de pessoas que mantenham esses servidores capacitados e estimulados a trabalhar com eficiência e efetividade. Nota-se ainda que, em razão das políticas salariais diferenciadas no serviço público, muitos servidores se deslocam para outras áreas dentro do próprio governo federal em busca de melhorar sua condição pessoal."

\subsubsection{Concordo}

6.2.2. de acordo

Comentários gerais para a questão 1.6

6.3. "O setor público em média paga melhor e tem atraído pessoas qualificadas para as suas carreiras e oferece oportunidades de qualificação no mínimo iguais às das empresas privadas. Por que funciona tão mal? Minha percepção é que existem ""disfuncionalidades"" no sistema político brasileiro que prejudicam enormemente a gestão pública. Além da questão da designação dos dirigentes, pode ser citado que o papel das Agências Reguladoras não é entendido pelos altos escalões do Executivo, Legislativo e até pelo Judiciário. Elas são o principal instrumento da implantação das políticas públicas. Interessante que no sistema financeiro esta função parece ser bem compreendida (ex: a separação de funções do BACEN e BB, com clara autoridade do primeiro). Mas não é percebida no setor de petróleo (ANP e Petrobras) e transportes. 
7. $O$ setor público federal de infraestrutura de transportes, atualmente: Incentiva a elaboração de planos de monitoramento e avaliação e os integra com outras instâncias $e$ instrumentos de planejamento?

7.1. "resposta afirmativa para incentiva a elaboração de planos de monitoramento e avaliação (dentro de limites específicos); -resposta negativa para integração com outras instâncias e instrumentos de planejamento (se existe, desconheço)"

7.1.1. Ok.

7.2. O Ministério dos Transportes no Brasil é limitado a implantar políticas e ações apenas para o transporte terrestre. O setor de infraestrutura de transportes inclui ainda os ministérios dos portos e da aviação civil, além do Ministério da Defesa no tocante ao controle do espaço aéreo e autoridade marítima brasileira. Esse arranjo institucional dificulta a coordenação de ações voltadas ao setor de transportes como um todo.

7.2.1. ver comentário 2 sobre a questão 1.5

7.3. Existem iniciativas, porém esta em um estagio inicial no MT juntamente com suas entidades vinculadas.

7.3.1. Ok

7.3.2. Ok

7.4. Planejamento praticamente inexistente.

7.4.1. Tem planejamento falta patrocínio para implementar.

7.4.2. Ok.

7.5. Pouca capacidade de articulação interna para a integração multimodal.

\subsection{1. $O K$}

Comentários gerais para a questão 1.7

7.6. $O$ comentário 1 resume a questão 1.7 
8. O setor público federal de infraestrutura de transportes, atualmente: Envolve os gestores financeiros e de recursos humanos $(R H)$ no detalhamento das iniciativas da retroação?

8.1. creio que sim, mas desconheço

8.1.1. Envolve mas não como deveria.

8.2. Nota-se que há uma dificuldade de gestão do setor público generalizada. Qualquer política de RH possui entraves de toda ordem, bem como o planejamento financeiro é pouco transparente e sujeito à oscilações frequentes, seja de recursos disponíveis para o desenvolvimento de ações, seja por erros na previsão de gastos para o setor.

8.2.1. Diria que é transparente mas realmente oscila bastante devido a politicas de Governo.

9. O setor público federal de infraestrutura de transportes, atualmente: Possui uma cultura avaliativa e de monitoramento?

9.1. Existem apenas ações esporádicas ou demandas emergenciais.

9.1.1. Descoordenada.

9.2. "O tema é incipiente para a infraestrutura de transportes."

Não foram registrados comentários gerais para a questão 1.9

10. $O$ setor público federal de infraestrutura de transportes, atualmente: Apresenta instrumentos que privilegiam o estabelecimento e manutenção de parcerias harmônicas para o adequada realização da retroação?

10.1. De um modo geral não há entrosamento, havendo muito corporativismo entre os órgãos federais.

10.2. "O processo de designação dos dirigentes não contribui para o estabelecimento de parcerias harmômicas. Incidentalmente, observei maior interação entre o Ministério dos Transportes e a ANTT no processo de concessão de rodovias do que no de ferrovias." 
10.3. O setor público não estimula a realização de parcerias, e quando o faz, é através de burocráticos e difíceis processos.

10.4. "Existem instrumentos como As RAE's - Reuniões de Acompanhamento da Estratégia e Planos estratégicos. Possui ferramentas de integração de dados que estão em implantação, porém ainda não esta amplamente estabelecida instituição."

Não foram registrados comentários gerais para a questão 1.10 .

11. $O$ setor público federal de infraestrutura de transportes, atualmente: Fomenta o desenvolvimento de atividades de monitoramento e avaliação?

11.1. Os órgãos costumam focar apenas em suas atribuições, havendo ausência de uma instância de coordenação, que pudesse enxergar o todo.

11.2. Não há uma política para monitoramento e avaliação. As ações existentes são pontuais.

11.3. O Ministério dos Transportes juntamente com seus órgãos vinculados (DNIT,VALEC,ANTT e EPL) tem desenvolvido a cultura de Gestão Estratégia Institucional.

11.4. Os sistemas formais não são retroalimentados.

Não foram registrados comentários gerais para a questão 1.11 .

12. $O$ setor público federal de infraestrutura de transportes, atualmente: Fomenta o desenvolvimento de empreendedores operacionais de um SMA?

12.1. O desenvolvimento de empreendedores de um SMA, quando realizado, parte da iniciativa dos próprios empreendedores ou de alguma política interna de alguma organização.

12.1.1. Entendo que a formação de empreendedores de uma SMA é de importância média.

12.1.2. Ok.

Não foram registrados comentários gerais para a questão 1.12 


\section{C.2 Tópico 2 - Grau de importância dos aspectos específicos}

Qual o atual grau de importância destes componentes para a criação e manutenção de um SMA para o setor público federal de infraestrutura de transportes?

13. Aspectos funcionais (Comentários para os itens 2.1, 2.2, 2.3 e 2.4)

13.1. Sem a criação de um SMA de políticas no setor de infraestrutura de transportes, continuaremos com pesquisas esparsas e assistemáticas sobre o tema, muitas vezes com sobreposição (ou lacunas) nos assuntos abordados. Sem falar na desnecessidade de diversas dessas pesquisas. Sem sistematização, por consequência, o Poder Executivo continuará enviando sinais inadequados à iniciativa privada, gerando, por consequência, projetos muitas vezes inadequados de infraestrutura de transportes (em modais inadequados, por exemplo).

13.2. "Todos os 4 item são de grande relevância para um SMA. O setor tem priorizado todos os 4 itens."

13.3. Coleta de dados, pesquisa e avaliação devem acontecer onde existe a falta de rotinas de monitoramento que gerem bases de dados. Já a qualidade do dados é um processo evolutivo a partir do momento que existam bases de dados a serem avaliadas e criticadas.

13.4. Temos que avançar muito, principalmente buscar a profissionalizaçao.

13.5. Todos são muito importante para se formar o sistema de dados permanente e consistente para a gestão, acompanhamento e planejamento do setor de logística e transportes no Brasil.

13.6. Todos os componentes mencionados são muito importantes, haja vista a necessidade de dados precisos, visando à estruturação de planos para os diversos modais de transportes.

13.7. Qualquer avaliação que se propõe sobre a gestão da infraestrutura de transportes prescinde de base de dados atualizada e de qualidade. Não há bases confiáveis ou levantamentos atualizados que permitam cenarizar a evolução do uso dos sistemas de transportes. 
14. Aspectos organizacionais (Comentários para os itens 2.5, 2.6, 2.7, 2.8 e 2.9)

Não foram registrados comentários.

15. Aspectos de finalidade (Comentários para os itens 2.10, 2.11, e 2.12)

Acho que faltou a avaliação da importância do papel dos dirigentes das organizações. 